\title{
'The Menace of Effeminacy': \\ Medical and Popular Discussions of Masculinity in Interwar New Zealand, c.1918-1939
}

Ailish Jean Wallace-Buckland

A thesis submitted to the Victoria University of Wellington in fulfilment of the requirements for the degree of Master of Arts in History

Victoria University of Wellington 


\section{ACKNOWLEDGEMENTS}

I owe the greatest thank you to both of my supervisors, Professor Kate Hunter and Professor Charlotte Macdonald. Without their expertise, guidance, and great care and understanding this thesis could not have been written. Throughout the process of writing this thesis the knowledge that their support and interest in my work was ever present kept me going. I feel incredibly lucky to have been able to work with them both.

To my fellow Old Kirk colleagues, your friendship has sustained me throughout this process. I have valued our conversations, laughter, and camaraderie as much as all that I have learnt through my research. Thank you to all my other dear friends too, you have kept me sane. I cherish our friendships.

A thank you is also owed to the incredibly friendly staff at the Hocken Collections, the Wellington Medical and Health Sciences Library, and the University of Otago Health Sciences Library who helped me find and access a number of sources for my thesis. Thank you also to Chris Brickell who kindly met with me, recommended sources, and boosted my morale when it was most needed. My research also owes another thank you to Kate Hunter who helped fund my trips to Dunedin, and who did some work for me at the State Library of New South Wales during her own research visits. I also want to acknowledge the funding support I received through the benefactors of the D. F. McKenzie Award, which helped me access printed materials for my research.

Finally, to Mum and Dad, I owe you the biggest thank you. We may be separated by distance, but your love and support has always been felt closely. I cannot thank you enough for all that you do for me. 


\section{TABLE OF CONTENTS}

$\begin{array}{lll}\text { Abstract } & \text { vii }\end{array}$

List of Abbreviations

Introduction

\section{Chapter One}

Legislation and Reports

Chapter Two

Medicine and Effeminacy

Chapter Three

Popular Culture and Effeminacy

Conclusion

Bibliography 


\section{ABSTRACT}

In January 1932, the Sydney-based lifestyle magazine Health and Physical Culture published an article titled 'The Menace of Effeminacy'. This article, written by Carl Hertzig, and read by magazine-subscribers across the Tasman, documented anxieties around the state of men and masculinity following the upheaval of the Great War. Touching on topics such as gender, psychology, eugenics, and sexuality this article and its concerns represent those that this thesis explores in order to understand what the 'fear of effeminacy' actually meant for New Zealanders during the interwar years (c.1918-1939). This thesis documents and analyses contemporary discussions of male sexuality and masculinity through a series of sources in order to establish the ways in which these concepts were understood in interwar New Zealand. Firstly, it examines some of the key pieces of legislation and reports that demonstrated official approaches, and ways of thinking, towards mental defectives, sexual offenders, and those with war neuroses. It then explores medical journals, and the dissertations of medical students; and finally, it analyses parts of popular print culture in Aotearoa/New Zealand, such as magazines and newspapers, in order to investigate and piece together the landscape in which said anxieties around effeminacy, masculinity, mental stability, and other deviations from the societally prescribed norm met. This thesis approaches these primary sources in such a way that acknowledges the evolutionary framework of understanding that was pervasive in medical circles during this era.

By thus examining the connections between constructions of the male body, homosexuality and effeminacy, late nineteenth to early twentieth century ideas around eugenics, and psychology and psychiatry, this work further uncovers the state of masculinity and male sexuality in New Zealand during the interwar period. This thesis argues that the 'threat' to masculinity perceived in a variety of venues was a mixture of anxieties around physical and mental wounds inflicted by the Great War; population concerns exacerbated by the exposure of the health-standards of troops, and worries of how to recover and reconstruct a virile society following four years of strife; concerns at the apparent loosening of sexual mores, and the changing manifestations of both masculinity and femininity; and ever increasing interest in the psychology of self, sexuality, and society. It adds to existing work on post-World War One masculinity by centring New Zealand discussions and understandings in a way that contributes to the broader literature on New Zealand twentiethcentury masculinity, psychology and psychiatry, eugenics, and male sexuality. 


\section{LIST OF ABBREVIATIONS}

BJOP

BMA

$H \& P C$

$H \& S$

NZMJ
British Journal of Psychology

British Medical Association

Health and Physical Culture

Health and Sunshine

New Zealand Medical Journal 


\section{INTRODUCTION}

In January 1932, the Sydney-based lifestyle magazine Health and Physical Culture published an article titled 'The Menace of Effeminacy'. ${ }^{1}$ This three-page spread, written by Carl Hertzig, ${ }^{2}$ detailed the so-called problem of effeminate men, and outlined how one should tackle it. "Many cases of effeminacy", Hertzig wrote, "are hidden beneath an exterior of marked masculinity and athleticism," an intriguing remark to make given the context of Health and Physical Culture as a magazine which promoted such ideals. Hertzig reported that whilst experts on effeminacy may differ in the conclusions they draw, it cannot be denied that "it exists in practically all countries and among people of almost every race." ${ }^{3}$ Hertzig's article was just one indicator of a widespread concern with the state of masculinity, and with conditions assailing the position of men in modern societies. This article, with its references to psychology, effeminacy, the evolutionary framework of understanding and eugenics, the war, and masculinity prompted a number a questions about that which Hertzig dubbed the 'menace of effeminacy'. Questions including: what did 'effeminate' mean? Why was it seen as a menace? How many people were concerned with it? Who was concerned about it? What caused said anxieties around effeminacy, and men's sexuality in this period; and in New Zealand in particular? It is these questions, among others, ${ }^{4}$ that this thesis seeks to answer by examining the nature of these discussions in the years c.1918-1939.

This thesis aims to document and analyse contemporary discussions of male sexuality and masculinity through a series of sources in order to establish the ways in which these concepts were understood in interwar New Zealand (1918-1939). It explores the implications of the changing conceptualisation of sexuality and gender in New Zealand following the disruption of the First World War by tracing discourses of male feebleness and effeminacy to

\footnotetext{
${ }^{1}$ Carl Hertzig, 'The Menace of Effeminacy', Health and Physical Culture, Vol.4, No.1, January 1932, pp.14-15, 40.

${ }^{2}$ Unfortunately, I have been unable to find any information out about who Hertzig was, and where he came from; and his name did not appear as attributed to any other articles in the other issues of Health and Physical Culture magazine that I examined for this thesis.

${ }^{3}$ Hertzig, p. 14 .

${ }^{4}$ Such as: To what extent, and in what ways, did the disruption of the Great War influence discourse around men's sexuality and masculinity in New Zealand between 1918-1939? To what extent did the Great War, particularly with its understandings of shell-shock and war neuroses, influence understandings of mental illness and sexuality? To what extent was sexuality viewed as a medical problem in post-WWI New Zealand? Did popular media in New Zealand reflect similar anxieties around effeminacy and male sexuality that British historians argue existed in interwar Britain? What influence did eugenics have on understandings of sexuality in interwar New Zealand?
} 
see whether it became as much of an issue for New Zealand doctors in the same ways as historians argue was the case for Britain. This thesis examines three places where these discussions were taking place: government legislation and official reports, medical literature, and popular print culture. It adds to existing work on post-World War One masculinity by centering New Zealand experiences and understandings in a way that contributes to the broader literature on New Zealand twentieth century masculinity, psychology and psychiatry, and homosexuality.

In his article, Hertzig tied effeminacy to the concept of inversion, stating that in the cases of many effeminate men, "they may be so advanced as to be actually classified as true inverts. $" 5$ He then supported this claim by referencing the nineteenth-century Austro-German psychiatrist and author Richard von Krafft-Ebing who declared that effeminacy was "a functional sign of degeneracy" (as well as associating it with "bi-sexuality"). ${ }^{6}$ Though Hertzig proposed that there is not "usually any homosexuality present" in such men, the way in which effeminacy was linked with a kind of degeneration acts as a signal to many historians of sexuality and gender that these effeminate men were being marked out as those who, through an understanding of an evolutionary hierarchy, were signalled to be those who were not fulfilling the functional expectations placed upon white, western, heterosexual men. ${ }^{7}$ In fact, rhetoric around the 'primitive' appeared in the article when Hertzig acknowledged that, "several native races have such [effeminate] males in their society."

The prevalence of "this cult of effeminacy", and the presence of so many effeminate young men, Hertzig suggests can be attributed to the Great War. He argued that as many fathers of this generation of men were away during "their most impressional [sic.] years" due to military service, that the then boys grew up around their mothers developing an unnatural connection (as Freud would suggest); and because this generation did not have to face warfare, but rather passively dealt with the effects of war on their life - through absent

\footnotetext{
${ }^{5}$ Hertzig, p. 14 .

${ }^{6}$ Ibid. Though, interestingly enough, he did note that "bi-sexuality" should not be, "conflicted with actual inversion", as, "many of our best men in public and professional life have been, to certain extents, bi-sexual." So here there appeared to be a distinction being made between the fully-blown effeminate man, and just the state of being bisexual.

${ }^{7}$ See Tracey Loughran, Shell-Shock and Medical Culture in First World War Britain (Cambridge: Cambridge University Press, 2017), p.43; Jessica Meyer, 'Separating the Men from the Boys: Masculinity and Maturity in Understandings of Shell Shock in Britain', Twentieth Century British History, Vol.20, No.1, 2009, pp.1-22; and Fiona Reid, Broken Men: Shell Shock, Treatment and Recovery in Britain 1914-1930 (London: Continuum, 2010).

${ }^{8}$ Hertzig, p.15. These men, the reader is told, are, "not only tolerated, but actually fostered," in the communities of "native races" where they live; though it is notable that whilst this may be okay for these people, for those in the civilised west, effeminacy is - as the article title suggests - dubbed a "menace" that must be dealt with.
} 
fathers, and malnutrition due to food shortages during these years - the "devastating effect" of it all was, resultingly, that they displayed effeminate behaviours, and acted in effeminate ways. ${ }^{9}$ The legacies of the Great War's impact on a generation had, thus, continued well after 1918. The variety of the anxieties around the effects of the war focused on problems such as 'shell-shock', as well as worries about boys and men, and masculinity throughout this period.

The "trait" of effeminacy was described by Hertzig in psychoanalytical terms (as can be seen in his description of its causation). ${ }^{10}$ The "remedy" is given as either being the possession of strong enough will power and self-control which with the right mentality could potentially revert this trait, or, when this was not an option, a round of psychoanalysis was suggested, with two years given as an optimistic cure timeline. ${ }^{11}$

What is also interesting is that some of the language that Hertzig, and those he referenced (such as Krafft-Ebing) used is that which would later be identified as indicative of a problematic gender identity. In Hertzig's definition of an invert (i.e. effeminate person), he wrote that he is "one in whom co-exists the soul of one sex and the body of the other". ${ }^{12}$ In mentioning groups of effeminate men in European and American cities, he described them as "dressing, and acting, fully as women." 13 Though these men were not framed in a way that they were sexually driven in their cross-dressing (in either a devious or criminal manner), ${ }^{14}$ it is noteworthy that others did view them is this way, and Hertzig declared that the effects of the existence of effeminacy and effeminate men (and women too) should be something society is worried about, especially in a population that is, "already nearing C3 race."15 Hertzig here signals to some of the other topics that interconnect with conceptions of masculinity and effeminacy, such as crime, race, cross-dressing and fashion, sexual identities, and urbanity.

Hertzig concluded his article by saying that: "The possessing of effeminate traits is less a cause of disease than of unhappiness", despite his claims that it had a negative effect on

\footnotetext{
${ }^{9}$ Hertzig, p.40.

${ }^{10}$ Hertzig, p.14. The idea that, "a male invert thinks and feels emotionally much in the same manner as a woman", is ascribed to the fact that the "parent image" of these men is one of a woman (a mother, nurse, sister, etc.); with an over-close association with this image being that which effects the unconscious of a man and ultimately resulting in his effeminacy (pp.14-15).

${ }^{11}$ Hertzig, p.40.

12 Hertzig, p. 14

${ }^{13}$ Hertzig, p.40.

${ }^{14}$ In fact, Hertzig wrote that such men were, "often quite sexless": Hertzig, p.15.

${ }^{15}$ Hertzig, p.40. He argued that whilst effeminacy, "in itself", is a state that, "is comparatively innocent and removed from sexual aberrations", those cases that are advanced and, "which may also have an hereditary history," are, "a menace from which some delivery should be sought."
} 
the vigour and virility of a population. ${ }^{16}$ He noted that: "It is also a state which is occupying the attention of psychologists," and, most significantly said that, "through them [effeminacy] is being better understood by the general public." 17 The notion that psychologists played a role in how something like effeminacy, and by association, masculinity, was understood by readers of Health and Physical Culture in the interwar period sparked the genesis of this thesis.

The prevalence of, and increased exposure to, men's mental illness during the Great War (1914-1918) created a crisis in Britain regarding understandings of masculinity, as well as of madness. Fuelling this crisis were the many and varied understandings of men's behaviour and psychology in the interwar period. One source that provides a window into how mental illness - in this case, shell-shock - was perceived in Britain is the 1922 Report of the War Office Committee of Enquiry into "Shell-Shock". ${ }^{18}$ This report acts as a touchstone for the kinds of areas understood to be linked to, and important in, discussions of men's mental illness - notions such as temperament, ethnicity, class, physical weakness, and heredity, amongst others. ${ }^{19}$ The kind of rhetoric used around shell-shock and other war neuroses by British war doctors, in some cases also framed sufferers as effeminate and un-manly in their comparisons to female hysterics. This kind of language, and understanding, as this thesis will demonstrate, was also present in New Zealand publications - of both the medical and popular kind. These publications are important for historians to examine as they preserve fragments of developing ideas about effeminacy and male sexuality from this period (1918-1939). New Zealanders were participants in such debates around shell-shock, and mental psychoses, via the existence of imperial medical networks, and by the incidence of shell-shock amongst New Zealanders who fought in the Great War. ${ }^{20}$

Though scholars of the history of insanity have explored the complex links between madness, sexual identity and femininity, the way in which these ideas converged regarding

\footnotetext{
${ }^{16}$ Hertzig, p.40.

${ }^{17}$ Ibid.

${ }^{18}$ Great Britain War Office Committee Enquiry into "Shell-shock", Report of the War Office Committee of Enquiry into "Shell-shock" (London: H.M.S.O., 1922).

${ }^{19}$ To contextualise these comparisons to female hysterics by British war doctors, see, for example: Elaine Showalter, The Female Malady: Women, Madness and English culture 1830-1980 (London: Virago, 1987). ${ }^{20}$ These imperial medical networks are outlined in Tamson Pietsch's book, Empire of scholars: Universities, networks and the British academic world 1850-1939 (Manchester: Manchester University Press, 2013); and my own honours thesis, 'Understanding Effeminacy and Masculinity in Discussions of Shell-Shock in British Medical Culture, 1914-1922', also established the importance of said networks.
} 
men and masculinity has been less studied. Hence, whilst British historians have examined the disruption of the war to sexual identities in the interwar period, and despite continued imperial ties, we know little of how those in New Zealand responded to wartime changes in psychological and psychiatric knowledge, or to popular conceptions of (largely male) sexual identity. $^{21}$

The work undertaken by New Zealand historians on sexuality in the early twentieth century has largely focused more on the physical reproductive body, with women being most prominently at the centre of this research. ${ }^{22}$ This has been the focus rather than on emerging expressions and perceptions of sexual identity as they were being discussed and defined in a variety of forums - from medical journals to the tabloid press. Many existing studies rely on the records of the justice system, focusing on sexual crimes, deviancy and punishment. ${ }^{23}$ This thesis uses the 'menace of effeminacy' to try to follow some of those threads of the social anxieties about sexual identity as expressed in transforming ideas about men and masculinity.

Understandings of sexuality and gender, and gendered behaviours, remained largely associated within 'evolutionary frameworks' of understanding (developed out of the theory of evolution and the notion of Social Darwinism) that were pervasive during the early twentieth century, particularly in international scholarship and medical training. This set of ideas shaped how many doctors conceptualised, and later made judgements on, certain behaviours

\footnotetext{
${ }^{21}$ For examples of British historians examining crises in (female) sexualities, see the work of historians such as Lucy Bland Modern Women on Trial: Sexual Transgression in the Age of the Flapper (Manchester: Manchester University Press, 2013); and Hera Cook, The Long Sexual Revolution: English Women, Sex, and Contraception, 1800-1975 (Oxford: Oxford University Press, 2004).

${ }^{22}$ For example, Barbara Brookes, 'Housewives' depression: the debate over abortion and birth control in the 1930s', New Zealand Journal of History, Vol.15, No.2, October 1981, pp.115-134, and Barbara Brookes, $A$ History of New Zealand Women (Wellington: Bridget Williams Books, 2016); Bronwyn Dalley, 'Lolly shops 'of the red-light kind' and 'soldiers of the King', New Zealand Journal of History, Vol.30, No.1, April 1996, pp.3-23; Jane Tolerton, Ettie: a life of Ettie Rout (Auckland: Penguin, 1992); Caroline Daley, Leisure and Pleasure: Reshaping and Revealing the New Zealand Body 1900-1960 (Auckland: Auckland University Press, 2003); and Angela Wanhalla, Matters Of The Heart: A History Of Interracial Marriage In New Zealand (Auckland: Auckland University Press, 2013). However, other historians did place men at the centre of their studies of New Zealand sexuality, such as Chris Brickell, Mates and Lovers: A History of Gay New Zealand (Auckland: Godwit, 2008).

${ }^{23}$ In her chapter 'Puritans and Pleasure Seekers', in Alison Kirkman, and Pat Moloney, Sexuality Down Under: Social and Historical Perspectives (Dunedin: University of Otago Press, 2005), pp.47-62, Caroline Daley further discusses this reliance on sources from the justice system, and how this also reflects the contemporary socio-political environments in which historians wrote these works. For examples of histories done about New Zealand homosexuality throughout the twentieth-century (i.e. beyond just the interwar decades), that do examine the more criminal aspects of it, see: Chris Brickell, "Waiting for Uncle Ben": Age-Structured Homosexuality in New Zealand, 1920-1950, Journal of the History of Sexuality, Vol.21, No.3, September 2012, pp.467-295, and Chris Brickell, 'Queens Gardens, 1949: The anxious spaces of post-war New Zealand masculinity’, New Zealand Geographer, Vol.68, No.2, August 2012, pp.81-91; Laurie Guy, Worlds in Collision: The Gay Debate In New Zealand, 1960-1986 (Wellington: Victoria University Press, 2002); and William C. Hodge, Homosexual law reform: questions and answers concerning the legality of male homosexual conduct in New Zealand: a discussion paper (Auckland: Human Rights Commission, 1985).
} 
as tied to notions of race, class, and gender. ${ }^{24}$ Given the aims of this thesis to explore both how New Zealand discussed and understood sexual identities in the interwar years, through examining both popular culture and medical literature, this study acknowledges this conceptual framework, and therefore also touches on topics such as eugenics, emotionality, and insanity.

Due to the nature of the aims of this thesis, and the questions it asks, the existing historiography that this work interacts with is multifaceted. This thesis brings together, and in some cases expands on, the work of historians from the fields of queer studies; masculinity studies; those who have worked on sexuality (along the binary of male and female); psychology and psychiatry, and insanity more broadly; eugenics; body culture(s) and disability; and networks. As historian Chris Brickell observes: "Few topics lend themselves to ambiguity as much as New Zealand masculinity, with all its equivocacy and imprecision," a point reinforced by this varied historiography. ${ }^{25}$

Male sexuality - in particular, homosexuality - in New Zealand is not a widely studied area of scholarship. There have, however, been some pioneering works undertaken most notably, by Chris Brickell. Brickell's 2008 book Mates and Lovers: A History of Gay New Zealand details male same-sex sexuality and intimacy from early British settler society in New Zealand in the 1840s, through to the 1990s. ${ }^{26}$ Despite the use of the term 'gay' in the book's title, one of Brickell's arguments surrounds the importance of language and terminology when it comes to writing a history of same-sex desire and practice. ${ }^{27}$ This study echoes Brickell's approach in terms of the way that I have had to approach the task of tracing discourse around effeminacy. Whilst Brickell's work is certainly impressive in its scope, and though it does touch on the interwar period (particularly in his second chapter, 'Of Queens and Men'), the focus of the book is more concerned with nineteenth-century stories, and on the latter half of the twentieth century. Thus Brickell's work is itself reflective of the broader trend in the historiography of male sexuality in New Zealand in its chronological focus. ${ }^{28}$

\footnotetext{
${ }^{24}$ See Loughran, p.72.

${ }^{25}$ Brickell, Mates and Lovers: A History of Gay New Zealand, p.8.

${ }^{26}$ Brickell, Mates and Lovers: A History of Gay New Zealand (Auckland: Godwit, 2008).

${ }^{27}$ Brickell, Mates and Lovers: A History of Gay New Zealand, pp.8-9.

${ }^{28}$ A 'trend' also illustrated by the collected works of the likes of Alison J. Laurie, and Linda Evans, Outlines: Lesbian \& Gay Histories of Aotearoa (Wellington: Lesbian and Gay Archives of New Zealand, 2005); and Allison Kirkman, and Pat Moloney, Sexuality Down Under: Social and Historical Perspectives (Dunedin: University of Otago Press, 2005); amongst others.
} 
Studies into the phenomenon of 'effeminacy', such as those undertaken by Alan Sinfield in The Wilde Century: Effeminacy, Oscar Wilde and the Queer Moment, ${ }^{29}$ Joseph Bristow's Effeminate England: Homoerotic Writing After 1885, ${ }^{30}$ and Tim Bergling's Sissyphobia: Gay Men And Effeminate Behavior, ${ }^{31}$ were useful to my understanding of what effeminacy was understood to be in the late nineteenth to early twentieth century, when it was first presented as an issue, and why. These studies demonstrated that following the infamous trials of Oscar Wilde in 1895, a man who was known to be an extravagant and effeminate dandy, ${ }^{32}$ 'effeminacy' came to be increasingly associated with those who Sinfield classified as, "the professionally idle, debauched, middle-class man." ${ }^{33}$ This association therefore carried certain negative connotations about men who were described as effeminate, who were seen as not properly functioning in society and as failing in their masculinity. Effeminacy was, Sinfield argues, "a contested construct", and addressed a far wider range of concerns than sexual orientation. ${ }^{34}$ Brickell echoed this when he wrote that effeminacy "was not always equated with same-sex desire", rather that at the turn of the century it, "implied physical 'weediness', excessive sentimentality, and aestheticism." 35 Whilst I agree with this point, and whilst I also recognise that even though some contemporaries did come to connect effeminacy and homosexuality (such as writers for The New Zealand Truth), ${ }^{36}$ other New Zealanders used the term to disparage youths who were "cissy boys" out to attract the opposite sex. ${ }^{37}$ Tracking the notion of effeminacy through medical and popular literature in New Zealand, I suggest that historians of queer history should not completely divorce the two notions of effeminacy and homosexuality when it comes to early twentieth-century New

\footnotetext{
${ }^{29}$ Alan Sinfield, The Wilde Century: Effeminacy, Oscar Wilde and the Queer Moment (New York: Columbia University Press, 1994).

${ }^{30}$ Joseph Bristow, Effeminate England: Homoerotic Writing After 1885 (New York: Columbia University Press, 1995).

${ }^{31}$ Tim Bergling, Sissyphobia: Gay Men And Effeminate Behavior (New York: Harrington Park Press, 2001).

${ }^{32}$ Sinfield, p.2.

${ }^{33}$ Sinfield, p.71. Sinfield later described how, "The notoriety of Wilde headed off the Victorian exploration of diverse models of same-sex relations and, in a twin move, afforded a simple stereotype as a peg for behaviour and feelings that were otherwise incoherent or unspeakable." (p.125). This stereotype was one that made its way to New Zealand (as Brickell notes, Mates and Lovers: A History of Gay New Zealand, p.84), and became one that became tied up in/with the work of sexologists such as Richard von Krafft-Ebing and Havelock Ellis (Sinfield, p.110), and following the Great War, with the influence of Freud too, helped with the development of "the possibility of a gay identity" (Sinfield, pp.162-163.)

34 Sinfield, p.109.

${ }^{35}$ Brickell, Mates and Lovers: A History of Gay New Zealand, p.84.

${ }^{36}$ See, for example, the article about 'Effeminate Eric' that Chris Brickell describes from a 1913 issue of The New Zealand Truth: Chris Brickell, Mates and Lovers: A History of Gay New Zealand, p.86.

${ }^{37}$ Brickell, Mates and Lovers: A History of Gay New Zealand, p.86.
} 
Zealand. ${ }^{38}$ Brickell himself hints at this point when he discusses the 1924 inquiry into Mental Defectives and Sexual Offenders. He reflected that though "Homoeroticism was not considered a form of mental deficiency as such," which most of the submissions to the inquiry were about, "it lay on the same plane." ${ }^{39}$ Homoeroticism, homosexuality, and effeminacy - as this thesis will further argue - were of concern to those influenced by the eugenic movement in New Zealand as they represented an "abandonment of the 'duty' to reproduce", and were, "presumed to be the result of insufficient moral control." 40 It is this, plus the "new language of "psychopathology' [that] emerged during the 1910s and 20s," as Brickell stated, that led to new ways of treating, and punishing, those men who were sexually deviant or divergent from the expected norm. ${ }^{41}$ This is where then, in the New Zealand historiography, the conversation has largely veered towards the criminal. Criminality and homosexuality is something that lives on the periphery of this thesis, as its focus remains on the medical and popular discussions of effeminacy, masculinity, and male sexuality rather than on those that strictly discuss deviancy, mental deficiency, and what were described as sexual perversions in a criminal light. ${ }^{42}$

Peter Boston has written about the criminal history of homosexuality in New Zealand in a number of conference papers, ${ }^{43}$ as well the 'crisis of masculinity' in the post-war rehabilitations of disabled soldiers from the First World War, in his honours thesis. ${ }^{44}$ Boston described the regulation of male sexuality through the containment of 'sexual perverts', a category, he proposed, the Department of Justice equated with homosexuality. He noted the significance of the establishment of an institutional space specifically for the imprisonment of

\footnotetext{
${ }^{38}$ Despite what Sinfield might protest. He asserted that, "To run the two", effeminacy and homosexuality, "together prematurely is to miss the specificity of their relations", despite their historical overlap (Sinfield, p.78) - which I do not believe I am doing, simply that I, along with Brickell, believe that there is more of interest to be explored in this interconnectivity in the specific New Zealand context (than perhaps has already been examined in Britain and elsewhere).

${ }^{39}$ Brickell, Mates and Lovers: A History of Gay New Zealand, p.93.

${ }^{40}$ Ibid.

${ }^{41}$ I.e. the white, heterosexual, married man who had sex to produce children for the nation.

42 Though this thesis is indebted to the work that has been done on such topics, as this plays a large part in current understandings of queer New Zealand history due to the status of homosexuality as criminal until 1986. For evidence of this history, see, for example: Brickell, Mates and Lovers: A History of Gay New Zealand, and Chris Brickell, 'Queens Gardens, 1949: The anxious spaces of post-war New Zealand masculinity'; Peter Boston, “A Heaven For Homosexuals': A Brief History Of The New Plymouth Prison For Sexual Offenders, 1910-1952', and Peter Boston, “'A Caged Tiger': The Regulation Of Male Sexuality In The New Zealand Penal System, 1917 To 1952'”, Unpublished Conference Paper, NZPGSA Conference, 1998; and Guy, Worlds in Collision: The Gay Debate In New Zealand, 1960-1986.

${ }^{43}$ Peter Boston, “A Heaven For Homosexuals': A Brief History Of The New Plymouth Prison For Sexual Offenders, 1910-1952', and Peter Boston, “A Caged Tiger': The Regulation Of Male Sexuality In The New Zealand Penal System, 1917 To 1952',

${ }^{44}$ Peter J. Boston, "“The Bacillus Of Work": Masculinity And The Rehabilitation Of Disabled Soldiers In Dunedin 1919 To 1939', Unpublished Ba(Hons) Thesis, Otago University, 1993.
} 
such men, i.e. "men convicted of buggery or an indecent assault on a male", at New Plymouth Prison. ${ }^{45}$ New Plymouth Prison facilitated the segregation of these inmates alongside feeble-minded offenders. ${ }^{46}$ The joint confinement of, and link made between, sex perverts and the feeble-minded is the same kind of association that this thesis demonstrates as existing in medical and popular culture sources in interwar New Zealand. Chapters of this thesis explore the reasoning behind this perceived interconnectivity of two such socially threatening groups. Boston argued that the task of the historian is to historicise the gradual changes in understandings of, and discussions about, gender and sexual identities, ${ }^{47}$ which this thesis does in this illumination of the changes in the discourse of both the medical and popular culture spheres between 1918-1939. Boston went on to suggest that through the establishment of a more intricate analysis of the history of New Zealand sexuality, through the recognition of diversities of class, ethnicity, and sexual orientation, "a more complex image of our society becomes apparent, one in which the past becomes more vibrant and the present more comprehensible." ${ }^{48}$ The aim of this thesis is to achieve this greater complexity of the history of effeminacy and deviant male sexuality and masculinity in interwar New Zealand.

This thesis works in conversation with the scholarship of Brickell and Boston, as well as Ana Carden-Coyne, Jock Phillips, and Adrian Bingham. Carden-Coyne investigated the reconstruction of the body damaged by warfare, and the ruined nerves of soldiers in Anglophone societies (Britain, Australia, and the United States) in the post-war era. She outlined the fact that in the interwar years: "Rehabilitating veterans and rebuilding masculine purpose were major problems facing governments, medical practitioners, physical educators and social reformers alike." ${ }^{49}$ Carden-Coyne concluded that classism and modernism were both ideologies at the centre of how Anglophone societies recovered from war and reconstructed their sense of normalcy, and, within that, a new framing of 'normal' masculinity. ${ }^{50}$ Where Carden-Coyne analyses discussions of men and masculinity in relation to the military-medical and commercial, this thesis undertakes a similar approach in the New

\footnotetext{
${ }^{45}$ Peter Boston, “A Caged Tiger': The Regulation Of Male Sexuality In The New Zealand Penal System, 1917 To 1952', p.1.

${ }^{46}$ Peter Boston, “A Heaven For Homosexuals': A Brief History Of The New Plymouth Prison For Sexual Offenders, 1910-1952', p.1.

${ }^{47}$ Peter Boston, “A Caged Tiger': The Regulation Of Male Sexuality In The New Zealand Penal System, 1917 To 1952 ', p.8.

48 Ibid.

${ }^{49}$ Ana Carden-Coyne, Reconstructing the Body: Classicism, Modernism, and the First World War (New York: Oxford University Press, 2009), p.161.

${ }^{50}$ Carden-Coyne, p.316.
} 
Zealand context. It illustrates how masculinity, and male sexuality were debated in the medical and popular print culture worlds of interwar New Zealand.

Masculinity is a key foundation of this thesis. Jock Phillips' A Man's Country? The Image of the Pakeha Male is a classic work on New Zealand masculinity from colonial-era Aotearoa to the 1990s. ${ }^{51}$ It is, however, deficient in its discussion of queer men in New Zealand, with its focus solely on the heterosexual New Zealand man. In the British context, historians such as Hera Cook and Lucy Bland have focused more on women and female sexuality. Cook, however, noted that: "In the aftermath of the First World War, historians of masculinity have found that a deeply anti-heroic mood emerged," and that, "This further advanced the modification of masculinity", that had already been set in motion by first-wave feminism."52 Bland proposed that whilst the post-war period was a, "time of flux and difficult transition", which, "contributed to heightened anxiety and great upheaval for both sexes", her focus still remained on the figure of the Modern Woman, who she says even "appalled" many returned soldiers in her modern femininity. ${ }^{53}$ British historians who more specifically focused on the problems of the mentally and physically weakened man during the Great War, and in the immediate post-war period, include those like Joanna Bourke. Bourke described how the period following the war was one that has been, "portrayed as the end of Victorian certainties", which included a kind of masculinity where men were valued in their role as breadwinners. She also proposed that the new masculinities of the interwar years can, and have been, "seen as a response to the perceived need to reassert manliness in a society undergoing rapid change." 54 This thesis aligns itself with this notion, which also speaks to the argument that Ana Carden-Coyne makes in her work, that through the need to rebuild societies contemporary forms of masculinity were asserted that both spoke to past traditions and reacted to the modern anxieties and the new conditions that men faced. ${ }^{55}$

This thesis also interacts with Adrian Bingham's work on the popular press in Britain. This work both utilises print-medium sources, and demonstrates their importance as spaces that facilitated and prompted debates around effeminacy, masculinity, and male sexuality. In his book Gender, Modernity, and the Popular Press in Inter-War Britain, Bingham argues that popular newspapers are an important historical source that should be used more to

\footnotetext{
${ }^{51}$ Jock Phillips in A Man's Own Country?: The Image of the Pakeha Male- A History (Auckland: Penguin Books, 1996).

${ }^{52}$ Cook, p. 183

${ }^{53}$ Bland, p.2.

${ }^{54}$ Joanna Bourke, Dismembering the Male: Men's Bodies, Britain and the Great War (London: Reaktion Books Ltd., 1999), p.14.

${ }^{55}$ Carden-Coyne, p.209.
} 
explore "the attitudes and identities of inter-war Britain, and in particular the reshaping of femininity and masculinity" in this period. ${ }^{56}$ Bingham has a whole chapter dedicated to masculinity in which he argues that 'the fear of 'effeminacy' was a repeated feature of press discourse at this time", in particular in the debates around mass unemployment and the effects of the 'dole', which he says can reveal to us the "anxieties about the character of the "modern man", held by those at the time. These were anxieties "which were intensified by the challenge seemingly posed by women entering the workforce in greater numbers." ${ }^{57}$ This thesis also explores the way in which unemployment was seen to threaten the masculinity of New Zealand men in the 1920s and 30s, establishing one of the factors that influenced conceptions of and exchanges about men and masculinity in interwar Aotearoa.

Ideas around men's mental and physical illnesses (in particular neuroses, and disabilities), and their relation to masculinity and male sexuality during and following the First World War have largely been produced in a British context, though certain New Zealand specific studies into shell-shock do exist. ${ }^{58}$ Indeed, Andreas De Block and Pieter R. Adriaens have argued that 'deficient' masculinity "keeps on haunting the literature." The reason being that when it comes to discussions of something that at times was described as a, “(mental) disease", i.e. sexual deviance, and at others was defined as a, "(mental) health" problem this causes issues for historians who need to address the historical terminology in their approaches. ${ }^{59}$ Networks of communication that existed in New Zealand with Britain, however, remained central to the lives of medical professionals and civilians alike in Aotearoa in the interwar period. ${ }^{60}$ New Zealanders relied on the physical publication of journals, books, newspapers, and magazines to disseminate and access knowledge accrued

\footnotetext{
${ }^{56}$ Bingham, p.1. I think that it would not be too much of a stretch here to also extend this 'reshaping' to apply to that printed in popular periodicals too.

${ }^{57}$ Bingham, p.20.

${ }^{58}$ The British works include those by the likes of Loughran, Shell Shock and Medical Culture in First World War Britain; Fiona Reid, Broken Men: Shell Shock, Treatment and Recovery in Britain 1914-1930; and Meyer, 'Separating the Men from the Boys: Masculinity and Maturity in Understandings of Shell Shock in Britain'. For the New Zealand texts, see: Gwen A. Parsons, 'The Construction of Shell Shock in New Zealand, 1919-1939: A Reassessment', Social History of Medicine, Vol.26, No.1, 2013, pp.56-73; and John Weaver, and David Wright, 'Shell Shock and the Politics of Asylum Committal in New Zealand, 1916-1922', Health and History, Vol.7, No.1, 2005, pp.17-40.

${ }^{59}$ Andreas De Block and Pieter R. Adriaens, 'Pathologizing Sexual Deviance: A History', Journal of Sex Research, Vol.50, No.3-4, 2013, p.294.

${ }^{60}$ Tamson Pietsch, in particular, outlines the centrality and importance of these knowledge networks in her 2013 book, Empire of scholars: Universities, networks and the British academic world 1850-1939. Additionally, Tony Ballantyne emphasizes the importance of imperial knowledge networks in a New Zealand context - for an example of this work, see his articles 'Strategic Intimacies: Knowledge and Colonization in Southern New Zealand'. Journal of New Zealand Studies, Vol.14, 2013, pp.4-18; and 'Thinking Local: Knowledge, Sociability and Community in Gore's Intellectual Life, 1875-1914'. New Zealand Journal of History, Vol.44, No.2, 2010, pp.138-56.
} 
through the war and in the post-war period on topics relating to mental disorders, gender, and sexuality. Views of male bodies and minds in the early twentieth-century were, as described above, largely understood through an evolutionary framework; and the history written on this topic employs similar methodologies to those of broader studies of sexuality. Evolving conceptions of eugenics were also central to these early twentieth century discussions, and this was true in both the British and New Zealand contexts - again, owing to the existence of the imperial knowledge networks. ${ }^{61}$ These largely British texts do, however, provide a strong foundation from which the history of interwar understandings of sexuality and gender can be approached. There does exist a body of work by historians on the history of insanity, body cultures, and eugenics, in New Zealand (and, more broadly, Australasian contexts) that this thesis also exists in conversation with. For example, Joy Damousi's examination of the spread of Sigmund Freud's work in the Antipodes; ${ }^{62}$ that written by Hamish Spencer on eugenic sterilisation in New Zealand; ${ }^{63}$ Angela Wanhalla's work on intermarriage and women in relation to eugenics; ${ }^{64}$ Charlotte Macdonald's review of significant eugenic moments in twentieth-century New Zealand; ${ }^{65}$ and Stephen Garton's investigation into eugenics in Australasia. ${ }^{66}$

Eugenics in New Zealand, as elsewhere, highlighted concerns about the declining birth-rate amongst 'white races'. Whilst there existed a fear of the Chinese, and other nonwhite 'races', in New Zealand at this time, the position of Māori was ambiguous and in some way exceptional. ${ }^{67}$ There existed an ideology of Aryan Māori (as argued in Edward Tregear's

\footnotetext{
${ }^{61}$ See Mathew Thomson's work for examples of this eugenic ideology at play: for example, Mathew Thomson, The Problem of Mental Deficiency: Eugenics, Democracy, and Social Policy in Britain, c.1870-1959 (Oxford: Clarendon, 1998); and M. Thomson, “'Savage Civilisation”: Race, Culture and Mind in Britain 1898-1939', in W. Ernst, and B. Harris (Eds.), Race, Science and Medicine, 1700-1960 (London: Routledge, 1999), pp.235-58. ${ }^{62}$ Joy Damousi, Freud in the Antipodes: A Cultural History of Psychoanalysis in Australia (Sydney: University Of New South Wales Press, 2005).

${ }^{63}$ Hamish G. Spencer, 'Eugenic Sterilisation in New Zealand', in Diane B. Paul, John Stenhouse, and Hamish G. Spencer (Eds.), Eugenics at the Edges of Empire: New Zealand, Australia, Canada and South Africa (Cham: Springer International Publishing, 2018), pp.85-106.

${ }^{64}$ Angela Wanhalla, Matters Of The Heart: A History Of Interracial Marriage In New Zealand (Auckland: Auckland University Press, 2013); and Angela Wanhalla, 'Debating Clause 21: 'Eugenic Marriage' in New Zealand', in Diane B. Paul, John Stenhouse, and Hamish G. Spencer (Eds.), Eugenics at the Edges of Empire: New Zealand, Australia, Canada and South Africa (Cham: Springer International Publishing, 2018), pp.107127.

${ }^{65}$ Charlotte Macdonald, 'Revisiting Three Eugenic Moments: 1903, 1928, and 1937: The Disappointments and Hopes of Antipodean Progressives', in Diane B. Paul, John Stenhouse, and Hamish G. Spencer (Eds.), Eugenics at the Edges of Empire: New Zealand, Australia, Canada and South Africa (Cham: Springer International Publishing, 2018), pp.219-241.

${ }^{66}$ Stephen Garton, "Liberty of the Nation': Eugenics in Australia and New Zealand and the Limits of Illiberalism', in Diane B. Paul, John Stenhouse, and Hamish G. Spencer (Eds.), Eugenics at the Edges of Empire: New Zealand, Australia, Canada and South Africa (Cham: Springer International Publishing, 2018), pp.21-40.

${ }^{67}$ Garton, p.32.
} 
influential 1885 text The Aryan Māori). This notion was popular, with a following including those among Māori and professionals, and Māori professionals. In this period 'race' was sometimes used to differentiate Māori from 'white' races, but also sometimes used to incorporate Māori within the white race when the concerns turned to external threats to the New Zealand population.

This thesis examines the discourse and perceptions of effeminacy, masculinity, and male sexuality in Aotearoa/New Zealand during the interwar period, 1918-1939. This work builds on that which I had undertaken during the writing of my History Honours dissertation, in which I examined how British doctors understood and discussed shell-shock in terms of masculinity and effeminacy. ${ }^{68}$ My suspicion, which led into the desire to research, was that the amount of rhetoric and knowledge that was produced during and after the Great War around men's mental illness (such as shell-shock and the other war neuroses) must have had some kind of impact on the way in which masculinity and male sexuality (heterosexual or homosexual, using modern terms) was framed in the post-war years. Hence my interest in taking this study into the interwar period. Whilst this does compose a part of the conclusions this thesis comes to, it also partially explains the time period this thesis examines. Additionally, whilst the end of the Great War (and the beginning of the Second World War) act as very useful bookends from a research point of view the two wars also act as markers of a sort for the different ways in which homosexuality, in particular, and by-association, effeminacy, was understood in the twentieth century. The wars' utility as markers of these shifting conceptions is due to the fact that although homosexuality remained criminalised until 1986, views of 'sexually deviant' men in New Zealand (which were remoulded and reconstructed in the interwar period following the experiences of the First World War) became largely pathologized following the Second World War. ${ }^{69}$

Homosexuality was viewed as a crime in colonial-era nineteenth century New Zealand, with men charged with same-sex activity being punished, either with imprisonment, hard labour, or flogging (or a combination of the above) ${ }^{70}$ The concept, and understanding,

\footnotetext{
${ }^{68}$ Ailish Wallace-Buckland, 'Understanding Effeminacy and Masculinity in Discussions of Shell-shock in British Medical Culture, 1914-1922', Honours thesis, Victoria University of Wellington, 2018.

${ }^{69}$ This pathologisation solidified even further following the British 1957 Wolfenden Report on homosexuality and prostitution (which played a discernible role in New Zealand debates on the topic). For more information, see: James Bennett, 'Keeping the Wolfenden from the Door? Homosexuality and the 'Medical Model' in New Zealand', Social History of Medicine, Vol.23, No.1, pp.134-152.

${ }^{70}$ Brickell, Mates and Lovers: A History of Gay New Zealand, p.30.
} 
of Takatāpui existed in pre-colonial New Zealand, however, with the view of same-sex desire as something criminal being a British settler import. ${ }^{71}$ Around the middle of the twentiethcentury the language used around homosexuality shifted to be more medical in nature, with same-sex actions and desire viewed in terms of 'disease'. ${ }^{72}$ There was a period in which queer men (and women) were sent to mental institutions where they were treated with therapies in order to cure them of their homosexuality. ${ }^{73}$ Homosexual relations were still seen as a criminal act into the latter half of the twentieth century, and it was not until the Homosexual Law Reform Act of 1986 that sexual activity between men over the age of 16 was decriminalised in New Zealand. ${ }^{74}$ This thesis examines a period during which there was a shift in rhetoric around male same-sex desire, from the criminal to the more medical, which occurred most critically during the interwar period, yet is not something that is widely discussed or dissected in the existing New Zealand historiography.

The importance of terminology to histories of gender, sexuality, and masculinity is something that my previous work on shell-shock also influenced, as such discussions around language are prominent in the work of many scholars of insanity. ${ }^{75}$ Language and terminology is also something that historians of sexuality $d o$ engage with. Chris Brickell, for example, in his book Mates \& Lovers: A History of Gay New Zealand comments on the importance of terminology when it comes to studies of what he dubs "homoerotic life". ${ }^{76}$ The term 'gay', he states, is anachronistic - that is, to a twenty-first century reader it connotes certain understandings around relationships, desires, and sexual acts between men, that Brickell argues, ${ }^{77}$ cannot simply be applied to the past without at least some recognition of the changing nature of, and meaning carried by, language.

\footnotetext{
${ }^{71}$ Elizabeth Kerekere, 'Part of The Whānau: The Emergence of Takatāpui Identity: He Whāriki Takatāpui', $\mathrm{PhD}$ Thesis, Victoria University of Wellington, 2017, p.59. It should be noted that the role colonisation plays on gender (identity) and sexuality in New Zealand, though not always at the forefront of this thesis, certainly simmers just below, or on the peripheral, of such discussions, especially in relation to evolutionary framework perceptions and the interests in eugenics. See also: Jessica Hutchings, and Clive Aspin (Eds.), Sexuality \& The Stories Of Indigenous People (Wellington: Huia Publishers, 2007) re. indigenous sexuality.

${ }^{72}$ Guy, p.37.

${ }^{73}$ James E. Bennett, and Chris Brickell, 'Surveilling The Mind And The Body: Medicalising And DeMedicalising Homosexuality in 1970s New Zealand', Medical History, Vol.62, No.2, 2018, p.200. You can see the remnants of this kind of thinking around homosexuality as something to be 'cured' in Western society still to this day, with the idea of conversion camps for LGBTQ+ peoples.

${ }^{74}$ Guy, p. 217.

${ }^{75}$ For many scholars of insanity, particularly those of shell-shock, the use of particular language and terminology is vital to make clear in the writing of said histories. For an example of a shell-shock historian who grapples with this linguistic dilemma, see Loughran, p.11.

${ }^{76}$ Brickell, Mates and Lovers: A History of Gay New Zealand, p.9.

${ }^{77}$ For more information on language and social constructionism in relation to sexuality and gender see: Chris Brickell, 'The sociological construction of gender and sexuality', Sociological Review, Vol.54, No.1, February 2006, pp.87-113.
} 
For the purposes of this thesis, I will be employing the contemporary terms where applicable in the primary sources under discussion. ${ }^{78}$ As Chris Brickell says, "we do need to look closely at people's own language if we really want to find out how they have understood their sexual desires". ${ }^{79}$ I have taken this to apply to those in the medical world, and wider society (as well as to those people who we would today classify as 'queer') in order to better understand how ideas of masculinity, homosexuality, and effeminacy were discussed in interwar New Zealand.

In order to examine the connections between constructions of the male body, homosexuality and effeminacy, late nineteenth to early twentieth-century ideas around eugenics, and psychology and psychiatry, this thesis utilises a combination of sources. It surveys legislation and official reports concerning mental defectives and sexual offenders; medical literature, from the purely psychological to the more general, and preventive medicine focuses; and popular magazine and print culture.

The medical sources, which chapter two utilises, include the British Journal of Psychology (BJOP), the New Zealand Medical Journal (NZMJ), and a selection of the Preventive Medicine dissertations written by fifth-year medical students at the University of Otago. For this thesis I accessed bound copies of the BJOP for the period of 1918-1939 from the Victoria University of Wellington Library. Most of these bound tomes contained the four volumes of the journal that were published each year. By working through all of the interwar volumes of the journal it became clear that the content within them that I deemed was relevant to my research aims and the purpose of my thesis could be placed into approximate categories. These categories include: theories related to a narrow definition of psychology and psychiatry; content related to eugenics, and the evolutionary framework of understanding, which also encompasses topics such as degeneration and regression; that related to emotions and emotionality; articles about sex and sexuality (as well as marriage); as well as a miscellany of other content that was more peripheral.

Whilst this thesis has a focus on Aotearoa/New Zealand, and the way that masculinity and male sexuality were understood and perceived between 1918-1939, I argue that the inclusion of this British medical journal remains significant to depicting the full picture. Print culture served as a continuous, and vital, tool for circulating knowledge within networks that

\footnotetext{
${ }^{78}$ Terms such as 'homosexuality' were starting to be utilised by those who studied sex like Richard von KrafftEbing, in his Psychopathia Sexualis (1892).

${ }^{79}$ Brickell, Mates and Lovers: A History of Gay New Zealand, p.8.
} 
encompassed New Zealand. ${ }^{80}$ In regards to this particular journal, as a psychology focused publication, these networks - whether personally amongst doctors, or through print culture (i.e. the distribution of books, journals, and articles) - are central to understanding when, why, and how certain psychological theories and practices reached New Zealand, and were taken up by New Zealanders. ${ }^{81}$

Established in 1887 by the New Zealand Branch of the British Medical Association (BMA), the $N Z M J$ was the official journal of the New Zealand Medical Association. For this thesis I have examined volumes of the journal from the period of $1918-1940 .{ }^{82}$ The $N Z M J$ is a peer-reviewed medical journal, and during the time-frame my thesis focuses on, the journal was printed in Wellington on Boulcott Avenue with six issues published per year. The authors of the articles published were largely medical professionals working in New Zealand, however there were also instances of certain works being reprinted from international journals. ${ }^{83}$ Each volume consisted of around 200 pages of articles, case reports, and correspondence, with additional pages for advertisements. Although the intended readership of the journal was medical practitioners (especially those who held membership to the New Zealand Branch of the BMA), as opposed to psychologists or psychiatrists, a sprinkling of content - in articles, but also in the advertisements - touched on topics related to psychology and psychiatry. The journal's issues also included content that comes under the umbrellas of evolutionary-framework thinking and eugenics, as opposed to more 'practical' medical, physical, or disease-specific instruction. Hence they are important in piecing together the bigger picture understanding of male sexuality in interwar New Zealand.

\footnotetext{
${ }^{80}$ See Tony Ballantyne, Webs of Empire: locating New Zealand's colonial past (Vancouver: UBC Press, 2014); Ballantyne 'Strategic Intimacies: Knowledge and Colonization in Southern New Zealand'; Ballantyne, 'Thinking Local: Knowledge, Sociability and Community in Gore's Intellectual Life, 1875-1914'; and Susann Liebich, 'Connected Readers: Reading Practices and Communities Across the British Empire, c. 1890-1930', $\mathrm{PhD}$ thesis, Victoria University of Wellington, 2012.

81 This is something that is also 'tracked' in this thesis through other sources, such as the magazines, to see when, where, and in what forms certain psychological topics were of interest in New Zealand, and how they were understood and shared.

${ }^{82}$ I was able to access to the NZMJ via three different libraries - the Victoria University of Wellington (VUW) Library (which only held the volumes from 1936-1940; however, as each volume was held in its individually published form rather than bound in a collection, these were practically the only copies of the journal that included the advertisement sections); the Wellington Medical and Health Sciences Library (in which I looked at the bound volumes for the years: 1918-1919, 1922, 1936, 1938, \& 1939 (for certain of the volumes missing from the VUW collection); and the University of Otago Health Sciences Library (where I had access to the bound volumes from1922-1925.) It is noteworthy that the bound collections of the journal did not include advertisements, as this can indicate to us as historians what librarians may have been thinking at the time in regard to what would be of future importance and utility to medical professionals, students, and historians who read the NZMJ.

${ }^{83}$ See 'Analytical Department', New Zealand Medical Journal, Vol.21, No.105, October 1922, pp.305-307 which states at the top of page 305 that it has been: "Reprinted from "The Medical Journal of Australia", October 22, 1921”.
} 
By examining 81 volumes of the NZMJ spanning the 23 year period of $1918-1940$, the content can be loosely classified into the following groups: psychology, psychiatry, and psychoanalysis; sex and sexuality; that which relates to eugenics, and/or population concerns; that which touches on official government inquiries and legislation passed, or state institutions; as well as a miscellany of content associated with other areas with which this thesis interacts, such as work, networks, and the Great War.

The Preventive Medicine dissertations that this thesis utilises are currently held by the Hocken Collections, part of the University of Otago, in Dunedin (the same university that the students themselves studied at). ${ }^{84}$ When selecting the essays to examine for this thesis, my approach was to look into those written during the interwar years whose titles indicated that they may provide information on the following topics: mental health, the physical body, masculinity and sexuality, and anything that would come under the branch of eugenics. ${ }^{85}$ From this initial selection I was able to choose 21 dissertations (spanning in time from 19261939) to read over two separate research visits to Dunedin, 19 of which provided at least some material that has proved useful to my research. Though their utility is somewhat limited by the restrictions put in place due to the personal and medical content in the essays, the Preventive Medicine dissertations nevertheless are a rewarding, and, so far, underutilised source that grants us insight into both the popular and niche interests of the medical community over a c. 50 year period. ${ }^{86}$

Whilst the dissertations themselves provide little personal information relating to their authors beyond the students' names, and that given in the acknowledgements or forwards of the essays (that is, if these writing conventions were included) - information that usually briefly stated how the work was undertaken, and included a thank you to any staff who aided the students during their research - some further comments can be made. Of the 21 dissertations examined, nine were co-authored, and four were undertaken by female students. ${ }^{87}$ Each was bound in a different manner, and around half were hand-written (as

\footnotetext{
${ }^{84}$ My thanks to Richard German of the Otago University Science and Health Sciences Libraries, who kindly sent me a list of titles.

${ }^{85}$ I was greatly aided in this selection by the chronological and themed lists that Richard German from the Otago Health Sciences Library provided me following an inquiry to the Otago Library Special Collections staff. There are over 200 dissertations from the 1923-1939 period, so this selection process was highly necessary to feasibly work through the sources available.

${ }^{86}$ Restrictions including the inability to photograph or scan any of the dissertations - which certainly lengthened visits to the Hocken; and the inability to identify any individuals named, or addresses listed, in them.

${ }^{87}$ One can also find out when these students graduated - if indeed they did - by looking at graduation lists; of which, Dorothy Page kindly provided in the back of her book Anatomy of a Medical School: A History of Medicine at the University of Otago 1875-2000 (Dunedin: Otago University Press, 2008).
} 
opposed to typed). Topics covered by the entire cohort were extremely diverse, covering subjects such as: housing, water supply, goitre, tonsils, teeth, influenza, as well as those more directly related to this thesis.

The 21 dissertations selected for this research can largely be grouped into four broad areas (plus a miscellaneous scattering): community health surveys; children, and infant mortality; those related to race, or eugenics; those that touch on psychology or psychiatry, and mental health and wellbeing. Some themes that commonly feature in the dissertations include discussions of medical and/or psychological networks; print culture; mental health, and wellbeing; the evolutionary framework of understanding, and the notion of heredity; acknowledgement of a link between the body and the mind; comments on feeblemindedness, and so-called mental defectives; in addition to views on Māori, as well as racial and eugenic topics.

The popular culture sources, which chapter three examines, feature The New Zealand Truth (The NZ Truth), Health and Physical Culture (H\&PC), Health and Sunshine (H\&S), and The Monocle: The New Zealand Monthly Magazine (The Monocle). The NZ Truth was, “for many years one of the country's most colourful, controversial and popular newspapers". ${ }^{88}$ Founded in 1905 by the Australian newspaper publisher, John Norton, and modelled on Australian papers, The NZ Truth was first published in 1906, printed in Wellington. ${ }^{89}$ The NZ Truth was a weekly national paper that won itself a large readership across New Zealand - it claimed circulation "to every town and village in the colony"90 - and though it may not have always drawn admiration, was a greatly influential newspaper in interwar New Zealand.

This thesis uses The NZ Truth as a primary source because it differs from the other print sources examined. It is a newspaper, rather than a magazine, with very broad circulation and a wide readership. It is a source of value to this thesis because of the different ways in which it could, and was allowed to discuss topics such as sexuality, and mental health.

The NZ Truth is accessible on Papers Past, and key words were utilised to find relevant articles from the period between 1918-1930.91 I acknowledge the limits and

\footnotetext{
88 'NZ Truth', Papers Past; paperspast.natlib.govt.nz; accessed 20 June 2019.

${ }^{89} \mathrm{Ibid}$. No issues are known to exist in the first year following the paper's founding, with the first one published in July 1906.

${ }^{90}$ Redmer Yska, Truth: The Rise And Fall Of The People's Paper (Nelson: Craig Potton Publishing, 2010), p.19.

${ }^{91}$ Results from the tabloid are only available up to 1930 online on Papers Past. The key words were more focused on the effeminate and degenerate side of things to try and follow that, as terms like "nerves" or "feebleminded" threw up hundreds upon hundreds of results (many of which were in fact, irrelevant to the purpose of this thesis. The search-words used were: Effeminate; effeminacy; effete; homosexual; fop; foppish; aesthete;
} 
criticisms of digital newspaper archives, which historians such as Kathryn M. Hunter, ${ }^{92}$ and Tony Ballantyne have described. ${ }^{93}$ But for tracking the dissemination of ideas, the digital form has distinct advantages, as noted by Catherine Bishop. ${ }^{94}$ Through examining the articles that came up using this search-methodology, one can broadly place them in the following categories: those related to effeminacy and/or homosexuality; those about sodomy; criminality; fops/aesthetes, and aesthetic/fashion culture(s). Articles about degeneracy; eugenics; sexuality; and, lastly, mental health, and shell-shock and other war neuroses.

Health and Physical Culture was a Sydney-based lifestyle magazine published monthly from Pitt Street between 1929-1943 and available in New Zealand. ${ }^{95}$ Founded in 1929 by Alfred J. Briton, and alternatively titled: Health and Physical Culture: Briton's Monthly Journal, the magazine covered a variety of topics it saw of interest to its readership. It described itself as, "A magazine devoted to the wider branches of physical education, embracing Physiology, Psychology, Hereditary, Eugenics, Economics, Anthropology, Public Health, Sex Hygiene and Education, Mental Hygiene, Industrial Welfare, Maternal and Child Welfare, Nutrition and Dietetics, etc." 96 The magazine, though devoted to the body, presented itself as, "written by authoritative people, and presented entertainingly for thinking men and women." ${ }^{97} H \& P C$ clearly saw itself as a magazine that would tackle concerns of its age, especially those related to physical and mental health and fitness across Australasia, as it outlined in its self-description. It is because of these concerns that this thesis uses the magazine as an avenue through which historians can understand anxieties around effeminacy, and male sexuality as a whole, as these topics crop up in the pages of $H \& P C$.

While available for purchase and subscription in New Zealand, no coherent collection of the magazine is available in New Zealand repositories. I relied on a range of access methods including interloaning and remote requests of issues between June 1930 to

aesthetic; degenerate; degeneracy; queer; dandy; invert; feeble; viril; virile; modern man; sexual; masculine; feminine + men; hysteria; mental defective; defective; shell shock; shell-shock; shellshock; sodomy; and heredity.

${ }^{92}$ Kathryn M. Hunter, 'Silence in Noisy Archives: Reflections on Judith Allen's 'Evidence and Silence Feminism and the Limits of History' (1986) in the Era of Mass Digitisation', Australian Feminists Studies, Vol.32, No.91-92, August 2017, pp.202-212.

93 Tony Ballantyne, 'Reading the Newspaper in Colonial Otago', Journal of New Zealand Studies, Vol.12, 2011, pp.47-63.

${ }^{94}$ Catherine Bishop, 'The Serendipity of Connectivity: piecing together women's lives in the digital archive', Women's History Review, Vol.26, No.5, September 2017, pp.766-780.

95 Though based in Sydney, the magazine found readership across the Tasman. Again, this cross-country readership also speaks to the importance of the international ties and networks that New Zealand had and took part in during the interwar period.

${ }^{96}$ From the research this thesis has undertaken, it appears as if this description was first printed in: Health and Physical Culture, 1 November 1935, p.7.

${ }^{97}$ Health and Physical Culture, 1 November 1935, p.7. 
November 1938 held at the State Library of New South Wales. As there was a large number - around 120 - of $H \& P C$ issues published monthly during the period of 1929-1939

(averaging at around 70 pages in length), issues and articles were chosen at first by their titles which were thought to in any way be relevant to the topics this thesis is concerned with (sexuality, masculinity/femininity, psychology, eugenics, etc.). As such they represent a conservative sample of the articles that may have contained commentary on masculinity.

Founded in 1936 by the then 29-year-old Trevor G. Bain, Health and Sunshine was a magazine devoted to improving the bodies and health of New Zealanders. This monthly magazine was published in Auckland between October 1936 to July 1937, with its articles written by Bain himself as a well as a number of other contributors (though little is known of them). I accessed volumes of Health and Sunshine from the Hocken Collections at Otago. The Hocken held only a few volumes of the short-lived magazine, ${ }^{98}$ though the magazine remains an important source for this thesis. For one, it is a New Zealand-based magazine published and created locally, which serves as a comparison point to the more 'internationally flavoured' Australasian Health and Physical Culture. It also combines the strictly physical and eugenic interests of this era with other things such as the more psychological, and sexuality-based subjects.

Health and Sunshine magazine combined nudist interests with other topics that are of concern in this thesis. Topics such as: psychology, and the discussion of hysteria and nerves; gendered behaviour, and expectations; population concerns, and virility; international networks, and precedents/comparisons; sport; fashion; mental wellbeing; sexuality and sex; as well as modernity; employment; and the Great War (and its effects). $H \& S$ gives us insight into the New Zealand nudist scene - which was inherently related to the physical culture movement; which in turn had links to broader debates around physicality, population, eugenics, and psychology. $H \& S$ therefore offers historians a lens into the ways such movements engaged with, and defined masculinity and male sexuality in New Zealand between 1918-1939.

The Monocle was first published in May 1937. Otherwise known as The New Zealand Quality Magazine or Everyman's: The Monthly Magazine for Men,${ }^{99}$ this magazine saw itself as, "a journal for goodfellows" - in other words, as a publication for men who were wanting to enrich themselves with information on a variety of topics seen by the magazine's

\footnotetext{
98 The Alexander Turnball Library also holds several volumes of $H \& S$.

${ }^{99}$ Everyman's was to be the original title.
} 
contributors as being beneficial to New Zealand men's mental, physical, fiscal, and social wellbeing. ${ }^{100}$

I accessed physical copies of individual volumes of the magazine for the period 19371939. These copies were available to me from the Hocken Collections, and though incomplete, allowed me to gain a general view on the topics that were frequently discussed in articles across the timespan in which The Monocle was published. ${ }^{101}$ The magazine covered topics ranging across love, sex, and marriage (as well as desire); philosophy and politics; work, and (un-)employment; entertainment such as sports and film; as well as fashion. In addition, The Monocle touches on themes that are significant to this thesis such as: bodies and physical health; population concerns (and eugenics); minds and mental health, as well as psychology and psychiatry; and, finally, masculinity and femininity.

This thesis is divided into three chapters. The first outlines some of the key pieces of legislation and government produced findings that demonstrated official approaches, and ways of thinking, toward mental defectives, sexual offenders, and those with war neuroses. The legislation and reports do not necessarily extensively, or exclusively, address masculinity rather they underpin the official political and administrative responses and approaches to things like mental diseases, eugenics, and marriage, which do reference masculinity and sexuality. Such official approaches were informed by and were in dialogue with both medical knowledge and popular social mores, which are the focuses of chapter two and three.

The second and third chapters are divided into themed sections that address central topics related to the discussion and debate around masculinity, and effeminacy. These themed sections include: Networks; Mental Health and Fitness; Psychology and Psychiatry; Evolutionary Framework of Understanding and Eugenics; Mind and Body; The Clothed Man and The Naked Man; and Sex, Sexuality, Marriage, and Masculinity. Chapter two examines perceptions of effeminacy in the medical world. It explores medical journals, the highly topic-specific BJOP, and the more general-natured $N Z M J$, as well as the Preventive Medicine dissertations of fifth-year medical students from Otago University. It establishes the psychological approaches to, and discussions of, effeminacy, masculinity, and mental illness circulating in the medical literature. Chapter two demonstrates the centrality of international

\footnotetext{
100 The Monocle, Vol.1, No.1, May 1937, p.3.

${ }^{101}$ The National Library also holds a number of volumes of The Monocle.
} 
networks to the development of, and access to, such knowledge, debates and hypotheses in New Zealand during the interwar years.

The third chapter investigates and pieces together the popular culture conceptions of effeminacy, masculinity, mental stability, and other deviations from the societally prescribed norms of physical, mental, and sexual fitness. Examining evidence from The NZ Truth and the three magazines, the chapter demonstrates that by the late 1930s a wide variety of debates and theories about effeminacy had entered popular discussion in New Zealand.

There is some crossover between both themes, and chapters one, two, and three. This thesis is not chronologically divided, but is structured in a way that addresses the subject and seeks to answer the questions by examination of very contrasting angles. Overall, however, it is possible to see some of the ways that a crisis in masculinity during the Great War became a topic of broad and wide-ranging popular debate during the subsequent two decades. Through vehicles as diverse as medical specialist journals through to niche publications concerned with nudism, the male body and mind came under significant scrutiny from legislators, professionals, voyeurs and gossips. 


\section{CHAPTER ONE}

\section{$\underline{\text { Legislation and Reports }}$}

In order to provide a base for the discussions of effeminacy and the anxieties around New Zealand masculinity that lie at the heart of this thesis, this chapter considers the official responses to 'problem' masculinity in the interwar years. It presents some of the most important legislation and government reports that acted as prominent political and administrative responses, and that provided the foundation for, and reference point to, a number of interwar discussions and debates of masculinity, effeminacy, and male sexuality in both the medical and popular print culture worlds during this era in New Zealand. Committees of Inquiry with evidence, reports, and proposed and final legislation presented official and authoritative views on a number of topics that repeatedly appear in the primary sources the following chapters of this thesis examines. These topics included issues such as mental disorders and deficiency, eugenics, marriage - and by extension, masculinity, and sexuality. ${ }^{1}$ The sources this chapter references are the Mental Defectives Act (1911), ${ }^{2}$ and Amendment (1928); ${ }^{3}$ the Mental Defectives and Sexual Offenders: Report of the Committee of Inquiry (1925); ${ }^{4}$ and the Report of the War Office Committee of Enquiry into "Shellshock" (1922). ${ }^{5}$

On 21 October 1911 an act was passed to "consolidate and amend the Law relating to the Care and the Control of Mentally Defective Persons" in New Zealand by the General

\footnotetext{
${ }^{1}$ Historians have already undertaken much work on the discussions of mental disorders, and insanity and gender in New Zealand. For example, see: Barbara Brookes, 'Papering over madness: accountability and resistance in colonial asylum files: a New Zealand case study', The Journal of Theory and Practice, Vol.22, No.3, July 2018, pp.356-374; and Barbara Brookes, 'Women and Madness: A Case-study of the Seacliff Asylum, 1890-1920', in Barbara Brookes, Charlotte, Macdonald, and Margaret Tennant (Eds.), Women in History 2 (Wellington: Bridget Williams Books, 1992), pp.129-147; Bronwyn Labrum 'Looking beyond the Asylum: Gender and the Process of Committal in Auckland, 1870-1910', The New Zealand Journal of History, Vol.26, No.2, October 1992, pp.125-144; Catherine Coleborne, 'Insanity, Gender and Empire; Women Living a 'Loose Kind of Life' on the Colonial Institutional Margins, 1870-1910', Health and History, Vol. 14, No.1, 2012, pp.77-99; and Catherine Coleborne, and Dolly MacKinnon (Eds.), Madness in Australia: Histories, Heritage and Asylum (Brisbane: University of Queensland Press, 2003); and Jennifer S. Kain, Insanity and Immigration Control in New Zealand and Australia, 1860-1930 (Cham: Springer International Publishing, 2019).

${ }^{2}$ Mental Defectives Act 1911.

${ }^{3}$ Mental Defectives Amendment Act 1928.

${ }^{4}$ Mental Defectives and Sexual Offenders: Report of the Committee of Inquiry Appointed by the Hon. Sir Māui Pōmare, K.B.E., C.M.G., Minister of Health, Appendix to the Journals of the House of Representatives, 1925 Session I, H-31A.

${ }^{5}$ Great Britain War Office Committee Enquiry into "Shell-shock", Report of the War Office Committee of Enquiry into "Shell-shock" (London: H.M.S.O., 1922).
} 
Assembly of the New Zealand Parliament. ${ }^{6}$ This Act, which came into operation on 1 March 1912, is often cited by its short-form title: the Mental Defectives Act 1911. ${ }^{7}$ This Act has been noted by some historians of insanity in Aotearoa/New Zealand as a significant turning point in both mental health law, and the treatment of patients in practice. ${ }^{8}$ It allowed people to admit themselves to mental hospitals voluntarily, and thus prompted the beginning of a decline in the stigma of committal and residence in mental institutions. ${ }^{9}$ However, this stigma, though in decline, had not fully waned by the time of the Great War. This prompted the New Zealand Army to call for the utilisation of half-way houses for returned soldiers who were suffering from 'shell-shock', as this meant that these men were not subjected to the full dishonour of being committed to asylums with full 'insane types', and could therefore retain some of their dignity and masculinity. ${ }^{10}$

In 1925, three years prior to the amendment to the Mental Defectives Act, the Committee of Inquiry into Mental Defectives and Sexual Offenders presented their report to Parliament. Commissioned by the Minister of Health Sir Māui Pōmare in 1923, the purpose of the formal enquiry was to "make broad recommendations about the treatment of mental defectives and sexual offenders". ${ }^{11}$ The committee travelled the length of the country in 1924, delivering their 34 page report the following year to ministers in parliament. Hamish G. Spencer remarked that much of the evidence in the submissions the Committee received, "focused on issues of sterilisation and desexualisation (castration)", consequently leading to the prominence of eugenic ideas in the report itself. ${ }^{12}$

Three years on then, in 1928, the 1911 Mental Defectives Act was followed by an amendment which, included, and, "anticipated separate training institutions for intellectually handicapped patients." 13 The 1928 Mental Defectives Amendment Act came into force on 1 January 1929, and it provided for the establishment of a special board whose function was, in large part, to compile a register of the names of all mentally defective people in New

\footnotetext{
${ }^{6}$ Mental Defectives Act 1911.

${ }^{7}$ Mental Defectives Act 1911.

${ }^{8}$ Bronwyn Labrum, 'Looking beyond the Asylum: Gender and the Process of Committal in Auckland, 18701910', The New Zealand Journal of History, Vol.26, No.2, October 1992, p.127.

${ }^{9}$ Warwick Brunton, 'Mental Health Services: Mental hospitals, 1910s to 1930s', Te Ara: The Encyclopedia of New Zealand; www.teara.govt.nz; accessed December 182019.

${ }^{10}$ John Weaver, and David Wright, 'Shell Shock and the Politics of Asylum Committal in New Zealand, 19161922', Health and History, Vol.7, No.1, 2005, pp.36-37.

${ }^{11}$ Hamish G. Spencer, 'Eugenic Sterilisation in New Zealand', in Diane B. Paul, John Stenhouse, and Hamish G. Spencer (Eds.), Eugenics at the Edges of Empire: New Zealand, Australia, Canada and South Africa (Cham: Springer International Publishing, 2018), p.87.

12 Spencer, p.88.

${ }^{13}$ Warwick Brunton, 'Mental Health Services: Mental hospitals, 1910s to 1930s', Te Ara: The Encyclopedia of New Zealand; www.teara.govt.nz; accessed December 182019.
} 
Zealand. ${ }^{14}$ The initial 1911 Act, the 1928 Amendment Act, and the 1925 report echoed the increasing interest in eugenic ideologies in New Zealand, which gained wider public renown following the Great War. There was, however, some discomfort in the wider community (and Parliament) over certain aspects of the 1928 legislation's more extreme recommendations evident in the difference between the initial Bill introduced to parliament and the final Act. Due to the failure to gain parliamentary approval, these sections of the Bill - clauses such as those that would provide for the sterilisation, and banning of marriage of mentally defective persons - were removed as it passed through Parliament in 1928 prior to the passing of the amendment to the Act. ${ }^{15}$

Though the amendment removed the above-stated clauses from the Bill, Spencer has argued that 1928 can still be seen, "in retrospect... as the 'high-water mark' of the eugenics movement in New Zealand," for the sheer fact that such measures were considered in the first place. 16 "In the case of New Zealand", Spencer also noted, "eugenic ideas clearly influenced the treatment of those considered mentally defective, to the point where sterilisation did occur in spite of its questionable legality," and in spite of its exclusion from this particular piece of legislation. ${ }^{17}$ These practices form part of the broader eugenic concerns in New Zealand during the early twentieth century. Proponents of eugenics were concerned with and sought to mould and control both the quality and quantity of the nation's population. ${ }^{18}$

Part of the desire to control population standards and size in New Zealand was the concern in the interwar period that there had been a reduction in family size. With the establishment of associations such as the Plunket Society, Diane B. Paul has noted that New Zealand had been able to achieve "the lowest (white) infant mortality rate in the world"; ${ }^{19}$ yet this did not mean that it was a nation free from concerns about family size and health, with

\footnotetext{
${ }^{14}$ Mental Defectives Amendment Act 1928.

${ }^{15}$ Spencer, p.85.

${ }^{16}$ Spencer, p.97.

${ }^{17}$ Spencer, p.98.

${ }^{18}$ Charlotte Macdonald, 'Revisiting Three Eugenic Moments: 1903, 1928, and 1937: The Disappointments and Hopes of Antipodean Progressives', in Diane B. Paul, John Stenhouse, and Hamish G. Spencer (Eds.), Eugenics at the Edges of Empire: New Zealand, Australia, Canada and South Africa (Cham: Springer International Publishing, 2018), p.220. This desire to control the population, Charlotte Macdonald has described, troubled New Zealand historians since they turned to the topic of eugenics in the late 1970s. Yet the debates around reports and legislation, and the clauses included in Bills but not Acts, demonstrates an intent to mould a population that to more modern sensibilities is viewed as "overbearing, distasteful, and repugnant." Macdonald, 'Revisiting Three Eugenic Moments: 1903, 1928, and 1937: The Disappointments and Hopes of Antipodean Progressives', p.236.

${ }^{19}$ Diane B. Paul, 'Truby King, Infant Welfare and Boundaries of Eugenics', in Diane B. Paul, John Stenhouse, and Hamish G. Spencer (Eds.), Eugenics at the Edges of Empire: New Zealand, Australia, Canada and South Africa (Cham: Springer International Publishing, 2018), p.245.
} 
the use of birth control remaining a contentious issue throughout the interwar years. ${ }^{20}$ Nor was New Zealand able to escape the effects of the Great War (it saw c.58,000 war 'casualties', of whom 16,000 died); ${ }^{21}$ or of the 1918 influenza pandemic (which saw the nation lose about half as many people to influenza in two months as had died in the whole of the war). ${ }^{22}$ Stephen Garton has outlined that whilst racial theory in New Zealand did not see Māori as an inferior race to Pākehā, there remained concerns around external factors - such as the "potential hordes of Asia" - and the exclusion of "undesirables" - such as mental defectives. ${ }^{23}$ This combination of anxieties, and the eugenic ideas presented as solutions to said problems, also influenced the ways in which men and masculinity were perceived in New Zealand as the construction of the ideal man acted in conversation with such emerging scientific theories, as well as with those of a specifically psychological nature. ${ }^{24}$

The 1928 Act is important to discuss in regard to this thesis as it shows a crucial part of the official and formal expression and response to eugenic ideas about mental defectives and sexual offenders - and by extension, on mental illnesses and neuroses, as well as those who were classified under the Criminal Code (i.e. those who committed acts such as buggery, sodomy, and sexual assault.) These parliamentary reports and legislation also acted as reference points for parts of the New Zealand population, especially those in the professional medical field in their views on, and interactions with, people that could be categorised under these acts as mental defectives, feeble-minded, or sexual offenders. Evidence of the involvement of medical professionals in these subjects can be seen when they are directly referenced in medical texts and publications, such as the New Zealand Medical Journal, and the Preventive Medicine dissertations, that chapter two of this thesis examines. ${ }^{25}$

The British War Office Commission's 1922 report into "Shell-shock" provided the British government with an official review of the condition commonly called shell-shock.

\footnotetext{
${ }^{20}$ Paul, p.258.

21 'First World War by the numbers', New Zealand History; www.nzhistory.govt.nz; accessed 28 July 2020.

22 'The 1918 flu pandemic', New Zealand History; www.nzhistory.govt.nz; accessed 28 July 2020.

${ }^{23}$ Stephen Garton, 'Liberty of the Nation': Eugenics in Australia and New Zealand and the Limits of Illiberalism', in Diane B. Paul, John Stenhouse, and Hamish G. Spencer (Eds.), Eugenics at the Edges of Empire: New Zealand, Australia, Canada and South Africa (Cham: Springer International Publishing, 2018), pp.31-32. For more on these ideas around Māori, see Garton's text, as he describes the influence of Edward Tregear's The Aryan Māori (1885) on eugenic and evolutionist views of Māori into the early twentieth-century. ${ }^{24}$ As can also be seen on the international stage - a topic discussed by historians such as Tracey Loughran in her book Shell-Shock and Medical Culture in First World War Britain (Cambridge: Cambridge University Press, 2017).

${ }^{25}$ For example, see: M. Christie, and R. Christie, 'A Study of Porirua Mental Hospital', Preventive Medicine Dissertation, University of Otago, 1936, p.12; 'Editorial', New Zealand Medical Journal, Vol.24. No.121, June 1925, pp.171-172; 'British Medical Association, New Zealand Branch: Meeting', New Zealand Medical Journal, Vol.27, No.141, October 1928, p.339; 'Liability of Medical Practitioners Certifying under Mental Defectives Act', New Zealand Medical Journal, Vol.29, No.154, December 1930, p.383.
} 
The purpose of the report, which collated the expertise of various authorities who had experience with shell-shock during the war, was to, "record for future use the ascertained facts as to its [shell-shock's] origin, nature and remedial treatment, and to advise whether by military training, or education, some scientific method of guarding against its occurrence can be devised." 26 The report brought together evidence from interviews with doctors, psychiatrists, academics, soldiers, and officers, in order to propose how the state, and the military, could proceed in: preventing such large numbers of sufferers of mental neuroses in future conflicts; curing the men still dealing with shell-shock in the post-war years; and it also outlined how to deal with those who were viewed as potential drains on the state and war pensions. ${ }^{27}$ The report was also referenced back to for an understanding of the causations, experiences, and character of men suffering with shell-shock and other war neuroses. It also influenced the way in which medical professionals, and government officials approached these men after the war - and ultimately, therefore, also impacted on their understandings of masculinity. ${ }^{28}$ Though British in origin, the 1922 report acted as an official and authoritative source from which New Zealand medical professionals read and referred back to as they faced male patients in the post-war period still suffering from shell-shock and other war neuroses; and thus shaped their perceptions of a New Zealand sense of masculinity. ${ }^{29}$

During the First World War it is estimated that around 80,000-200,000 soldiers were treated for 'shell-shock' by the British Army. ${ }^{30}$ It must be noted, however, that official statistics were and still are hard to pin-down, and the 1922 report even commented on this

\footnotetext{
${ }^{26}$ Great Britain War Office Committee Enquiry into "Shell-shock", Report of the War Office Committee of Enquiry into "Shell-shock" (London: H.M.S.O., 1922), p.3

${ }^{27}$ For a summary of the report's conclusions see: Great Britain War Office Committee Enquiry into "Shellshock", Report of the War Office Committee of Enquiry into "Shell-shock" (London: H.M.S.O., 1922), pp.190193

${ }^{28}$ Ted Bogacz argued that whilst the Enquiry both recognised that the war and the experience of shell-shock had thrown into question some of, "the most fundamental inherited conceptions of how a man ought to act" (in the way that the concepts of 'cowardice' and 'insanity' came to be newly understood), it also perpetuated ideas and ideals formed in pre-war discourses regarding Darwinism, and the evolutionary framework model of understanding that stressed the significance of heredity and individual character when it came to regression and the development of mental neuroses. In short, the report both offered a summation of the new approaches to expectations of how men should behave, as well as perpetuating some of the pre-existing beliefs. Ted Bogacz, 'War Neurosis and Cultural Change in England, 1914-22: The Work of the War Office Committee of Enquiry into "Shell-Shock", Journal of Contemporary History, Vol.24, 1989, p.249.

${ }^{29}$ This point has been made in previous works such as: Peter J. Boston, “"The Bacillus of Work": Masculinity and the Rehabilitation of Disabled Soldiers in Dunedin 1919 To 1939', Honours Thesis, University of Otago, 1993; Weaver, and Wright, pp.17-40; and Gwen A. Parsons, 'The Construction of Shell Shock in New Zealand, 1919-1939: A Reassessment', Social History of Medicine, Vol.26, No.1, 2013, pp.56-73.

${ }^{30}$ Joanna Bourke, Dismembering the Male: Men's Bodies, Britain and the Great War (London: Reaktion Books Ltd., 1999), p.109. See Laurinda Stryker, 'Mental Cases: British Shellshock and the Politics of Interpretation', in Gail Braybon (Ed.), Evidence, History and the Great War: Historians and the Impact of 1914-18, p. 160, for a further explanation on why this number varied so much/why it is hard to determine an exact figure of shellshock sufferers.
} 
itself. ${ }^{31}$ The number of New Zealand cases is equally as hard to pinpoint. ${ }^{32}$ The report was commissioned in 1920 to act as a definitive investigation on the issue, as the British government sought ways to deal with those men who continued to come forth for war pensions due to their inability to work, following the Armistice of November 1918, caused by the mental stresses, and neuroses they suffered from because of their war experiences.

Unemployment was a great anxiety for most nations in the post-war period. The mentally and physically disabled ex-soldier presented practical challenges and produced a fear of nations appearing weak or vulnerable. ${ }^{33}$ The goal for many nations following the war was swift and successful reconstruction, ${ }^{34}$ and part of reconstruction was a thriving economy which lessened citizens' reliance upon government aid, such as war pensions.

The "Shell-shock" report, therefore, was one way for the British government to take back control over the burgeoning problem of mentally disabled men, with similar official government approaches occurring in New Zealand. ${ }^{35}$ This official report also acted as a touchstone for professionals - general practitioners to psychiatric specialists - to assess current and future patients suffering from neurasthenia and other neuroses, and it undoubtedly shaped the way in which treatment was undertaken and how the 'shell-shocked' themselves were viewed. ${ }^{36}$ An official document such as this report can also be read by historians for an official perspective on the kind of topics that are inherently entangled with mental illness, especially mentally ill men - topics such as: masculinity, eugenics and race, class, and the evolving field of psychology. The issue of 'problem' men and masculinity was large in the immediate post-war years and continued to be a concern throughout the interwar period. The 1922 report helps to establish one of the ways in which the experiences of the war aided medical professionals in approaching such topics. In addition, New Zealand

\footnotetext{
${ }^{31}$ Great Britain War Office Committee Enquiry into "Shell-shock", Report of the War Office Committee of Enquiry into "Shell-shock" (London: H.M.S.O., 1922), p.7. This also means that for New Zealand, it is hard to attribute a number to the number of shell-shocked soldiers, especially given the way they were handled upon return from the Front as explained in: Weaver, and Wright, pp.17-40; and Parsons, pp.56-73.

${ }^{32}$ Though the inclusion of neurasthenic cases (i.e. the shell-shocked) for treatment at Brockenhurst, No.1 New Zealand General Hospital, is telling in its implication that the New Zealander army saw such large numbers of cases of mental incapacity that they accepted the need for such treatments. Weaver, and Wright, pp.17-40; and Parsons, p.24, and p.34.

${ }^{33}$ A topic examined by Ana Carden-Coyne, Reconstructing the Body: Classicism, Modernism, and the First World War (New York: Oxford University Press, 2009); Carolyn J. Dean, The Frail Social Body: Pornography, Homosexuality, and Other Fantasies in Interwar France (Berkeley: University of California Press, 2000); Peter J. Boston, "“The Bacillus of Work": Masculinity and the Rehabilitation of Disabled Soldiers in Dunedin 1919 To 1939', Honours Thesis, University of Otago, 1993 respectably, amongst others.

${ }^{34}$ Carden-Coyne, p.22.

${ }^{35}$ Weaver, and Wright, pp.17-40; and Parsons, pp.31-33.

${ }^{36}$ Parsons, p.57.
} 
medical professionals, because of the international medical and knowledge networks, were aware of, and read, the 1922 British report.

The aftermath of the Great War, in addition to the other concerns outlined regarding population size, fitness, and the influenza pandemic, fed into the increased public, government, and medical appetite for, and interest in, public health and preventive medicine. The 1920 Health Act ushered in a major reorganisation of the Department of Health; and it, along with the reports and legislation this chapter has discussed, established a context in which preventive medicine (as taught at the University of Otago Medical School, the only one in the country at this time) became a linchpin of public health and medical approaches in interwar New Zealand.

The legislation and government reports that this chapter discusses help to establish the general intellectual, and bureaucratic framework within which the medical and popular culture sources the following chapters analyse existed and interacted with. The preventive interests which characterise all of these acts, inquiries, and resultant reports is an aspect of the exploration of the 'menace' of effeminacy that is further investigated in the second chapter of this thesis, in particular. It is perhaps unsurprising that the great disturbance and fall-out of the First World War prompted countries' interests in the ability to prevent further tragedy, to prepare for future conflicts, and to restore their populations to full strength and vitality. A failure of masculinity, or in sexuality (i.e. that which was not fulfilling reproductive means), therefore hindered this great reconstruction; and the manner in which men, masculinity, effeminacy, and male sexuality were understood will now be examined through the medical and popular culture lenses. 


\section{CHAPTER TWO}

\section{Medicine and Effeminacy}

The interwar period was one of great changes and great contradictions. The First World War created substantial schisms between old ways of life and the new, whilst life simultaneously changed very little (or in small ways) for some. Yet this tumult also acted as a driver to the appearance and proliferation of many new branches of medicine and sciences of the mind. In particular, it was the accelerating point for psychology and psychoanalysis. The war also brought about a flood of shell-shock, or more broadly, war neuroses, patients. These patients, and their conditions, in turn, provoked searching questions about contemporary notions of masculinity - especially given the perceived inherent masculinity of soldiers from a variety of societies. ${ }^{1}$ The mental impacts of the war, and the effects on the study of the mind and psychology, occurred alongside the fall-out of the physical destruction that industrial warfare inflicted. $^{2}$ This chapter brings together discussions produced by the medical world in order to elaborate on this 'crisis' of masculinity, effeminacy, and male sexuality in Aotearoa/New Zealand during the years between the First and Second World Wars (1918-1939). It does so by examining several sources in circulation in the interwar years.

The sources this chapter will discuss are threefold: The British Journal of Psychology (BJOP), The New Zealand Medical Journal (NZMJ), and Preventive Medicine dissertations written by fifth-year University of Otago medical students between 1926-1939. Throughout the examination, and consideration, of these primary sources, major themes that are central to this thesis will come across. Themes which reflect the different historiographical approaches to, as well as the varied areas in which, masculinity and male sexuality were discussed in

\footnotetext{
${ }^{1}$ A subject that has been explored extensively, see: Elaine Showalter, The Female Malady: Women, Madness and English culture 1830-1980 (London: Virago, 1987); Tracey Loughran, 'A Crisis of Masculinity? Re-writing the History of Shell-shock and Gender in First World War Britain', History Compass, Vol.11, No. 9, September 2013, pp.727-738; Joanna Bourke, 'Effeminacy, Ethnicity and the End of Trauma: The Sufferings of 'ShellShocked' Men in Great Britain and Ireland, 1914-39', Journal of Contemporary History, Vol. 35, No.1, January 2000, pp.57-69; Jessica Meyer 'Separating the Men from the Boys: Masculinity and Maturity in Understandings of Shell Shock in Britain', Twentieth Century British History, Vol.20, No.1, 2009, pp.1-22; and Fiona Reid, Broken Men: Shell Shock, Treatment and Recovery in Britain 1914-1930 (London: Continuum, 2010) amongst others.

${ }^{2}$ Historians such as Ana Carden-Coyne, Reconstructing the Body: Classicism, Modernism, and the First World War (New York: Oxford University Press, 2009); Joanna Bourke Dismembering the Male: Men's Bodies,

Britain and the Great War (London: Reaktion Books Ltd., 1999); and others have detailed more of the physical disabilities and impairments inflicted by the war, and the effects this had on men and their self, as well as societal perceptions, of their masculinity.
} 
regard to interwar New Zealand. Coming from a medical approach allows concerns to be brought together regarding the war disabled, whether physically or mentally; eugenic fears, and ways of thinking (which were on the rise around the world during this period); and the evolutionary framework of understanding - which is very much a close relation to, and enabler of the conception and development of eugenic anxieties. Tied to eugenic concerns is the medical approach to reproduction and sexuality largely as related to the state of populations. ${ }^{3}$ Ostensibly these things were understood, or rather couched, in medical terms during this period, hence I think it is important for this thesis to approach similar topics in this way too, as it brings us - as historians - closer to the contemporaneous perceptions of such concepts.

This chapter places the importance of international knowledge networks at its centre, with the medical journals, especially, demonstrating this as a place in which these networks were made real via ink and paper; and where new and evolving theories regarding health, race, character, mental illness and psychology, and sexuality were discussed. It is some of those theories which were explored and questioned in different ways again when it came to the dissertations that the medical students undertook at the University of Otago in these years.

Discussion within and through these networks attested to New Zealanders' participation in the global medical arena. By examining their role as authors, subscribers, readers, and users of the medical texts this chapter discusses, we as historians can see the ways in which New Zealanders discussed and conceptualised medical ideas and theories, i.e. when, how, and in what ways. ${ }^{4}$ These medical text discussions come together to help us fathom how wider understandings of masculinity and male sexuality were understood in the interwar period.

\footnotetext{
${ }^{3}$ The physical side of such, in terms of the body and its relation to eugenics and population concerns, is something that has been much discussed in the existing historiography. For example, in works such as: Caroline Daley, Leisure and Pleasure: Reshaping and Revealing the New Zealand Body 1900-1960 (Auckland: Auckland University Press, 2003); Charlotte Macdonald Strong, Beautiful and Modern: National Fitness in Britain, New Zealand, Australia and Canada, 1935-1960 (Wellington: Bridget Williams Books, 2011); and Hera Cook, The Long Sexual Revolution: English Women, Sex, and Contraception, 1800-1975 (Oxford: Oxford University Press, 2004).

${ }^{4}$ It is notable that New Zealand, at the time, was shaped by particular features: by the shape of medical education at the time, with one Medical school, but one that increasingly came to value Public Health (as evidenced by their Preventive Medicine focus); a Department of Health that had recently been restructured by the 1920 Health Act, and with a rising profile in the public and political debate; and it was a society that had just recently experienced World War I, and was continuing to deal with and work through the mournful and tumultuous aftermath throughout the 1920s.
} 
In 1904 the British Psychological Society (BPS), with the help of, amongst others, the well-known English psychiatrist W. H. R. Rivers, established the BJOP. ${ }^{5}$ The journal was published by Cambridge University Press in quarterly instalments, with its articles covering a variety of topics pertaining to the perceived interests of professional psychologists and psychiatrists - i.e. the journal's subscribers, who were likely to be themselves members of the BPS, or were simply medical practitioners or interested parties in the study of psychology. The authors of the content published in the $B J O P$ were medical professionals, namely psychologists or psychiatrists, or just those in the medical world who had overlapping skills and knowledge with the growing discipline that was psychology during the interwar period. ${ }^{6}$

This chapter examines volumes of the BJOP published between 1918-1939, as a journal that provides historians an insight into the psychological sphere. Its printed form captures the evolving discussions psychologists and psychiatrists were participating in during a period in which the discipline continued to expand and filter out into the broader medical consciousness. The process of dissemination of this knowledge was aided by the networks created by the print culture that this journal was part of. The volumes this thesis examines reveal these discourses, and the popular concerns of its authors and readers during the interwar years; and whilst the ideas and understandings of male sexuality, masculinity, and effeminacy may not always be explicit in them, this thesis argues that they nevertheless are revealing when it comes to said topics when one uses a broader scope to place the articles alongside the other sources in this chapter and in the following chapter on popular culture publications.

The New Zealand Medical Journal, established in 1887, covered a variety of topics including those such as psychology and psychiatry, as well as those that related to the evolutionary framework of understanding and eugenics. These subjects, addressed in journal articles, or advertisements in volumes this thesis examined from 1918-1940, illustrate the significance of the NZMJ to the study of masculinity and effeminacy in New Zealand. It was a journal written, and published in Aotearoa, presenting a particularly New Zealand approach, despite the international networks it still participated in. It is also noteworthy that medical journals were not just communications between medical professionals, but also

\footnotetext{
5 Tracey Loughran, Shell-Shock and Medical Culture in First World-War Britain (Cambridge: Cambridge University Press, 2017), p.31.

${ }^{6}$ A cross-over that had become more prevalent too, given the utilisation of a wide variety of medical professionals to deal with the great numbers of mentally impaired soldiers during the Great War.
} 
between manufacturers, potential customers, advertisers, and editors. ${ }^{7}$ This is particularly pertinent given the volumes of the $N Z M J$ accessed for this thesis that still retained the advertisements in their bound form, as this part of the journals adds an extra layer to the authored content.

An analysis of the $N Z M J$ alongside the $B J O P$ is important for the work this thesis engages in due to the ability to compare the ways in which the British and New Zealand medical professionals discussed matters relating to insanity and mental health, masculinity, sexuality, and eugenic and population concerns. Though it is also noted that the journals differ largely in their subject matter because of their concentrations - i.e. the $N Z M J$ was more about general medical practice, whilst the $B J O P$ was a highly specialised publication.

This chapter also looks at a selection of Preventive Medicine dissertations to provide broader insight into medical thinking - i.e. that which occurred outside of published medical journals and of interest to students at an advanced state in their studies who were about to embark on their careers as qualified medical professionals. These dissertations were unpublished essays written by fifth-year medical students at the Otago Medical School, completed as a Terms Requirement. ${ }^{8}$ Written between 1923 to 1977, they cover a vast number and range of topics, and, though variable in their quality and completeness, prove a valuable primary resource on many aspects of public health and life in New Zealand. ${ }^{9}$ In the aftermath of the First World War, as returned servicemen "swelled the postwar classes", ${ }^{10}$ it became evident that the Medical School had outgrown a number of its buildings; and several departments had to extend themselves to meet the field's evolving demands. One such department was Preventive Medicine, which, as Dorothy Page has stated, "had to expand because it was [thought] probable that much of the medicine of the future would be preventive rather than curative". ${ }^{11}$ The fifth-year dissertations therefore reflect the increased interest in New Zealand in the field of public health and medicine that was proactive rather than reactionary.

\footnotetext{
${ }^{7}$ Though talking of the popular press, Adrian Bingham pointed out the importance of the negotiations made between publishers, advertisers, and their readerships during the interwar period in particular, a point which I argue can equally be applied to these medical journals. See Adrian Bingham, Gender, Modernity, and the Popular Press in Inter-War Britain (Oxford: Clarendon Press, 2004), p.31, p.154, and p.190.

${ }^{8}$ They were research projects that mostly dealt with areas of public health (though some did examine specific hospitals or other medical institutions), and often picked up on topics of contemporary interest to the medical students at the time.

${ }^{9}$ Preventive Medicine Research Dissertations/Essays Request Form, Hocken Collections, University of Otago, signed by myself on the two occasions I requested access to the dissertations (5 April 2019, and 12 June 2019).

${ }^{10}$ Dorothy Page, Anatomy of a Medical School: A History of Medicine at the University of Otago 1875-2000

(Dunedin, Otago University Press, 2008), p.76.

${ }^{11}$ Page, p.78.
} 
In 1923 Charles Hercus, professor of public health and bacteriology at the Otago Medical School, inaugurated a scheme that allowed his public health students to opt-out of an end of year examination and to instead take on the task of writing a research essay. ${ }^{12}$ This endeavour came as no surprise to Hercus' colleagues given that from the outset of his career he emphasised the importance of preventive medicine, as well as the experience of research to those working in the field of public health. ${ }^{13}$ In the first year of this programme, all but two of the sixty students chose the option of writing a preventive medicine dissertation over an examination. ${ }^{14}$

In 1924 the New Zealand Medical Journal published an article by Hercus himself on the work being done by the students from the Department of Preventive Medicine at the University of Otago. The article explained how: "Much of this work has been carried out in the homes of the people, and for this reason alone has a definite value." Hercus further expressed an interest in making better known this student work when he proposed that, "With the permission of the Editor," the journal would from time to time publish, "any of such investigations which may be of interest to the profession." 15

This chapter, by analysing these three different medical sources, illustrates how the medical strata of New Zealand society generated and understood masculinity, effeminacy, and male sexuality between 1918-1939. In order to best present the development and discussion of these understandings, this chapter has been split into five sections. These sections are: Networks; Mental Health and Fitness; Psychology and Psychiatry; Evolutionary Framework of Understanding and Eugenics; and Sex, Sexuality, Marriage, and Masculinity.

\section{NETWORKS}

The importance of knowledge networks and "webs of correspondence" in New Zealand is something that the historian Tony Ballantyne has made clear in his work. Ballantyne argued that it is through the transmission of the experience of others, via the written word, that the most valuable information available is passed on. ${ }^{16}$ Susann Liebich has also proposed that

\footnotetext{
12 Page, p.95.

${ }^{13}$ Derek A. Dow, 'Hercus Charles Ernest', Te Ara: The Encylopedia of New Zealand; www.teara.govt.nz; accessed 12 August 2019.

${ }^{14}$ Page, p.95.

${ }^{15}$ Charles E. Hercus, 'Studies from the Department of Preventive Medicine Otago University, Dunedin, New Zealand', New Zealand Journal, Vol.23, No.113, February 1924, p.27.

16 Tony Ballantyne, 'Thinking Local: Knowledge, Sociability and Community in Gore's Intellectual Life, 1875 1914', New Zealand Journal of History, Vol.44, No.2, 2010, pp.147-148.
} 
print culture played an integral role in facilitating these networks; ${ }^{17}$ and the Australian scholar, Tamson Pietsch has written about the ways in which these networks helped to keep New Zealand connected to the wider community of scholars in the British imperial world. ${ }^{18}$ The medical sources that this chapter discusses demonstrate the significance of these networks, and the communication that occurred through the printed word (whether journals or collated findings, such as the work of the Otago Medical School students), in relation to evolving understandings of masculinity and male sexuality in the interwar period in Aotearoa.

The British Journal of Psychology is relevant to the purposes of this thesis in uncovering New Zealand perceptions of effeminacy, masculinity, and male sexuality (more broadly) even though it is a British journal because of the central importance that international knowledge networks held throughout the interwar period. Additionally, as a journal that pertained to the interests of psychologists and this emerging field, the $B J O P$ was vital as a place that gathered and shared the new theories and approaches to what were described as psychological problems. The physical journal itself, which was able to be shipped around the world, enabled New Zealanders (i.e. those medical professionals who had to deal with such cases) who were interested in psychology to remain up to date and take part in discussion. Print culture, and the benefits it held, was a vital part of professional life.

There were sustained discussions of Sigmund Freud and his theories (amongst mentions of, and interactions with, other international psychoanalysts, for example, Sándor Ferenczi) throughout the volumes of the $B J O P$ during the interwar period. These theories, as related to mental disorders, psychology, and sexuality will be discussed further on in this chapter; however, their presence (i.e. of the theories of an Austrian thinker) in a British journal illustrates the interconnectivity of the field of psychology, even in its early growth stages in the 1920s and 30s, and that Freudian ideas were being taken seriously by this time.

Psychology was an international discipline, so its debate naturally was conducted across borders. When it comes to the authors of BJOP articles, this too demonstrates the centrality and importance of international knowledge networks, as a fair number of contributors came from outside of Britain. Amongst this number included Sigmund Freud himself; his daughter, Anna Freud; as well as Carl Jung, the Swiss psychiatrist and

\footnotetext{
${ }^{17}$ Susann Liebich, 'Connected Readers: Reading Practices and Communities Across the British Empire, c. 1890-1930', PhD Thesis, Victoria University of Wellington, 2012, p. 226.

${ }^{18}$ See her book for a full discussion of the importance of these networks in particular relation to the intellectual world: Tamson Pietsch Empire of scholars: Universities, networks and the British academic world 1850- 1939 (Manchester: Manchester University Press, 2013).
} 
psychologist who founded analytical psychology; Sándor Ferenczi, a Hungarian psychoanalyst, and associate of Freud; and Albert Einstein (whose letter correspondence with Freud about war was printed by the journal); as well as others. ${ }^{19}$ Here one can therefore see the ways in which these networks contributed to discussions on psychological topics that are of interest to this thesis when they touch on topics such as sex and sexuality, eugenics, and mental disorders; and that would then have been read in New Zealand by medical professionals, psychologists and psychiatrists, and other interested persons, who in turn, exercised an influence on diagnosing and treating patients in New Zealand.

International knowledge networks played an important role in the development of, and content published in, the NZMJ. New Zealand remained part of global medical networks after the Great War, and those European (as well as American) networks continued to help shape the kind of thinking and debate amongst medical professionals (and others) in Aotearoa. Much like the $B J O P$, the existence of the physical volumes of the NZMJ not only act as good historical sources for historians of many disciplines but at the time of their publication they provided somewhere for New Zealand medical professionals to develop theories, present ideas, and interact with international debates.

The significance of international networks to information and articles provided in the $N Z M J$ can be seen through the continued references to the New Zealand Branch of the British Medical Association (BMA) throughout the volumes of the journal published between 19181940. This recurring feature usually noted the members of the branch who attended Council meetings, the key points raised (and resolved) during the meeting, and if there were any new members attending. The New Zealand branch of the BMA was established ten years after the New Zealand Medical Association was formed in 1886 and continued its association with the BMA until 1967. ${ }^{20}$ This link to the British medical sphere (as well as broader international networks associated with the BMA) is indicative of the influence of said networks and international connections to the ways in which New Zealanders working in the medical profession understood, discussed, and debated different theories around the latest treatments for, and approaches to, issues relating to mental disorders and disorderly sexuality.

\footnotetext{
${ }^{19}$ For example Anna Freud is referenced (through her publications) in volumes such as 'Publications Recently Received', British Journal of Psychology, Vol.22, July 1931, p.92, and 'Publications Recently Received', British Journal of Psychology, Vol.29, January 1939, p.312; Carl Jung wrote the article, 'Instinct and the Unconscious III', British Journal of Psychology, Vol.10, 1920, pp.15-23; and Sándor Ferenczi was mention in a number of volumes, including in 'Publications Recently Received', British Journal of Psychology, Vol.18, July 1927, p.92.

20 ‘NZMA History’, New Zealand Medical Association; www.nzma.org.nz; accessed 23 June 2020.
} 
Other examples of these international networks include comments on the ties established during the Great War. In the February 1940 volume of the NZMJ J. Hardie Neil, in his article about 'Early Medical Education in the Pacific', stated that, "The Great War established a strong bond between American, British, and Australasian surgeons." ${ }^{21}$ Though here Hardie Neil is talking about surgeons, these international relationships (present before the war, and strengthened by it) ${ }^{22}$ extended beyond that specific field. This can be seen in a number of $N Z M J$ volumes that either reference journals from Britain; ${ }^{23}$ in the existence of the Australian and New Zealand Medical Association in London, ${ }^{24}$ and the Australian and New Zealand Association for The Advancement of Science as joint Australasian associations; ${ }^{25}$ or where articles had been reprinted from other international journals. ${ }^{26}$

Despite being produced by medical students and not medical professionals with existing contacts and networks within the wider medical community, the Preventive Medicine dissertations nevertheless drew from those webs of knowledge. They did this by citing the works of doctors and other specialists on the medical topics they had chosen to write about in their dissertations and, in some cases, they also drew from prior fifth-year dissertations done by students who had come before them.

W. A. Fitzherbert quotes Charles Macfie Campbell in his 1931 dissertation titled 'The Prevention of Mental Diseases in New Zealand'. ${ }^{27}$ Campbell was a Scottish born psychiatrist who studied across Europe (from Edinburgh, to France and Germany), and later practiced in

\footnotetext{
${ }^{21}$ J. Hardie Neil, 'Early Medical Education in the Pacific', New Zealand Medical Journal, Vol.34, No.209, February 1940, p.14.

${ }^{22}$ A point that Tamson Pietsch has asserted, see: Pietsch, pp.129-130.

${ }^{23}$ For example see the numerous references to articles from the Lancet, and the British Medical Journal: 'Correspondence', New Zealand Medical Journal, Vol.36, No.195, October 1937, pp.336-337; Charles Burns, 'Coronary Thrombosis - A Clinical Review', New Zealand Medical Journal, Vol.36, No.196, December 1937, p.379; Douglass Robb, 'The Complete Spinal Anaesthetist', New Zealand Medical Journal, Vol.37, No.198, April 1938, p.86; and J. M. Thwigg, 'Experiences with Zinc Protamine Insulin', New Zealand Medical Journal, Vol.37, No.201, October 1938, p.264. And in one review of Marie Stope's Married Love, there is a reference to multiple journals: "The British Medical Journal, The Lancet, The Times, The Athenaeum and The Christian Commonwealth all approve "Married Love", and it has been translated into many foreign languages...", in Reviews', New Zealand Medical Journal, Vol.22, No.108, April 1923, p.138.

24 'Australian and New Zealand Medical Association, London', New Zealand Medical Journal, Vol.24, No.119, February 1925, pp.25-26.

25 'Australian and New Zealand Association for The Advancement of Science', New Zealand Medical Journal, Vol.25, No.190, December 1936, pp.419-420. Plus the printing of information regarding the Australasian medical congress, in which topics such as mental disorders, psychiatry, and delinquency were papers for discussion, see: 'Australian Medical Congress', New Zealand Medical Journal, Vol.25, No.126, April 1926, p.85; and 'Australasian Medical Congress', New Zealand Medical Journal, Vol.25, No.129, October 1926, p.301.

${ }^{26}$ For example, 'Analytical Department', New Zealand Medical Journal, Vol.21, No.105, October 1922, pp.305-307.

${ }^{27}$ W. A. Fitzherbert, 'The Prevention of Mental Diseases in New Zealand', Preventive Medicine Dissertation, University of Otago, 1931, p.3.
} 
the United States where he became President of the American Psychiatric Association (19361937) ${ }^{28}$ Here Fitzherbert quotes an article of Campbell's from 1924 - 'A Present-day

Conception of Mental Disorders' - in order to help articulate the problem of mental disorders in New Zealand. ${ }^{29}$ Fitzherbert also goes on to quote Mercier, most likely the British psychiatrist Charles Mercier; ${ }^{30}$ and he provides examples from English courts of cases about mental disorders. ${ }^{31}$ In both of these instances Fitzherbert shows the continued ties to English scholarship and Britain as a place where New Zealanders could and should look for preexisting approaches to problems that they were now facing.

The fifth-year student Nola M. Ivory, though writing about a different topic than Fitzherbert (infantile mortality), made comment on the importance of international data for the New Zealand based work. Ivory's point was one of comparison, through which the state of New Zealand infantile mortality rates could be better contextualised - made clear in the statement, "Such statistics as were obtainable of other countries are used for the sake of comparison" 32 Alongside statistics, Ivory also quotes from the British medical journal The Lancet; ${ }^{33}$ and includes in the bibliography of the dissertation references from several other international journals, such as a piece from the South African Medical Record quoted in the British Medical Journal, the Medical Journal of Australia, and the Journal of Hygiene. ${ }^{34}$ Here one can see the variety of international medical journals just one Otago Medical School student drew from for their own dissertation. This practice, however, was not uncommon. Gordon N. Findlay in his dissertation, 'A General Survey of Cripples with Special Reference to Crippling Disease in New Zealand', also referenced work from the British Medical Journal; ${ }^{35}$ G. F. Hall referenced Mental Hygiene and the Journal of Mental Science in his bibliography. ${ }^{36}$ John T. Shearer's references in his dissertation about 'Typhoid in Seacliff

\footnotetext{
${ }^{28}$ Graham Richards, 'Charles Macafie Campbell', Oxford Dictionary of National Biography; www.oxforddnb.com; accessed 9 July 2020.

${ }^{29}$ Fitzherbert, p.3. He uses Campbell's conception of mental disorders (from a talk given at Harvard) to help articulate the issue, as he sees it, in New Zealand.

${ }^{30}$ Ibid.

${ }^{31}$ Fitzherbert, p.17.

${ }^{32}$ Nola M. Ivory, 'Infantile Mortality', Preventive Medicine Dissertation, University of Otago, 1930, p.3.

${ }^{33}$ Ivory, p.9, and pp.27-28.

${ }^{34}$ Ivory, un-numbered bibliography pages.

${ }^{35}$ Gordon N. Findlay, 'A General Survey of Cripples with Special Reference to Crippling Diseases in New Zealand', Preventive Medicine Dissertation, University of Otago, 1931, p.100.

${ }^{36}$ Findlay, un-numbered bibliography pages.
} 
Mental Hospital' included one to the Munich Medical Journal; ${ }^{37}$ and A. D. G. Blanc and R. J. Paul referenced an article published in the Lancet in 1935. ${ }^{38}$

In some cases, students also drew from prior fifth-year dissertations done by students who had come before them. For example, E. S. Jamieson and O. L. Eaton's historical section about the development of psychiatry and mental hospitals is very similar (if not, in parts, seemingly identical), to the way in which, the year prior, T. C. Sutherland and N. A. Priest wrote their 'History' of mental deficiency. ${ }^{39}$ This demonstrates a sustained interest in such topics, like mental deficiency, by students, and also the topicality of such subjects in the interwar period. Additionally, whilst listing these references may seem undue, it arguably is not as such examples demonstrate the varied and extensive ways in which these fifth-year students were interacting with international scholarship from their base in Otago during the interwar years (i.e. they used this international scholarship, even though most of their topics addressed very local problems).

\section{MENTAL HEALTH AND FITNESS}

Following the Great War New Zealand, much like many other countries, was presented with the problem of dealing with an unprecedented number of returned soldiers dealing with the mental effects of war. Gwen Parsons, as well as John Weaver and David Wright, have written about how New Zealand treated these soldiers suffering from bad nerves, or more extreme neuroses upon returning to our shores. ${ }^{40}$ Other historians have hinted at the connections between masculinity and war neuroses. ${ }^{41}$ What this chapter does is further demonstrate these links in the New Zealand medical context, and this section illustrates how the experiences of

\footnotetext{
${ }^{37}$ John T. Shearer, 'Typhoid in Seacliff Mental Hospital', Preventive Medicine Dissertation, University of Otago, 1938, p.49.

${ }^{38}$ A. D. G. Blanc, and R. J. Paul, 'A Survey of Unorthodox Medical Treatment and the Sale and Promotion of Proprietary Medicines, Therapeutic Devices and Cosmetics Within New Zealand', Preventive Medicine Dissertation, University of Otago, 1939, p.13.

${ }^{39}$ E. S. Jamieson, and O. L. Eaton, 'Nelson Mental Hospital: An Historical Survey and a Public Health Examination', Preventive Medicine Dissertation, University of Otago, 1932, pp.4-12; and T. C. Sutherland, and N. A. Priest, 'Mental Backwardness and Mental Deficiency in Children (With Reference to Special School for Boys At Otekaike)', Preventive Medicine Dissertation, University of Otago, 1932, pp.3-4.

${ }^{40}$ See Gwen A. Parsons, 'The Construction of Shell Shock in New Zealand, 1919-1939: A Reassessment', Social History of Medicine, Vol.26, No.1, 2013, pp.56-73; and John Weaver, and David Wright, 'Shell Shock and the Politics of Asylum Committal in New Zealand, 1916-1922', Health and History, Vol.7, No.1, 2005, pp.17-40.

${ }^{41}$ For example, see: Tracey Loughran, Shell Shock and Medical Culture in First World War Britain (Cambridge: Cambridge University Press, 2017), pp.115-148; and Peter J. Boston, "The Bacillus of Work": Masculinity and the Rehabilitation of Disabled Soldiers in Dunedin 1919 To 1939', Honours Thesis, University of Otago, 1993.
} 
war led to an increased interest in, and focus on, mental health and fitness in interwar New Zealand.

Some articles in the BJOP made clearer than others the centrality of the experiences of the Great War to their discussions. Book recommendations, full consultations of, and references to, war neuroses and shell-shock appear throughout the volumes of the BJOP examined for this thesis. John MacCurdy's War Neuroses, published in 1918, was advertised in the 'Publications Recently Received' section of the May 1919 journal. ${ }^{42}$ MacCurdy's work is criticised by the journal's reviewer, but the criticism itself is indicative of the way war experience was placed as vital to the understanding of certain medical fields and approaches to diagnoses. The reviewer states: "For those who have had longer experience than Capt. MacCurdy in the psycho-neuroses of war, especially for those who have seen cases near the firing line, it is not difficult to criticise some of the conclusions to which he has come", making clear the deference given to those with greatest war experience. ${ }^{43}$

One of the ways that the $N Z M J$ demonstrated an active interest in mental disorders and their treatment, whilst being a medical journal that did not have that as its sole focus, was through the advertisements it ran. The physical copies of the journal that were able to be examined for this thesis did not all contain the advertisements from each volume of the NZMJ published (due, in some part, to how the copies had been bound). However, those advertisements that were accessible contained various references to places, terminology, and aspects of the burgeoning field of mental disorders. One recurring advertisement printed on the reverse of the journal cover or on the first page of a number of volumes was one for Ashburn Hall, which described itself as "A Private Hospital for the Care and Treatment of Mental and Nervous Disorders". ${ }^{4}$ The presence and placement of this advertisement (in the volumes that were available for this thesis $)^{45}$ is valuable to think about when it comes to the interest of the medical professionals (and others) who would have read the $N Z M J$ and been exposed to the clinic, as one that was influenced by the likes of Sir Truby King and aimed to

\footnotetext{
42 'Publications Recently Received', British Journal of Psychology, Vol.9, May 1919, p.372. The reviewer demonstrated MacCurdy's experience, when they wrote, "This is one of the most remarkable books which have appeared during the war. It is written by an American physician who, with intimate previous experience of the psycho-neuroses of civil life, came to England in 1917 and paid brief visits to seven different hospitals, in order to advise the medical profession in America on the special problems which his country was about to face on its entry into the war."

${ }^{43}$ Publications Recently Received', British Journal of Psychology, Vol.9, May 1919, p.372.

44 'Ashburn Hall', New Zealand Medical Journal, Vol.35, No.186, April 1936, inside cover.

${ }^{45}$ This advertisement is also seen in a number of other volumes of the NZMJ including: 'Ashburn Hall', New Zealand Medical Journal, Vol.35, No.187, June 1936, inside cover; 'Ashburn Hall', New Zealand Medical Journal, Vol.36, No.191, February 1937, inside cover; and 'Ashburn Hall', New Zealand Medical Journal, Vol.37, No.202, December 1938, p.xxxix.
} 
provide "every advantage that experience can suggest" for the care of those "Voluntary

Boarders suffering from incipient nervous and mental disorders, as well as certified patients of both sexes." 46 The Ashburn Hall advertisements, like those that advertised various medicines and assortments that targeted "nerves", 47 "nervous disorders", 48 "neurasthenics", 49 and those with "nervous troubles",50, and readers who were "run-down and depressed",51 all demonstrate a perceived interest from the editors of the $N Z M J$ in its readership for products and treatments for said nervous disorders.

In addition to these advertisements, the $N Z M J$ also printed a number of articles and reviews that demonstrated an interest in mental disorders (as reflected the increased weight that was given to them in broader medical communities). For example, in the August 1918 issue, there is a review of Arthur F. Hurst's Medical Diseases of the War. The review describes how, "the first eleven chapters are on war neuroses, and are valuable alone for the classification they supply on functional nervous diseases in soldiers." The review goes on to describe Hurst's views on shell-shock. ${ }^{52}$ A year later, the journal published a full review of G. Elliot Smith, and T. H. Pear's Shell-shock, and its Lessons which details the condition that

\footnotetext{
46 'Ashburn Hall', New Zealand Medical Journal, Vol.35, No.186, April 1936, inside cover. The use of language such as 'voluntary boarders', echoes the sentiments that historians such as Weaver and Wright, and Parsons have discussed around the desire to alleviate the stigma of mental illnesses and disorders following the war for returned soldiers (see Weaver, and Wright, pp.17-40; and Parsons, pp.56-73); and it also imitates that which was outlined in the government reports and legislation discussed in chapter one (for example, in the Mental Defectives Act 1911). The idea behind this aversion of stigma then, also related to differentiating returned soldiers (i.e. men) from the generally insane, and the large swathes of female patients previously admitted to, what were then called, asylums.

${ }^{47}$ Like one for MILO titled, 'Disordered Nerves- R/ MILO THE FORTIFIED TONIC FOOD', New Zealand Medical Journal, Vol.35, No.187, June 1936, p.xiv.

${ }^{48}$ Like the advertisement for 'OVALTINE - In Nervous States' which recommended Ovaltine due to, "A study of the manifestation of nervous disorders, such as neurasthenia, hysteria and the various types of neurosis" that showed a linkage between these disorders and an "impairment of the general nutrition of the patient", in 'OVALTINE- In Nervous States', New Zealand Medical Journal, Vol.37, No.198, April 1938, p.xxiv. Or for others that addressed "nervous states" and "the numerous forms of neurasthenia" see: 'Ovaltine', New Zealand Medical Journal, Vol.37, No.202, December 1938, p.xxix; and 'MIST DAMIANAE CO. (Hewlett's)', New Zealand Medical Journal, Vol.37, No.202, December 1938, p.xxv.

${ }^{49}$ For example, like in the advertisements for: 'TESTONAD' that was recommended "In all cases of sexual disharmony, impotence, general neurasthenia, etc" in New Zealand Medical Journal, Vol.36, No.191, February 1937, p.xxxv; and 'CARNACTION', New Zealand Medical Journal, Vol.36, No.192, April 1937, p.xxxvii; or 'SANATOGEN', New Zealand Medical Journal, Vol.36, No.193, June 1937, p.xxxii, which was advertised as being particularly of value in "cases of malnutrition, and more especially in dealing with neurasthenics"; or for 'MEDINAL', New Zealand Medical Journal, Vol.36, No.195, October 1937, p.xxvi, used to help with sleep in a variety of cases, including "neurasthenia and mental disorders."

${ }^{50}$ Like the advertisement for 'GREENOSAN TABLETS Supplied by N. M. Peryer Ltd.', New Zealand Medical Journal, Vol.35, No.187, June 1936, p.xv.

${ }^{51}$ Like the advertisement for 'LIVOGEN', New Zealand Medical Journal, Vol.36, No.195, October 1937, p.xliii.

52 'Reviews', New Zealand Medical Journal, Vol.17, No.80, August 1918, pp.149-150.
} 
is shell-shock, and indicates how the authors believe it is best treated. ${ }^{53}$ The reviewer stated that the authors made clear that, "The war has forced upon the British people a rational and humane method of caring for and treating mental disorder among soldiers", something that they hoped would not end with the end of the war, "but [that] will become established and extended after the war. In this respect, they [the authors] maintain, we still lag behind the Germans." ${ }^{4}$ The "we" here is interesting given its publication in this New Zealand medical journal, which reflects the broader definition of the 'British' in the medical profession. Therefore, it perhaps also acted as a call for New Zealanders in the medical profession to evaluate and improve their responses and treatments of those soldiers, and general civilian patients with mental disorders. A call that seems to insinuate that these people were not being treated well enough, and that therefore indicates how medical professionals - and wider society - viewed them as inferior, or problematic, in juxtaposition to the virile ideal of men, in particular.

The $N Z M J$ also published a number of more general articles on mental disorders and diseases. For example, the June 1923 review of Handbook for Mental Nurses (Handbook for Attendants on the Insane); 55 and that of William A. White's, Insanity and the Criminal Law. ${ }^{56}$ J. R. Closs published an article about 'The Nervous Breakdown' in the August 1927 issue of the NZMJ. Like in the advertisements discussed above, Closs tied nervous breakdown to neuroses, hysteria, and the psychoses. ${ }^{57}$ The October 1927 editorial was devoted to 'Treatment of the Insane'; ${ }^{58}$ and other articles referenced Mental Hospitals and institutions. ${ }^{59}$ In the June 1932 issue, the journal published Corban Assid Corban's (Assistant Medical Officer, Tokanui Mental Hospital) 'Reflections on Occupational Therapy in Mental Treatment', in which he argued that the "outside world frequently entertains the grossest misconceptions concerning asylum patients", and proposed that occupational work can help

\footnotetext{
53 'Reviews', New Zealand Medical Journal, Vol.18, No.87, October 1919, pp.273-274. This is also a book mentioned and reviewed in the BJOP: 'Publications Recently Received', British Journal of Psychology, Vol.10, November 1919, p.130.

54 'Reviews', New Zealand Medical Journal, Vol.18, No.87, October 1919, p.273.

55 'Reviews', New Zealand Medical Journal, Vol.22, No.109, June 1923, p.194.

56 'Reviews', New Zealand Medical Journal, Vol.22, No.110, August 1923, pp.254-255.

57 'Reviews', New Zealand Medical Journal, Vol.26, No.134, August 1927, pp.159-160.

58 'Editorial - Treatment of the Insane', New Zealand Medical Journal, Vol.26, No.135, October 1927, pp.232233.

${ }^{59}$ For example: the editorial piece that discussed Mental Hospital reforms, in 'Editorial', New Zealand Medical Journal, Vol.24, No.121, June 1925, pp.171-172; plus the reference to the Lebanon Mental Hospital where ANZAC forces were treated during the war, in 'Lebanon Mental Hospital- New Zealand Memorial Villa Fund', New Zealand Medical Journal, Vol.29, No.149, February 1930, p.41.
} 
"restore the balance" when it comes to mental illness. ${ }^{60}$ The June 1937 issue included a review of the book Diagnosis of Some Delusional Insanity Types in General Practice by Edwin Hopewell-Ash, a London based doctor; ${ }^{61}$ and the December issue of the same year saw reviews for both Sir James Purves-Stewart's latest edition of The Diagnosis of Nervous Diseases, and T. A. Ross' The Common Neuroses. ${ }^{62}$ In the August 1938 issue, there is a review of I. M. Selare's Mental Training in Observation Wards, that, "gives a brief but comprehensive insight into the nature of mental disorders and their treatments". ${ }^{63}$

In the December 1922 issue of the NZMJ Stuart Moore, Lecturer in Clinical Medicine at Otago Medical School, wrote an article on 'The Treatment of Psychic Disorders'. In it he argued that the use of the term "functional" to, "describe the milder mental disorders such as hysteria, the obsessive or compulsive neuroses, anxiety states, and neurasthenia, should be discarded." 64 This kind of rhetoric was familiar from debates around shell-shock and other war neuroses cases, demonstrating the influence of that war experience with such cases in the post-war practice and interaction with patients. ${ }^{65}$ Moore went on to discuss the value of psychoanalysis in the treatment of these mental diseases. ${ }^{66}$ It is also worth noting that Moore was one of the most regular contributors to the $N Z M J$ when it came to commentary on mental disorders in interwar New Zealand ${ }^{67}$ In the December 1927 issue, Stuart Moore wrote a piece titled 'Mental Hygiene- The Magnitude of the Mental Hygiene Problem in New Zealand' in which he argued that, "the Mental Hygiene problem is proportionately about as large in New Zealand as it is in other countries, e.g., England and the United States of America." He wrote that the "number [of patients in asylums in New Zealand] is greater than the sum of the daily average populations in the Dominion of all the general hospitals, all the infectious diseases hospitals, all the tuberculosis sanatoria, and all the maternity hospitals

\footnotetext{
${ }^{60}$ Corbin Assid Corbin, 'Reflections on Occupational Therapy in Mental Treatment', New Zealand Medical Journal, Vol.31, No.163, June 1932, pp.191-192.

61 'Reviews', New Zealand Medical Journal, Vol.36, No.193, June 1937, p.214.

62 'Reviews', New Zealand Medical Journal, Vol.36, No.196, December 1937, pp.418-419.

63 'Reviews', New Zealand Medical Journal, Vol.37, No.200, August 1938, p.238.

${ }^{64}$ Stuart Moore, 'The Treatment of Psychic Disorders', New Zealand Medical Journal, Vol.21, No.106, December 1922, p.325.

${ }^{65}$ See, for example the work of Tracey Loughran, Shell Shock and Medical Culture in First World War Britain (Cambridge: Cambridge University Press, 2017), pp.53-54.

${ }^{66}$ Moore, 'The Treatment of Psychic Disorders', p.325.

${ }^{67} \mathrm{He}$ also wrote a number of pieces on psychology and psychoanalysis, for example see: 'Correspondence', New Zealand Medical Journal, Vol.12, No.109, June 1923, pp.187-188; Stuart Moore, 'The Basis of Neurotic Thought and its Significance in General Practice', New Zealand Medical Journal, Vol.21, No.163, June 1932, pp.198-206; and Stuart Moore, 'The Status of Psychology', New Zealand Medical Journal, Vol.36, No.196, December 1937, pp.389-392.
} 
administered by the State". ${ }^{68}$ Moore then also wrote-in to defend himself against the critique of the December 1927 piece by Dr Theodore Gray (who by this point, in 1928, was the successor of Sir Truby King as the head of the Mental Hospitals Department). ${ }^{69}$ Moore maintained his conclusion "that Mental Medicine was one of the largest and most important branches of Medicine, and that it does not receive the attention it deserves" in New Zealand. This was a state that Gray's figures and work confirmed. ${ }^{70}$ This emphasis on the size of the problem of mental disorders in interwar New Zealand in Moore's articles reflects the broader heightened interest in the medical sphere of said disorders following the influx of cases of soldiers suffering from neuroses in the Great War.

One article that particularly demonstrates the increased interest in mental disorders by general practitioners (and others) following experiences of the Great War is that titled 'The Value of Hanmer to the General Practitioner: Suitable and Unsuitable Cases'. Written by P. Chisolm, the Hanmer Medical Superintendent, and Robert Baxter, the Deputy Medical Superintendent, for the June 1922 issue of the $N Z M J$, this article outlines the benefit of the Queen Mary Hospital at Hanmer Springs. ${ }^{71}$ As general practitioners across New Zealand, "must from time to time have encountered cases of functional nervous disease," which Chisolm and Baxter state (despite the best efforts of these GPs) failed to be sufficiently treated, they argue that there has been a general need in New Zealand for a specialist institution which "devotes itself entirely to the treatment of the neurotic". ${ }^{72}$ The Queen Mary Hospital was to be this institution. In fact, the Queen Mary facilities were in reality used to house the shell-shock, or general neurasthenic, military cases following the First World War; and were used as an in-between for these cases and the 'insane' ones. ${ }^{73}$ Hanmer was an institution that weathered the effects of the large numbers of post-war mental health patient

\footnotetext{
${ }^{68}$ Stuart Moore, 'Mental Hygiene- The Magnitude of the Mental Hygiene Problem in New Zealand', New Zealand Medical Journal, Vol.26, No.136, December 1927, p.256.

${ }^{69}$ Warwick Brunton, 'Theodore Grant Gray', Te Ara: The Encyclopedia of New Zealand; www.teara.govt.nz; accessed 6 July 2020.

70 'Correspondence', New Zealand Medical Journal, Vol.27, No.140, August 1928, pp.275-276. Gray’s complaint, as Moore understood it, was that he was "tarnish[ing] the fair name of New Zealand", in his conclusions on Mental Hygiene and Hospitals in New Zealand. This concern (if we are to take Moore's word for it) seems to link Gray's concerns not only to the perception of the treatment of mental disorder cases in New Zealand as sub-par, but also to the idea that Moore exaggerated the number of patients itself which would make the country look bad.

${ }^{71}$ P. Chisolm and Robert Baxter, 'The Value of Hanmer to the General Practitioner: Suitable and Unsuitable Cases', New Zealand Medical Journal, Vol.21, No.103, June 1922, pp.140-144.

${ }^{72}$ Chisolm and Baxter, p.140. Though the pair do argue here that "a deep analysis as is outlined in Freud's work" is unnecessary when it comes to the vast majority of patients.

${ }^{73}$ Weaver, and Wright, p.29. Though Chisolm and Baxter refute the idea of framing Hanmer as a "half-way house to a mental hospital", despite the "tendency to use the hospital for this purpose": Chisolm and Baxter, p.143.
} 
cases in New Zealand, and where treatments evolved in recognition of the increased awareness and application of psychoanalytic theories.

Heightened awareness of 'mental hygiene' in the interwar period, while it might have focused on women and child-rearing to some extent, inevitably swung back to focusing on men and masculinities when war again became a real possibility. The editorial piece for the October 1939 issue, 'The Medical Profession of New Zealand in War', indicates the way in which the military and medical communities learnt from their experiences of shell-shock and the other war neuroses as resulted from the Great War. ${ }^{74}$ The piece commends the use of Psychological Boards, "who directed intelligence tests and tests of mechanical aptitude" during the recruitment of troops; going on to state that: "Such exercises are easily arranged and require little time to complete, but their selective value is unquestionable". ${ }^{75}$ Though referencing the work done by the United States Army, the inclusion of such comments is telling in terms of the respect given to the psychological condition of soldiers, and of the desire for men in the community at large to meet these requirements always, should the need arise for their military enlistment. The article even states that, "Great physical strength is not needed, but straightness of limb, sound organs, and an alert mind, psychologically well balanced, are the pre-requisites of the efficient soldier". ${ }^{76}$ Reflecting this societal, and militaristic, desire for virile, healthy (in mind and body) men to be available to serve as soldiers, there is also the great recognition here of the fact that 'mental' factors were important for efficient soldiering in modern war.

The response of New Zealanders to the expanding knowledge and specialisation regarding mental disorders and neuroses can be seen in some of the Preventive Medicine dissertations. This is seen in the topic choices, and their content too, as well as in the existence and insistence on greater measures being undertaken regarding Public Health (of which mental health and fitness came under).

As discussed in chapter one, there was, by 1928, a legislative and bureaucratic context within which medical professionals worked. ${ }^{77} \mathrm{~W}$. A. Fitzherbert, in his dissertation on 'The Prevention of Mental Diseases in New Zealand', cited the Mental Defectives Act 1911 and

\footnotetext{
74 'Editorial', New Zealand Medical Journal, Vol.38, No.207, October 1939, pp.301-303.

75 'Editorial', New Zealand Medical Journal, Vol.38, No.207, October 1939, p.302. However, in the December issue of the same year, in a letter of correspondence, the writer argues that the introduction of psychological tests will only make the standard of recruits even higher, and more difficult to meet - which in their view are already too excessive: 'Correspondence', New Zealand Medical Journal, Vol.38, No.208, pp.431-433.

${ }^{76}$ Editorial', New Zealand Medical Journal, Vol.38, No.207, October 1939, p.302.

77 A context within and through which their interactions with, and views of, patients with mental disorders and other 'deviant' problems (regarding sexuality, for example), were formed.
} 
the amendment to it from $1928 .^{78}$ T. C. Sutherland and N. A. Priest too cite the Mental Defectives Act and amendment, as well as the 1925 report of the Committee of Inquiry into Mental Defectives and Sexual Offenders. ${ }^{79}$ In both instances of these references to the different reports and legislation in these Preventive Medicine dissertations, the medical students mention them in relation to how the problem of mental diseases and disorders can be addressed in New Zealand, and in order to clarify the terms and diagnostic terminology they use within their own research. The influence of the authoritative views on such Public Health problems as mental disorders and deviant sexualities can therefore be seen through their presence in the dissertations of fifth-year medical students. These students may not yet have been qualified doctors, yet they were still citing such sources, and being informed by them, when making their own assessments of the state of mental health in interwar New Zealand.

The language and phrases used by some of the fifth-year students also hints at the influence of the Great War and the broader exposure to men's mental health. For example, Fitzherbert, Jamieson and Eaton, and G. F. Hall all discuss "neurasthenic" cases. ${ }^{80}$ Though 'neurasthenia' and 'neurasthenic' were diagnostic terms used before the war, they came to take on certain connotations during it and was used when both somatic and psychic characteristics were present. A. D. G. Blanc and R. J. Paul in their dissertation on the sale and promotion of unorthodox medical treatments discussed the sale of nerve tonics, which, as with neurasthenia, links the mind and body when it comes to mental and physical unfitness. ${ }^{81}$ The "wounded soldier" is also referenced, ${ }^{82}$ and though it is in regards to physically disabled men this kind of influence of the exposure to physical and mental wounds during the war is what Ana Carden-Coyne argues had a significant impact on the ways in which men, and their masculinity, were imagined in the post-war period. ${ }^{83}$ Two students, T. C. Sutherland and N. A. Priest, even stated in their work that, "it must be admitted however that the

\footnotetext{
${ }^{78}$ Fitzherbert, p.29

79 Sutherland, and Priest, pp.6, 8, 10-11, and 74.

${ }^{80}$ Fitzherbert, p.17, 22; Jamieson, and Eaton, p.20, 126; G. F. Hall, 'St Joseph's Boys' Home, Waverly, Dunedin: A Physical \& Mental Survey’, Preventive Medicine Dissertation, University of Otago, 1939, p.ii.

${ }^{81}$ Blanc, and Paul, p.28: They discuss the sale and use of nerve tonics as a serious issue in terms of "national fitness"; and they argue that: "For a young country like this, and for our almost perfect living conditions and environment, this is a disgraceful state of affairs," that so many claim to suffer from "so-called nerves". They link this to information in the popular media - "we do not hesitate to indict the continuous disease propaganda reaching us through the newspapers and periodicals and through our public utilities - the post, and commercial broadcasting service" - something that will be further discussed in relation to 'nerves' and mental disorders in the following chapter.

${ }^{82}$ Findlay, pp.94-95: "The wounded soldier made a big contribution to the cause of the cripple by producing a world wide conversion in the attitude of the public toward a sympathetic understanding of deformity. All now have a personal acquaintance with the cripple. Deformity is observed without superstition or dread."

${ }^{83}$ Carden-Coyne, p.14.
} 
methods now use[d] for classification and training [around mental health] have arisen in great part as the result of the Great War" ${ }^{\prime 4}$ - so here they directly admit that the experiences of the war shaped the ways in which those in New Zealand interacted with mental health and wellbeing and made diagnoses. This thesis also suggests that this indicates an influence which seeped out into broader perceptions of men and masculinity. The pair also wrote that: "So many men became neurotic or insane [under] that trial [the war] that not only medical men but also the general public were brought face to face with the problem. The result has been a good one. There is now an efficient method of segregation for each class of defective combined with particular training for that class." This recognition of the war's impact on not only the medical professionals, but also the wider New Zealand public, in their exposure to mentally neurotic men, according to Sutherland and Priest's view at least, undoubtedly altered the way in which such men were viewed, and by extension, altered the perception of their masculinity.

Leading up to the eve of the Second World War, the increased focus on the potential for mental illness, and the interrelation of physical and mental health, also shaped the perspective of medical professionals in Aotearoa towards men, masculinity, and male sexuality. There was a sustained interest in mental health and fitness, and its treatment, management, and containment from 1918 all the way up to 1939. G. F. Hall demonstrates this maintained interest in his 1939 dissertation 'St. Joseph’s Boys' Home, Waverly, Dunedin: A Physical \& Mental Survey', in which he analyses the medical examination forms and intelligence tests used to denote the mental hygiene of the schoolboys. ${ }^{85}$ This notion of mental hygiene is also something that Fitzherbert commented on in relation to psychological clinics and the 1925 Inquiry. ${ }^{86}$ The interest in New Zealand institutions that serviced the mental health needs of its population was also a topic that interested some of the fifth-year medical students. This is evidenced by R. H. Pitchaithy's discussion of Nelson Mental Hospital and farm; ${ }^{87}$ M. Christie and R. Christie's 'A Study of Porirua Mental Hospital';88

\footnotetext{
${ }^{84}$ Sutherland, and Priest, p.4. The pair also wrote that of the war that, "So many men became neurotic or insane [under] that trial that not only medical men but also the general public were brought face to face with the problem. The result has been a good one. There is now an efficient method of segregation for each class of defective combined with particular training for that class."

${ }^{85}$ G. F. Hall, 'St Joseph's Boys' Home, Waverly, Dunedin: A Physical \& Mental Survey', Preventive Medicine Dissertation, University of Otago, 1939.

${ }^{86}$ Fitzherbert, p.34.

${ }^{87}$ R. H. Pitcaithy, 'Health Survey of Nelson', Preventive Medicine Dissertation, University of Otago, 1926, p.24.

${ }^{88}$ M. Christie, and R. Christie, 'A Study of Porirua Mental Hospital', Preventive Medicine Dissertation, University of Otago, 1936.
} 
and John T. Shearer's examination of the Seacliff Mental Hospital (related to its reaction to, and treatment of, typhoid cases - which is also evidence of the way in which mental health was tied to physical health during this period). ${ }^{89}$ These dissertations, though less direct in their relation to clear understandings of men and masculinity in interwar New Zealand, nevertheless demonstrate that increased interest in mental wellbeing in Aotearoa following the Great War.

\section{PSYCHOLOGY AND PSYCHIATRY}

Undeniably entangled with the increased interest in mental disorders as a whole, was the rise of psychology and psychiatry in the interwar period. Psychological theories, and interest in key figures in the field like Sigmund Freud, played out in the medical sources this thesis examines (in a way that mirrored their rise across the western world). Joy Damousi proposed that, "It can be said that World War I marked the beginnings of the acceptance of psychoanalysis as a useful psychotherapeutic tool", and that, "equally it can be said that psychoanalysis came into its own in the 1920s and 1930s." 90 Whilst Freud and psychoanalysis may not have become as dominant a force in New Zealand (and Australia) until the post-World War II era, ${ }^{91}$ the interwar years still remained a highly significant and active period in the field of psychology, with much open debate in the 1920s and 30s about mental stability and sexuality taking place too. ${ }^{92}$

The BJOP directly addressed and examined topics related to psychology and psychological theories, as discussed here in relation to the ways in which they either explicitly, or implicitly, discussed sex, sexuality, and masculinity. Examples of this, and the vast topics the journal covered can be seen through the copious mentions of Sigmund Freud and his theories. Across several issues of the $B J O P$ various prominent psychiatrists and psychoanalysts - including W. H. R. Rivers, C. G. Jung, and Charles S. Myers - debated the concept of 'The Unconscious'. ${ }^{93}$ Freud's account of the unconscious mind was one of the

\footnotetext{
${ }^{89}$ John T. Shearer, 'Typhoid in Seacliff Mental Hospital', Preventive Medicine Dissertation, University of Otago, 1938.

90 Joy Damousi, Freud in the Antipodes: A Cultural History of Psychoanalysis in Australia (Sydney: University Of New South Wales Press, 2005), p.53.

${ }^{91}$ Damousi, p.2.

92 Damousi, p.89, and p.115.

${ }^{93}$ For direct discussions see for example: Maurice Nicoll, 'Why is the 'Unconscious' Unconscious I', British Journal of Psychology, Vol.9, October 1918, pp.230-235; W. H. R. Rivers, "Why is the 'Unconscious' Unconscious II', British Journal of Psychology, Vol.9, October 1918, pp.236-246; Ernest Jones, 'Why is the 'Unconscious' Unconscious'? III', British Journal of Psychology, Vol.9, October 1918, pp.247-256; C. G. Jung,
} 
central theories of psychoanalysis, and was one that influenced the ways certain medical professionals approached and understood diagnoses and disorders such as shell-shock and the war neuroses.

The discussion around the role of psychology and psychoanalysis is also relevant when it came to disorders such as the neuroses, and, especially, hysteria. This is due to the gendered connotations of hysteria, which Elaine Showalter made clear in her 1987 book The Female Malady: Women, Madness and English culture 1830-1980. ${ }^{94}$ In a 1922 article by A. G. Tansley it was noted that the Swiss psychiatrist and psychoanalyst (and the founder of analytical psychology) Carl Jung came to apply the conception of the causation of certain conditions including "hysteria and other pathological mental conditions" to the "repression of painful memories", as Freud had outlined in his work. ${ }^{95}$ This notion of repression being tied to the origins of mental disorders, alongside the regard given to heredity, was commonly discussed. ${ }^{96}$ The ways in which repression (and regression) was viewed as being intertwined with sexuality or not, and how this was expressed in Freudian theories was more hotly contested however.

Though broader in its scope than the $B J O P$, the $N Z M J$ did also cover psychology and psychiatry-based topics in the articles it published. The journal published some articles that were wholly dedicated to the topic but references also cropped up in other articles that were seemingly less to do with psychological subjects. Whilst some of the $N Z M J$ articles directly addressed Freud and his theories, as Eric Hobsbawm argued, "the influence of Freud extends far beyond the diverging and conflicting schools of psychoanalysis, and even beyond those who have ever read a line written by its founder." ${ }^{, 97}$ It is this approach that this thesis takes in terms of following the traces of Freud, psychology and psychiatry in order to see where and when it potentially had its impact in the NZMJ.

\footnotetext{
'Instinct and the Unconscious III', British Journal of Psychology, Vol.9, May 1919, pp.15-23; and Charles S. Myers, 'Instinct and the Unconscious II', British Journal of Psychology, Vol.10, November 1919, pp.8-14. ${ }^{94}$ Elaine Showalter, The Female Malady: Women, Madness and English culture 1830-1980 (London: Virago, 1987). It must be noted, however, that these connotations relating to shell-shock have been contested by other historians such as Laurinda Stryker in her work, Laurinda Stryker, 'Mental Cases: British Shellshock and the Politics of Interpretation', in Gail Braybon (Ed.), Evidence, History and the Great War: Historians and the Impact of 1914-1918, pp.154-171.

${ }^{95}$ A. G. Tansley, 'The Relations of Complex and Sentiment. II', British Journal of Psychology, Vol.13, October 1922, p.114.

${ }^{96}$ For example, see: Carveth Read, 'The Unconscious', British Journal of Psychology, Vol.9, May 1919, p.288; T. H. Pear, 'Critical Notice', British Journal of Psychology, Vol.11, April 1921, p.350; and F. C. Bartlett,'Feeling, Imaging and Thinking', British Journal of Psychology, Vol.16, July 1925, p.19.

${ }^{97}$ Eric Hobsbawm, How to Change the World: Reflections on Marx and Marxism (London: Little Brown Books, 2011), p.212.
} 
There were, however, several issues of the $N Z M J$ that did directly discuss Freud. For example, in the review of C. G. Jung's Collected Papers on Analytical Psychology, Freud is credited as founding the study of analytical psychology. Additionally, the reviewer commented that, "It appears to be a characteristic of the psychoanalysts... to wrap up their meaning in a jumble of high-sounding terms which often is quite unintelligible", yet Jung himself a founding figure in the field of psychology - has, managed to make clear the "necessary material" to understand this new discipline. ${ }^{98}$ In the review of The Essentials of Psycho-Pathology in the August 1936 issue, it is noted that the author's approach to psychology is "mainly Freudian", though "he has not, however, restricted himself solely to one school but has taken what he needs from various sources", ${ }^{99}$ an approach that many medical professionals (and psychologists and psychiatrists themselves) who were not Freudian purists took during this period. The August 1937 issue of the NZMJ also contained a review that referenced Freud. It was of William R. Houston's The Art of Treatment, in which the reviewer noted that whilst Houston's oversimplification of a system of psychology was confusing, his pages on Freud, "should be read by everyone." ${ }^{100}$ I. M. Allen's article 'Neurasthenia With Depression'101, and both the reviews for The Clinical Examination of the Nervous System ${ }^{102}$ and Clinical Studies in Psychopathology: (A Contribution to the Aetiology of Neurotic Illness) ${ }^{103}$ also comment on the use of Freudian 'style', as well as noting the work of other important psychologists (i.e. Jung, and Adler).

The increased interest in psychology as a discipline manifested in a variety of ways in the NZMJ. It was present in advertisements - for example, the April 1936 volume includes an advertisement for a 'Diploma in Psychology (Industrial)' to be taken up at the London School of Hygiene and Tropical Medicine. ${ }^{104}$ It also showed up in the 'Books Received' section of the journal, a place that demonstrated the expanding areas of interest of the readership of the NZMJ. ${ }^{105}$

\footnotetext{
98 'Reviews', New Zealand Medical Journal, Vol.17, No.77, February 1918, p.41.

99 'Reviews', New Zealand Medical Journal, Vol.35, No.188, August 1936, p.271.

100 'Reviews', New Zealand Medical Journal, Vol.36, No.194, August 1937, pp.271-272.

${ }^{101}$ I. M. Allen, 'Neurasthenia \& Depression', New Zealand Medical Journal, Vol.32, No.169, June 1933, pp.122-133.

102 'Reviews', New Zealand Medical Journal, Vol.21, No.104, August 1922, p.244.

103 'Reviews', New Zealand Medical Journal, Vol.38, No.204, April 1939, p.136.

104 'London School of Hygiene and Tropical Medicine', New Zealand Medical Journal, Vol.35, No.186, April 1936, p.xxi.

${ }^{105}$ For example, in the acknowledgement of the receipt of Practical Child Psychotherapy by Curt Boenheim in, 'Books Received', New Zealand Medical Journal, Vol.38, No.205, June 1939, p.228.
} 
In the June 1923 issue the 'Correspondence' section published a piece written by Stuart Moore, "“The State of Medical Literature": As Illustrated by that of Psychoanalysis'. ${ }^{106}$ In this letter Moore argues that one of the journal's previous editorial pieces on psychoanalysis was, "an attack on, and condemnation of, this subject"; and he goes on to list his critique of the way the NZMJ discussed and presented psychoanalysis in great detail. ${ }^{107}$ Moore, as an avid enthusiast of the need to discuss mental disorders and psychology and psychoanalysis in New Zealand, also published a piece titled 'The Status of Psychology'. ${ }^{108}$ In this article from 1937 Moore proposed that: "The medical profession and public opinion in New Zealand is ten to fifteen years behind U.S.A. and England in its recognition of the status that analytic psychology has won, and of its value." For Moore it seemed little had changed since his letter of complaint to the NZMJ 15 years prior. ${ }^{109}$ Moore went on to argue that "Analytic psychology should be given by medicine the status and evaluation of other specialties, e.g. eye, ear and throat" 110 - a sentiment that those working in preventive medicine echoed when it came to the population benefits for New Zealanders and their mental fitness. ${ }^{111}$ Moore then concluded his piece with a run-down of the successful results of cases he had treated with psychoanalysis, possibly in an attempt to persuade other medical professionals who read the journal of the benefits the treatment could have for their own patients. This kind of exposure helped disseminate the evolving ways of treating and thinking of male patients too, as it could frame a particular approach to their perceived masculinity.

The NZMJ also demonstrated further networks with the likes of the British Journal of Psychology - in terms of the kind of topics being discussed and published. For example, in the October 1923 issue, an article by Arnold W. Izard titled 'The Subconscious Mind' was published. ${ }^{112}$ This article added to the existing psychological debates about the unconscious

\footnotetext{
106 'Correspondence', New Zealand Medical Journal, Vol.22, No.109, June 1923, pp.187-188.

107 'Correspondence', New Zealand Medical Journal, Vol.22, No.109, June 1923, p.187. See the full piece for all of Moore's qualms.

${ }^{108}$ Stuart Moore, 'The Status of Psychology', New Zealand Medical Journal, Vol.36, No.196, December 1937, pp.389-392.

${ }^{109}$ Moore, 'The Status of Psychology', p.389.

${ }^{110}$ Moore, 'The Status of Psychology', p.390.

${ }^{111}$ See, for example: Fitzherbert, p.21.

112 Arnold W. Izard, 'The Subconscious Mind', New Zealand Medical Journal, Vol.7, No.111, October 1923, pp.289-297. In this article Izard stated that though he did not wholly agree with Freud's conclusions on psychoneuroses as being caused by "unresolved complexes" that were "sexual and infantile" in nature. He does, however, also note that he views sex as not entirely unimportant in such cases, and he discusses the types of instinct, sexual instinct included (pp.291-292).
} 
that Freud fostered, and that the BJOP published in a series of corresponding articles on the topic, notably in the 1918-1919 volumes of the journal. ${ }^{113}$

The influence of Freud and the general approach of psychoanalysis can be seen in some of the Preventive Medicine dissertations, for example when W. A. Fitzherbert references "Freud's classification" when discussing the "immense numbers of minor mental diseases including the neuroses... some forms of neurasthenia, [and] chronic hysteria." 114 Though Fitzherbert is the only fifth-year student whose dissertation directly names Sigmund Freud, there are several of the other students who allude to him and his theories when discussing psychoanalysis and psychotherapy. For example, Gordon N. Findlay talks of the benefits of psychotherapy for patients with arthritis as he says it, "is useful in that it includes suggestion, hope and encouragement, and helps towards perseverance in treatment which is essential to improvement". ${ }^{115}$ A. D. G. Blanc and R. J. Paul mention psychoanalysis in brief when questioning if the practice could be dubbed as "faith-healing", as they approvingly argue the benefits of such is in its, "psychological effect upon the patient". ${ }^{116}$ In their discussion of the history of insanity, M. Christie, and R. Christie argue that, "In New Zealand, drugs are less resorted to than in the older established countries", and that "Psychotherapy, by the methods of hypnosis, suggestion, and persuasion, is used but is of subsidiary importance". ${ }^{117}$

The mind and body brought together through the lens of psychology and psychiatry as emerging disciplines is also something that is evident in these student dissertations. Much like the uniting of the two in discussions of shell-shock and neurasthenia, some of the Preventive Medicine dissertations take a similar approach in more explicit psychological discussions. ${ }^{118}$ For example, in Lindsay R. Stewart's assessment of 'Student Life in Knox College. From a Public Health Aspect', he notes that "it is apparent that student life as a

\footnotetext{
${ }^{113}$ For example, see articles in BJOP volumes such as: British Journal of Psychology, Vol.9, October 1918; British Journal of Psychology, Vol.9, May 1919; and British Journal of Psychology, Vol.10, November 1919. ${ }^{114}$ Fitzherbert, p.16.

${ }^{115}$ Findlay, p.80.

${ }^{116}$ Blanc, and Paul, p.6.

${ }^{117}$ Christie, and Christie, p.7. They argue that psychotherapy and, "expert suggestion and hypnosis proved of comparatively little applicability and efficiency in treatment and cure of hereditary, nutritional, organic [\&] toxic deviations from normal", placing more of a focus on the outdoors, recreation, work, and full-rest to treat and cure people with mental disorders. This kind of thinking as perhaps more indicative of the evolutionary framework of understanding way of thinking, in that it's more about rest and 'will-power', or heredity, rather than something psychically wrong with patients.

${ }^{118}$ For example: in Findlay, p.80, he is referring to psychotherapy for the treatment of the physical condition, arthritis; and the dissertations on Māori tended to relate the physical surroundings and health of their subjects to their mental state; as does G. F. Hall's dissertation, whose title even gives away as much, G. F. Hall, 'St Joseph's Boys' Home, Waverly, Dunedin: A Physical \& Mental Survey’, Preventive Medicine Dissertation, University of Otago, 1939.
} 
whole has a most important effect on the body and mind of the student." ${ }^{119}$ He then goes on to link this point to the fact that: "It is now being realised, especially in America... that mental hygiene is as important as physical hygiene to the student," and that, "This is a "Psychoneurotic Age" in which under-graduates are faced with a different mode of life than that to which they are used." ${ }^{120}$ Here the terminology "Psychoneurotic Age" psychologises the mental and physical wellbeing of students, and Stewart (quoting from a source simply cited as Bradshaw) demonstrates the way in which psychological lexicon became intertwined with larger medical issues. The prevention aspect of these dissertations in relation to psychological or psychiatric problems is also made clear by W. A. Fitzherbert. He proposed that, "The majority of psychogenic psychoses, psychoneuroses, and neuroses may be aborted if adequate treatment is provided in the early stages." 121 This was an argument echoed by many in the medical field who had responded to the large numbers of shell-shock and war neuroses cases during and after the Great War. This stress on the prevention of mental disorders also seeps into the ways in which it all interacts with eugenic theories and concerns around the New Zealand population.

Where the psychology of Māori is concerned, the dissertations that addressed this topic will be discussed further in the following section. However, what is noteworthy is that the actual psychological wellbeing of certain iwi was less addressed in the dissertations this thesis examines. Rather, the physical surroundings and other health concerns of the iwi the fifth-year students studied is more at the forefront of these reports.

\section{EVOLUTIONARY FRAMEWORK OF UNDERSTANDING AND EUGENICS}

The evolutionary framework of understanding that pervaded medical spheres throughout the late nineteenth, and early twentieth century offered much in the way of defining masculinity and male sexuality. Tracey Loughran has argued that the broadened understandings of mental disorders and neuroses through the experiences of shell-shock during the war, helped to "[form] a bridge between Darwinian and Freudian understandings of human mind and behaviour." 122 To further uncover medical approaches to effeminacy and masculinity, one

\footnotetext{
${ }^{119}$ Lindsay R. Stewart, 'Student Life in Knox College. From a Public Health Aspect', Preventive Medicine Dissertation, University of Otago, 1939, p.38.

${ }^{120}$ Ibid.

${ }^{121}$ Fitzherbert, p.21.

${ }^{122}$ Loughran, Shell Shock and Medical Culture in First World War Britain, p.3.
} 
must therefore engage with the evolutionary framework ways of understanding (Darwinist views), and eugenic outlooks.

Throughout the issues of the BJOP there is evidence of an evolutionary framework of understanding (in terms of psychology) and eugenic views from the authors of articles in this period. One of the ways in which this way of thinking is expressed is through the concept of 'regression' - either a regression to, or from something (when it comes to psychological traumas). In order for regression to be understood as a concept, one must also accept that there is some sort of hierarchy in ways of being - a scale that slides between 'primitive' to 'civilised', with regression as a negative act, a step backwards towards an 'uncivilised' state'. ${ }^{123}$ Use of this terminology, and evidence of this view of cases, can be seen, for example in articles such as Carveth Read's 'The Mind of the Wizard', which references both "backward peoples", 124 and "backward savages." 125 W. H. R. Rivers, known for his anthropological work, as well as his psychiatric career, also mentions "savage communities". ${ }^{126} \mathrm{He}$ advocated for the benefits in studying the "mental process in [such] rude and backward forms of human society" 127 due to what they can reveal of the regressive states of psychoses. ${ }^{128}$ In his discussion of 'Social Factors in Mental Retardation', G. M. Robson also proposes that "the backward peoples of the world" 129 may be worth studying to understand those classified as mental and moral defect - i.e. delinquents - as related to the difficulties of social adjustment in the modern European world. ${ }^{130}$ The use of 'backward' in relation to children is also employed, ${ }^{131}$ much in the same way it is used by the Preventive Medicine students.

\footnotetext{
${ }^{123}$ Loughran, Shell Shock and Medical Culture in First World War Britain, p.48.

${ }^{124}$ Carveth Read, 'The Mind of the Wizard', British Journal of Psychology, Vol.9, October 1918, p.153.

125 Read, p. 171.

${ }^{126}$ W. H. R. Rivers, 'Psychology and Medicine', British Journal of Psychology, Vol.10, March 1920, p.187.

${ }^{127}$ Rivers, 'Psychology and Medicine', p.188.

${ }^{128}$ Ibid. Rivers states that, "Much as we may disagree in detail, there is general agreement that in neurosis and psychosis there is in action a process of regression to primitive and infantile states." He also argued that the, "frequency of the psychoneuroses in the great communities of the modern world is the direct consequence of the fluid and unorganised character of their civilisation"; and that in "savage communities" that are free from the external influence of modernity though, "the cruder forms of mental disorder, such as imbecility and idiocy, are not uncommon," yet when it comes to the psychoneuroses they are, "absent or hardly to be detected." (pp.187188). Here Rivers indicates to the notion that modernity (i.e. through a shift in society, modern warfare, etc.) resulted in the increased numbers of the psychoneuroses and that because the European mind was so much more complex than the "primitive" mind, this is why they struggled in this way.

${ }^{129}$ G. M. Robson, 'Social Factors in Mental Retardation', British Journal of Psychology, Vol.22, October 1931, p.134.

${ }^{130}$ Ibid.

${ }^{131}$ In a review of Cyril Burt's The Backward Child (1937), in 'Critical Notice', British Journal of Psychology, Vol.28, January 1938, p.346.
} 
In his October 1918 piece on the unconscious, Maurice Nicoll discussed the likes of Jung, Meyer, Hock, and MacCurdy who taught, "that they [the two groups of functional insanity] are manifestations of a retreat or regression to a more primitive stage of human adaptation". ${ }^{132}$ In the April 1933 issue's review of the recently received publication, Helene Deutsch's Psycho-Analysis of the Neuroses, it is commented that she outlines a scheme to "illustrate as clearly as possible how psycho-analysis traces the origin of neurotic disease to: "(1) fixation of the libido, (2) regression and (3) the so-called current or 'actual' cause,"”, thus aligning regression to neuroses. ${ }^{133}$

These medical sources show that New Zealand medical professionals had knowledge of, discussed, and were interested in the evolutionary framework as an explanatory regime for masculine failings or faults. Other examples of the evolutionary framework can be seen in reviews of books such as Captain G. Pitt-Rivers' Some Problems in Mental Anthropology and the Problem of Civilisation. This book is said to deal, "in general with disintegrative and integrative forces which are to be found in the primitive community." 134 Once again, seemingly in an effort to understand the running of this primitive society so that 'civilised' Europeans can learn from it when it comes to the discipline of psychology. ${ }^{135}$ In E. O. Lewis' review of Cyril Burt's The Young Delinquent, the focus is brought back to the role heredity place in criminality - particularly because it is noted that in an investigation of Brixton prison, "twice as many of the prisoners on remand were insane as were feeble-minded". ${ }^{136}$ Burt, and Lewis in turn, question where and in what ways heredity comes into play - whether it is directly genetic, or rather if it is also due to other constitutional conditions such as, "dull or defective intelligence, excitable and unbalanced temperament, or over-development of some single primitive instinct." 137

In the October 1926 issue of the BJOP a review of Geraldine Coster's PsychoAnalysis for Normal People was printed. The review states that the book is "an effort to set forth the simplest possible way the main principles of analytical psychology in its application

\footnotetext{
${ }^{132}$ Maurice Nicoll, 'Why is the 'Unconscious' Unconscious? I', British Journal of Psychology, Vol.9, October 1918, p.233.

133 'Publications Recently Received', British Journal of Psychology, Vol.23, April 1933, p.415.

134 'Publications Recently Received', British Journal of Psychology, Vol.16, July 1925, p.67.

${ }^{135}$ Another piece which similarly focused on civilisation was the review of Freud's Civilization and its discontents: 'Publications Recently Received', British Journal of Psychology, Vol.21, January 1931, p.334. See also the review of History, Psychology and Culture by A. Goldenweiser, in which the reviewer described how Goldenweiser, "considers theories of primitive mind and culture, dealing especially with English evolutionist views, and with those of Sir James Frazer, Lévy Bruhl, Wilhelm Wundt, and Sigmund Freud": in 'Publications Recently Received', British Journal of Psychology, Vol.24, July 1933, p.124.

${ }^{136}$ E. O. Lewis, 'Critical Notice', British Journal of Psychology, Vol.16, January 1926, p.250, and p.252.

${ }^{137}$ Lewis, p.252.
} 
not to the insane, perverted or abnormal, but to the ordinary people whom we meet every day". ${ }^{138}$ Here there is this distinction made between "normal people" and those dubbed as 'abnormal', a judgement statement that brings with it connotations similar to those described in the discussion of W. A. Fitzherbert's comment about "the normal man". ${ }^{139}$ The January 1931 issue also included a review of V. E. Fisher's An Introduction to Abnormal Psychology, which presented a study of those suffering from mental disorders, including, "the various psychoneuroses and psychoses"; and ended with Freudian topics such as "sleep, dreams and suggestion", as well as looking at another of the eugenic terms, the 'feeble-minded'. ${ }^{140}$

The notion of 'temperament' also ties-in to eugenic concerns and evolutionary ways of viewing the supposed 'civilisation' of groups of peoples during the interwar period. It also appeared in a number of submissions to the Report of the War Office Committee of Enquiry into "Shell-shock". ${ }^{141}$ Temperament can be seen discussed in BJOP articles such as the reviews from the October 1928 issue of S. D Porteus and Marjorie E. Babcock's Temperament and Race which is, "commended to all readers who are interested in the important psychological questions which are involved in the control and administration of groups and in colonisation", ${ }^{142}$ and Constance Bloor's Temperament, A Survey of Psychological Theories. ${ }^{143}$ In the October 1929 issue P. E. Vernon also wrote an article about 'Tests of Temperament and Personality'; 144 and Raymond B. Cattell wrote 'Temperament Tests. I. Temperament' printed in the January 1933 issue. ${ }^{145}$ The July 1932 issue included a review of the book Constitution-Types in Delinquency by W. A. Willemse. 146 'Constitution' was another term that appeared frequently in this setting and time, and refers to the mental, moral, and physical make-up of people - i.e. it signals the overlap of a range of paradigms, such as the physiological and the psychological.

Discussions of emotion, and an understanding of its role in the origins of neuroses and psychoses, is also an area that relates to the evolutionary framework of understanding - in a similar way that 'temperament' and 'constitution' did. References to emotion in terms of

\footnotetext{
138 'Publications Recently Received', British Journal of Psychology, Vol.17, October 1926, p.164.

${ }^{139}$ Fitzherbert, p.4.

140 'Publications Recently Received', British Journal of Psychology, Vol.21, January 1931, p.334.

${ }^{141}$ For example see: Great Britain War Office Committee Enquiry into "Shell-shock", Report of the War Office Committee of Enquiry into "Shell-shock” (London: H.M.S.O., 1922), p.51, p.81, p.97.

142 'Publications Recently Received', British Journal of Psychology, Vol.19, October 1928, p.202.

${ }^{143}$ 'Publications Recently Received', British Journal of Psychology, Vol.19, October 1928, p.203.

${ }^{144}$ P. E. Vernon, 'Tests of Temperament and Personality', British Journal of Psychology, Vol.20, October 1929, pp.97-117.

${ }^{145}$ Raymond B. Cattell, 'Temperament Tests. I. Temperament', British Journal of Psychology, Vol.23, January 1933, pp.308-329.

146 'Publications Recently Received', British Journal of Psychology, Vol.23, July 1932, p.77.
} 
psychology, and criminality, can be seen, for example, in the July 1929 issue of the BJOP with the review of the book Emotion and Delinquency: A Clinical Study of five hundred Criminals in the Making by L. Grimberg. ${ }^{147}$ The specific emotion of fear was something that was often debated in relation to war neuroses and shell-shock, due to concerns over how to deal with soldiers who otherwise seemed mentally fit becoming afflicted with said disorders. For example, F. Aveling wrote an article titled 'Note on the Emotion of Fear as Observed in Conditions of Warfare' for the October 1929 issue of the journal which used notes written at La Lovie in 1917. ${ }^{148}$ Much of the discussion surrounding emotion, and fear, had to do with self-control, and 'will power' of the soldiers who were faced with unprecedented forms of warfare. ${ }^{149}$ Discussions of the concept of 'will' and self-control can be seen, for example, in the article also written by F. Aveling, 'The Psychology of Conation and Volition', in which he queries the current theories on 'volition' and 'will'. ${ }^{150}$

Concerns around unemployment and the state of 'civilised' populations, which tapped into eugenic concerns about 'degeneration' (similar to 'regression') can also be seen in volumes of the BJOP. For example, the July 1936 issue includes a review of N. W. Morton's book Occupational Abilities: A Study of Unemployed Men; ${ }^{151}$ and the October issue of the same year also published a review of Nathan Israeli's Outlook upon the Future of British Unemployed, Mental Patients and Others - these categories, it should be noted, are all to do with a shared loss of independence. ${ }^{152}$ Gainful or productive employment, it is important to remember, played a central part in notions of masculinity in this period, so unemployment and unemployability disturbed this status.

The evolutionary framework of understanding, and eugenic approach can also both be seen in articles from the $N Z M J$ during the interwar period. For example, the editorial from the

\footnotetext{
147 'Publications Recently Received', British Journal of Psychology, Vol.20, July 1929, p.93. See also 'Publications Recently Received', British Journal of Psychology, Vol.22, July 1931, p.93: the review of Emotions of Men (1930) By F. H. Lund.

${ }^{148}$ F. Aveling, 'Note on the Emotion of Fear as Observed in Conditions of Warfare', British Journal of Psychology, Vol.20, October 1929, pp.137-144. Here too is the admission that whilst some of this approach was not new, the war had a great impact on the understanding of mental disorders nevertheless: "Although there is much omission, for the purpose of this paper a certain amount of psychological commonplace has been included; but at the same time there are certain observations which appear to be new, or at any rate newly emphasized in the conditions of warfare" (p.137).

149 This is something that Aveling too comments on: "Occasions for the eruption of fear were certainly not lacking; and opportunities for the exercise of self-control were as frequent as were the occasions tending to disequilibrate emotional stability": Aveling, "Note on the Emotion of Fear as Observed in Conditions of Warfare', pp.137-138.

${ }^{150}$ F. Aveling, 'The Psychology of Conation and Volition', British Journal of Psychology, Vol.16, April 1926, pp.339-353.

151 'Publications Recently Received', British Journal of Psychology, Vol.27, July 1937, p.108.

152 'Publications Recently Received', British Journal of Psychology, Vol.27, October 1936, p.235.
} 
October 1918 issue, 'Nervous Debility', links modernity and employment to neurasthenia, stating that, "It is no exaggeration to state that the majority of professional and business men in this country are neurasthenic". ${ }^{153}$ The piece is concerned with the issue as they note that: "our New Zealand soldiers are as liable to nervous disorders as British troops", ${ }^{154}$ and the issue is that, "Neurasthenia and the like are sometimes acquired but more often hereditary". ${ }^{155}$ So whilst it justifies the worries around New Zealand working men (as they are just as at risk as those in Britain likely are) what underpins it is essentially this hereditary concern - demonstrative of the evolutionary framework way of thinking in terms of relating parentage to mental disorders, or even the possibility of them. The article also reflects the preventive interests of treating mental disorders and hereditary problems, which in turn mirrors the purpose and existence of the Preventive Medicine dissertations that discuss similar topics and ties in with theories underpinning eugenic thinking around population surveillance and control. ${ }^{156}$

In the editorial piece of the June 1936 issue of the $N Z M J$, 'The Consequences of Leisure', we see another of the ways in which the evolutionary framework of thinking tied itself to worries around unemployment, and the effects this could have on men. The article references Alexis Carrell's Man the Unknown and points out that he deplores: "the modern refinements of technology and the sheltering of youth, which tend to weaken the race."157 This critique of the 'Modern Man' goes on to berate their unwillingness to work hard, in the way of the past, and argues that "we are far from having solved this momentous problem of idleness created by prosperity, modern machinery or unemployment." 158 What underpins these criticisms is that idea that the race is being weakened; and that, "Certain forms of modern life lead directly to degeneration". ${ }^{159}$ Concerns around delinquency, unemployment, loss of independence, modern life and modern warfare, and mechanisation all help to pinpoint that these concerns were specifically about men and masculinity. The unemployed referred to in these articles were not women; and these issues were all very alarming particularly unemployment, as Melanie Nolan has argued - in the male breadwinner

\footnotetext{
153 'Editorial', New Zealand Medical Journal, Vol.17, No.81, October 1918, p.176.

154 Ibid.

155'Editorial', New Zealand Medical Journal, Vol.17, No.81, October 1918, p.177.

${ }^{156}$ See in 'Editorial', New Zealand Medical Journal, Vol.17, No.81, October 1918, p.177, where it is argued that, "It is very important that the pre-neurasthenic state should be recognised and treated, and it is very easily overlooked but much more amenable to treatment than when the disease is definitely and obviously established."

157 'Editorial', New Zealand Medical Journal, Vol.35, No.187, June 1936, p.143.

158 Ibid.

159 Ibid.
} 
economy. ${ }^{160}$ Modernity's impact on sexuality, masculinity and femininity (and the psychology of this) is also featured in BJOP articles between 1918-1939. The review of Meyrick Booth's book Youth and Sex talks about the rapid changes the modern world; though the reviewer notes that whilst it is "interesting enough to read... nothing very definite emerges." 161 The NZMJ also contained a number of about the concerns of malingering. ${ }^{162}$

The February 1937 article 'Malnutrition and a C3 Population', written by F. M. Spencer, demonstrates eugenic concerns around the New Zealand population as exposed by the Great War. ${ }^{163}$ Spencer wrote in response to what he said were, "constant references in the Press during the past few months", with his piece being an investigation to the current state of the New Zealand population as, "It was well recognised during the War that our population was not nearly as fit as had been fondly imagined."164 Whilst Spencer's article examines the physical health of children more than their mental fitness, ${ }^{165}$ its discussion of heredity, and its broader placement in the landscape of increased concerns around population size and health following the Great War is what makes it noteworthy for this thesis, especially as it was men who were measured-up against 'C.3' standards. ${ }^{166}$

Worries about depopulation, or weakened existing populations, very much ties into anxieties around effeminacy and masculinity in the ways the former was expressed. For example, in an editorial about 'Birth Control' the author wrote that: "When many of the best and bravest of our young men have perished in the Great War and when the urgent need of this country and the Empire is population, it is not only surprising that Malthusianism should be advocated by medical men or even by laymen, but it is monstrous." 167 This then steers towards the idea that most of New Zealand's "best and bravest" men have died, and left behind weak, cowardly, and un-masculine men. These men who already did not live up to masculine ideals, were also now actively choosing not to have children (as advised by certain

\footnotetext{
${ }^{160}$ Melanie Nolan, 'Antipodean Aspirations and the Difficulties of Regulating For Decent Work Now and Then?', New Zealand Journal of Employment Relations, Vol.39, No.2, April 2014, p.43.

161 'Publications Recently Received', British Journal of Psychology, Vol.23, July 1932, p.81.

162 See, for example: 'Auckland Clinical Society', New Zealand Medical Journal, Vol.35, No.185, February 1936, pp.45-46, for a case of "Professional Invalidism" and malingering.

${ }^{163}$ F. M. Spencer, 'Malnutrition and a C3 Population', New Zealand Medical Journal, Vol.36, No.191, February 1937, pp.4-20. 'C3' was used as a classification for recruits of "the lowest grade of physical fitness for military service in World War I”: 'C3', Merriam Webster; www.merriam-webster.com; accessed 9 July 2020.

164 Spencer, p.4.

${ }^{165}$ Coming at a time when fitness of the population, adults and children amongst that, was in the public debate. For more on this topic (of physical fitness) see Macdonald, Strong, Beautiful and Modern: National Fitness in Britain, New Zealand, Australia and Canada, 1935-1960.

166 Spencer, p.8. See also the Dr. J. P. S. Jamieson, 'Presidential Address', New Zealand Medical Journal, Vol.37, No.198, April 1938, pp.72-77, in which Jamieson lamented the standards of New Zealanders as a race. 167 'Editorial', New Zealand Medical Journal, Vol.21, No.106, December 1922, p.342.
} 
medical professionals, who the writer of this piece, and other $N Z M J$ subscribers, strongly disagree with). ${ }^{168}$ The author of this article then takes things a step further, and makes implicit the racial concerns tied to all of this anxiety too, when he says: "If countries suitable for the white races are not to be fully populated and developed by the white races, it means one of two results, either these countries will be over-run by coloured races, or there will be the most bloody and horrible wars for racial supremacy. The mind shrinks from either alternative." $" 169$

Similar concerns such as these are seen in an editorial piece from 15 years later, though with Britain as the main focus this time. "Now there is a chorus of alarm at the menace of depopulation of Great Britain and her colonies," the author writes, and then goes on to question whether, "this menace [is] real?" - to which the response is, to the educated person on the topic, most clearly yes. ${ }^{170}$ The answer to this problem is framed as dependent on, "a change of heart of young people - young women in particular" - the emphasis on young women in this capacity is something that many historians have already examined. ${ }^{171}$ In terms of this thesis there was also a considerable concern about the fitness and reproductive capacity of young men; and by 1937 they represented a threat, especially considering the proportion of men who suffered unemployment in New Zealand during the early 1930s. In the December 1927 Editorial on 'Mental Defectives', the article-writer points out that New Zealand, though a small nation, has the particular benefits of, "opportunities here for moral, mental and physical betterment which are denied to older more populous countries"; and that it is imperative something is done to fix the population because the alternative - of "the degenerate, ineffective, abnormal and dependency class of the community" increasing at its current rate - is (perhaps in this case, quite extremely put), "in course of time [that] the State will be overthrown." ${ }^{172}$ Here the (extreme) outcome of these fears of depopulation and problem populations being unchecked is felt strongly, and helps to explain why ideas such as the 'menace' of depopulation, and effeminacy, continued to reoccur over the interwar period.

\footnotetext{
168 'Editorial', New Zealand Medical Journal, Vol.21, No.106, December 1922, p.342.

169 Ibid.

170 'Editorial', New Zealand Medical Journal, Vol.36, No.194, August 1937, p.215.

${ }^{171}$ For example, see Angela Wanhalla's work which discusses the role of women as both agents and subjects of eugenics and population anxieties during the interwar period: Angela Wanhalla, 'To 'Better the Breed of Men': women and eugenics in New Zealand, 1900-1935', Women's History Review, Vol.17, No.2, April 2007, pp.163182.

172 'Editorial', New Zealand Medical Journal, Vol.26, No.136, December 1927, p.268.
} 
Comments on the possibility, or desire, for sterilisation were also aired in the NZMJ during this period as related to the broader up-take in interest in eugenics in New Zealand. ${ }^{173}$ The August 1922 issue of the NZMJ ran a piece titled 'Mental Defects Among School Children', written by Alfred Clark, the Medical Inspector of Schools, which used the kind of language reflected in the legislation as discussed in chapter one. ${ }^{174}$ Clark states that he does not " think that public opinion is yet ready to acquiesces in any suggestion of sterilisation of these cases, but happily segregation is almost equally effectual in preventing multiplication." 175 In a meeting of the New Zealand Branch of the BMA, recorded in the October 1926 issue of the NZMJ, the Branch discussed the 1925 Inquiry into Mental Defectives and Sexual Offenders and its advocacy for the, "powers of segregation and of sterilisation" under the control of a Eugenic Board. ${ }^{176}$ Angela Wanhalla has argued though, that despite certain interests and appeals of the use of such eugenic boards, there was little agreement over how exactly these powers should be enacted, which ultimately led to the rejection of the full powers of sterilisation and prohibitions on marriage in the 1928 Amendment to the Mental Defectives Act. ${ }^{177}$ A point that has also been elaborated on by Charlotte Macdonald, when she outlined that some of the main opposition to the inclusion of the clause for sterilisation in the 1928 Amendment came down to a strong argument, "against the state exercising powers... on the basis of a defined category of "social defective", that was, they argued, "far too loose and lacking medical veracity."178

The linking of mental and physical health also demonstrates evolutionist views regarding the origins of mental disorders, and 'healthy' races along the spectrum of primitivity to civilisation. Examples of this association between the mental and physical can

\footnotetext{
${ }^{173}$ For general mentions of sterility and sterilisation, see, for example: 'Reviews', New Zealand Medical Journal, Vol.24, No.120, April 1925, p.117, which included a review of Fertility and Sterility in Human Marriages (which had a section on 'The Determining Causes of Male Sterility'; and noted that, "Great stress is laid on a complete and exhaustive investigation of the general condition, physical and psychological, of both parties to the marriage before local causes are investigated" which ties the mentally unfit with sexuality and issues of sex and marriage, and reproduction; or see 'Reviews', New Zealand Medical Journal, Vol.36, No.195, October 1937, p.343, for a review of Eugenical Sterilisation.

${ }^{174}$ Alfred Clark, 'Mental Defects Among School Children', New Zealand Medical Journal, Vol.21, No.104, August 1922, pp.215-219.

${ }_{175}$ Clark, p.219.

176 'British Medical Association Meeting - New Zealand Branch', New Zealand Medical Journal, Vol.25, No.129, October 1926, p.292.

${ }^{177}$ Angela Wanhalla, 'Debating Clause 21: 'Eugenic Marriage' in New Zealand', in Diane B. Paul, John Stenhouse, and Hamish G. Spencer (Eds.), Eugenics at the Edges of Empire: New Zealand, Australia, Canada and South Africa (Cham: Springer International Publishing, 2018), p.107.

${ }^{178}$ Charlotte Macdonald, 'Revisiting Three Eugenic Movements: 1903, 1928, 1937: The Disappointments and Hopes of Antipodean Progressives', in Diane B. Paul, John Stenhouse, and Hamish G. Spencer (Eds.), Eugenics at the Edges of Empire: New Zealand, Australia, Canada and South Africa (Cham: Springer International Publishing, 2018), pp.229.
} 
be seen in the NZMJ on a number of occasions, such as in the August 1936 review of George W. Henry's The Essentials of Psycho-Pathology. It is noted that: "To him the mental and physical are two facets of the one problem of human relationships and their emotional concomitants." 179 This also appears in discussion of occupational therapy, which Peter J. Boston has noted Sir Truby King advocated over the use of Freudian psychotherapy, which in turn had benefits for the self-perception of the masculinity of the patients this therapy was used on - it helped them retain a sense of "masculine self-esteem." 180

Discussions of emotions, much as in the BJOP, also appear in the $N Z M J$, and also use the evolutionary framework of understanding. For example, in Stuart Moore's 'The Basis of Neurotic Thought and its Significance in General Practice', he argues that, "Primitive man is highly emotional", and talks about how "primitive men" are described by psychoanalysts that study them. ${ }^{181}$ The relation of emotion to self-control, and also of insanity to criminality, is something that was also discussed in the $N Z M J$, as seen by the editorial piece from the August 1928 issue, 'Law and Medicine'. This article questions the criminal responsibility of those diagnosed with insanity, as related to self-control and instinct. ${ }^{182}$ Notions of self-control (and the ability to have power over ones emotions and actions) during the interwar period were central to both understandings of the development and treatment of mental disorders, ${ }^{183}$ and of sexual desires and the possibility for homosexuality in all-male environments. ${ }^{184}$

The evolutionary framework of understanding, plus interest in eugenics and theories related to both are ideas that can be found in the Preventive Medicine dissertations. This is perhaps most evident in the dissertations that look at different groups of Māori. In 1937 J. M. Staveley's dissertation was a 'Public Health Survey of the Whangamata Maoris, With Special Reference to Their Psychology'. He started his sub-section on 'The Psychology of the Group' with a remark that demonstrates the evolutionist-approach to Māori (and beyond) that remained in the first-half of the twentieth century. He wrote, "As Elsdon Best ["MAORI MYTH AND RELIGION”] has remarked “- myth and religion are inseparable when dealing

\footnotetext{
179 'Reviews', New Zealand Medical Journal, Vol.35, No.188, August 1936, p.272.

${ }^{180}$ Peter J. Boston "The Bacillus of Work": Masculinity and the Rehabilitation of Disabled Soldiers in Dunedin 1919 To 1939', p.25, and p.104. For example, see: Corban Assid Corban, 'Reflections on Occupational Therapy in Mental Treatment', New Zealand Medical Journal, Vol.31, No.163, June 1932, pp.191-198.

${ }^{181}$ Stuart Moore, 'The Basis of Neurotic Thought and its Significance in General Practice', New Zealand Medical Journal, Vol.21, No.163, June 1932, p.200.

182 'Editorial', New Zealand Medical Journal, Vol.22, No.140, August 1928, p.264.

${ }^{183}$ Loughran, Shell Shock and Medical Culture in First World War Britain, pp.69-71.

${ }^{184}$ Chris Brickell, 'Sexology, the Homo/Hetero Binary, and the Complexities of Male Sexual History', Sexualities, Vol.9, No.4, 2006, p.440
} 
with barbaric races." So are the Public Health and the Psychology." 185 In effect, Staveley was categorising Māori as a "barbaric race", and that also frames them as a danger to public health. Staveley also describes Māori as lacking "any pride of race", and having a, "marked inferiority complex where the pakeha [sic.] is concerned", something that Staveley argues is a feature of the "psychological make-up" of Māori (i.e. in, "his constant endeavour to please the pakeha [sic.]". ${ }^{186}$ This dissertation alone therefore demonstrates the idea that hierarchical ways of viewing race, i.e. Māori as 'inferior' to Pākehā, were part of how at least some of the fifth-year Otago Medical students approached the world. ${ }^{187}$

Staveley was not the only fifth-year student who, in discussion of Māori, demonstrated views that aligned with evolutionary framework kind of thinking. Jean M. Sandel wrote in her dissertation on Te Rohe Pōtae Māori the following:

Although handicapped by the non-existence of records, and to an even greater extent, by the language barrier, these observations may serve to indicate something of the absorbing interest in this psychological problem - the interaction of a stone-age people with the whites, who have endeavoured, in a short century, to speed up their civilisation by a thousand years. ${ }^{188}$

She quite clearly pinpoints here that the "psychological problem" of this iwi is their backwardness compared to the civilised Pākehā. Later in the dissertation though, Sandel seems to hint that it was the influence of the Pākehā in their contact with this group of Māori that corrupted them. She states: "Nowhere is the European to blame for the improvidence, immorality, and degeneracy of the Maori people, more than in the King Country" and that it is the, "early experiences with the pakeha [sic.] which are responsible for very many of their [the Te Rohe Pōtae Māori's] bad habits." ${ }^{189}$ Here then Sandel seems to want to view this

\footnotetext{
${ }^{185}$ J. M. Staveley, 'Public Health Survey of the Whangamata Maoris, with Special Reference to Their Psychology', Preventive Medicine Dissertation, University of Otago, 1937, p.21.

${ }^{186}$ Staveley, $\mathrm{p} 33$. He goes on to argue that, "The fostering of a strong racial pride is all important in the [Maori] problem, as this would give a solid basis for the reconstruction of a stable psychology which is the only foundation of a future [Maori] culture." (p.34) This indicates that he believes that their lower psychological wellbeing is a result of low "racial pride" (due to the supposed inferiority of the Whangamata Māori), which too presents this kind of hierarchical view of the group, and demonstrates how this way of thinking got tied in with the increasing interest in and use of psychological knowledge.

${ }^{187}$ See also: G. B. A. Cowie, and R. A. Wilson, 'Public Health Survey of Maoris in North Wairarapa District', Preventive Medicine Dissertation, University of Otago, 1934, pp.10-11. The pair do not go into detail in their dissertation beyond that relating to housing and public buildings, however, they do preface their work by stating that they examined, "the descendants of this weak tribe who although vanquished in tribal warfare did not transfer their energies to useful and profitable channels," thus you see them designating this group of Māori as "weak" and unsuccessful, i.e. lesser than successful Pākehā.

188 Sandel, p.2.

${ }^{189}$ Sandel, p.11.
} 
group of Māori as a "stonge-age people" 190 whilst also commenting that it was the interaction with Europeans that pushed them away from, "their original high level of health and mental vigour". ${ }^{191}$ This seeming juxtaposition reflects some of the confusion and complexity of this kind of evolutionary, psychological, and sexuality-focused thinking in interwar New Zealand; but, it nevertheless demonstrates how this framework of understanding could be applied in the perception of the purported ideals of New Zealand masculinity and sexuality. ${ }^{192}$

Beyond a discussion of Māori, the evolutionary framework of understanding, and eugenic thinking, can be seen when the medical students discuss heredity. Heredity, and concerns around parentage and lineage, was of high importance when it came to eugenic concerns about the future population of New Zealand, as a grasp of heredity inferred a way to control it, and as a result, control the makeup of a population. E. S. Jamieson and O. L. Eaton included a table on the "Causes of Insanity in Admissions" for Nelson Mental Hospital for the period 1885-1930, and commented that it is noticeable that there has been an "increase in the percentage due to heredity". ${ }^{193}$ When discussing "feebleminded", backward, and/or degenerate children T. C. Sutherland and N. A. Priest, A. M. Stanton, and G. F. Hall reference the parents of said children, and comment on their mental capacity and fitness too indicating the notion that something like feeblemindedness could be passed on from parent to child. ${ }^{194}$

Hall's dissertation is particularly interesting in this regard too as he looks at the Medical Examination forms used to assess the mental and physical capabilities of the students from St. Joseph's Boys' Home. ${ }^{195}$ These examinations tested the "mental condition" (from bright-fair-dull) and "nervous system" (normal or abnormal) of the schoolboys, ${ }^{196}$ and allowed them to be classified along the scale of emotionally intelligent to mentally

\footnotetext{
${ }^{190}$ Sandel, p.2.

${ }^{191}$ Sandel, p. 132.

192 I.e. the ideal outlined by Jock Phillips in A Man's Own Country?: The Image of the Pakeha Male- A History (Auckland: Penguin Books, 1996): that of the virile, heterosexual Pākehā.

${ }^{193}$ Jamieson, and Eaton, pp.138-139. They do note (p.139) that, "The tendency is to put down more and more cases to hereditary influence, and that may account for the increase", however they also state that, "there is also a corresponding increase in the congenitals, which, perhaps, inclines one to the opinion that the increase in the former, the hereditary, is to some extent real." The fact that the congenital and hereditary cases, "account for over one third of the admissions" (p.139) demonstrates that those working in such institutions as the Nelson Mental Hospital (that this 1933 dissertation examines) were aware of, and concerned with, the rising number of 'insanity' cases linked to heredity; and thus when it comes to population concerns and views of what a healthy, sane, New Zealander should look like their heritage certainly played a part (and concerned those worried about emasculation, degeneration, and a weakening of the New Zealand 'race').

${ }^{194}$ See Sutherland, and Priest, pp.58-59; A. M. Stanton, 'Backward Children: What Is Being Done For Them In New Zealand', Preventive Medicine Dissertation, University of Otago, 1936, p.19; Hall, p.4.

${ }^{195}$ G. F. Hall, ‘St Joseph’s Boys’ Home, Waverly, Dunedin: A Physical \& Mental Survey’, Preventive Medicine Dissertation, University of Otago, 1939.

196 Hall, inserted Medical Examination forms (unnumbered).
} 
defective. ${ }^{197}$ In regards to the role heredity plays, Hall argued that "It is important to note that contrary to the general lay belief, hereditary influences are believed to condition mental level almost to the exclusion of the influence of environment", effectively illustrating the centrality of things like heredity and the evolutionary framework of understanding when it came to assessing the mental capacity and fitness of the youth (and beyond) of New Zealand. This scale of abnormal to normal, though focusing more on the "abnormal" due to the perceived problems this caused, is important here in that it indicates that there was a "normal". A normal or ideal of mentally fit, capable, physically fit, boys and men that was in use, being discussed, and of interest to these senior level medical students.

Nola M. Ivory's dissertation that discusses infant mortality argued that the general decline in infant mortality rates in New Zealand is similar to that of "all civilised countries" so there is nothing one can attribute specifically to do with New Zealand here. ${ }^{198}$ Yet, she goes on to state that, "it is no wonder that a people who come from a good stock should be a particularly virile race", ${ }^{199}$ referring to New Zealanders - in particular, Pākehā New Zealanders. ${ }^{200}$ This, arguably, links the superior heredity, and "stock" of people to the success of the New Zealand 'race'. It implicitly presents the idea that those not of this "good stock" are weakening the general population, and increasing things like infant mortality, and are therefore a problem.

Some of the Preventive Medicine dissertations reflected evolutionary framework thinking and eugenic concerns in their commentary on particular groups. For example, in their '[A] Hygienic Survey of the New Zealand Division of The Royal Navy', L. F. Johnson, and G. R. Nicks outlined that amongst the "Defects and Diseases Which Disqualify" men aiming to join the Navy as recruits included those with, "A weak constitution, imperfect development or important malformation, physical weakness either hereditary or acquired". ${ }^{201}$ The concept of having a 'weak constitution' can be seen as tied to the same sort of thinking

\footnotetext{
${ }^{197}$ Hall, p.32, and p.36.

198 Nola M. Ivory 'Infantile Mortality', Preventive Medicine Dissertation, University of Otago, 1930, p.17.

${ }^{199}$ Ivory, p.19.

${ }^{200}$ M. Watson, who wrote their dissertation after Ivory, commented on something similar: "With such a climate it is only natural that the virility of the race should be correspondingly high - as we can obviously assume it is. Further, the population is, with the exception of Maoris and a small percentage of Chinese, relatively homogenous", homogenously European. M. Watson, 'Infant Mortality \& Infant Feeding', Preventive Medicine Dissertation, University of Otago, 1933, p.15.

${ }^{201}$ L. F. Johnson, and G. R. Nicks, 'A Hygienic Survey of the New Zealand Division of the Royal Navy', Preventive Medicine Dissertation, University of Otago, 1935, p.24. The pair do comment however that, "in New Zealand owing to the great disproportion of applicants to successful candidates, the standard of mental, medical and physical fitness is unusually high" (p.32). This shows that there were various ideals of mental fitness (as well as the other factors that constituted ideal men in New Zealand) that they may have been dependent on time, place, and occupation.
} 
that underpinned concerns around neurasthenia and the nervous states of men, and citizens. A. D. G. Blanc and R. J. Paul pointed out the existence of this "nervous group" in society, when they discussed the "therapeutic success" of laymen selling unorthodox medical treatments and medicines in their work that otherwise called for a halt of said treatments. ${ }^{202}$

M. Christie and R. Christie, in their examination of Porirua Mental Hospital, wrote that one of the possible preventive forms of treatment for those admitted to the hospital includes the use of the Eugenics Board. ${ }^{203}$ They note the creation of this board in accordance with a section in the Mental Defectives Amendment Act, and that its function is to register "all mentally defective persons in New Zealand" to provide them with "proper supervision" and fulfil the need for "care, and examination by the psychological clinics" that reports to the Eugenic Board call for. ${ }^{204}$ Here we can see how the interest in, and application of eugenics, and a eugenically coded approach to dealing with the 'mentally defective' population in New Zealand. As Peter J. Boston proposed, the ways in which men who were mentally or physically unfit were viewed as having failed to live up to, in this case, eugenic ideals also influenced how the virility and masculinity of these men were perceived. ${ }^{205}$

\section{SEX, SEXUALITY, MARRIAGE AND MASCULINITY}

In many volumes of the British Journal of Psychology there are references to how Freud and Freudian theories view sexuality. Whilst not all of those who cite these theories in their articles agree with Freud, the presence of said disputed theories is what concerns this thesis. For example, the October 1918 issue of the BJOP mentions "Freud's theory of Sex"; 206 in the March 1920 issue W. H. R. Rivers mentions those of "the most prominent school of students of the psychoneuroses" - i.e. followers of Freud - who believe that sexual instinct plays a part in the origin of war neuroses (though Rivers himself debates this somewhat). ${ }^{207}$ Ernest Jones' article 'Some Problems of Adolescence' notes the importance of the sexual factor in treatment from psychoanalysts, ${ }^{208}$ as well as discusses the concept of "Sexual maturity" when it comes to Freud's theories. ${ }^{209}$ In the January 1924 issue, James Drever and Ernest Jones

\footnotetext{
202 Blanc, and Paul, pp.20-21.

${ }^{203}$ Christie, and Christie, p.12.

204 Ibid.

${ }^{205}$ Peter. J. Boston, "The Bacillus of Work": Masculinity and the Rehabilitation of Disabled Soldiers in Dunedin 1919 To 1939’, p.69.

${ }^{206}$ Ernest Jones, 'The Theory of Symbolism', British Journal of Psychology, Vol.9, October 1918, p.193.

${ }^{207}$ W. H. R. Rivers, 'Psychology and Medicine', British Journal of Psychology, Vol.10, March 1920, p.191.

${ }^{208}$ Ernest Jones, 'Some Problems of Adolescence', British Journal of Psychology, Vol.8, July 1922, p.32.

209 Jones, 'Some Problems of Adolescence', p.39.
} 
wrote corresponding articles about 'The Classification of the Instincts', and they both mention the role of sex and sexual instincts in relation to Freudian theories. ${ }^{210}$ The same issue also included a review of William McDougall's 1923 An Outline of Psychology by James Drever, in which he again comments on Freud and sexuality. ${ }^{211}$ There is a review of Sándor Ferenczi's Further Contributions to the Theory and Technique of Psycho-Analysis in the July 1927 issue - a book in which he is said to discuss many different topics, including "Sexual Theory". ${ }^{212}$ Jones published another article on the topic in the January 1936 issue, in which he acknowledges the work Freud did on psychoanalysis and the various sexual impulses. He wrote that: "His [Freud's] conclusions on the forms of infantile sexuality, indeed the very existence of this, were for long bitterly opposed, but now have been widely accepted and extended by later workers, by Abraham, Ferenczi, myself and others" - thus outlining how said theories became so central to the work of psychoanalysts and psychologists at large. ${ }^{213}$ Additionally, other psychologists and psychiatrists who discussed sexuality were also referenced in the pages of the $B J O P .^{214}$

In his discussion of 'Instinct and the Unconscious', W. McDougall comments on W. H. R. Rivers' understanding that suppressions and dissociations that can accompany psychoneuroses are connected with both, "the instincts of sex and of self-preservation or

\footnotetext{
${ }^{210}$ James Drever, 'The Classification of the Instincts', British Journal of Psychology, Vol.14, January 1924, pp.248-255; and Ernest Jones, 'The Classification of the Instincts. II', British Journal of Psychology, Vol.14, January 1924, pp.256-261.

${ }^{211}$ James Drever, 'Critical Notice', Vol.14, January 1924, p.310, writes that, "A dismissal of the Freudian exaggeration of 'sexuality' - if it is an exaggeration - is scarcely sufficient notice of the Freudian development even in an 'outline' of normal psychology, in view of the important aspects of Freudian psychology which are quite independent of the 'sexuality' findings. At the same time we can hardly refuse an author the privilege of selecting and arranging his own subject-matter".

212 'Publications Recently Received', British Journal of Psychology, Vol.18, July 1927, p.92.

${ }^{213}$ Ernest Jones, 'Psycho-Analysis and the Instincts', British Journal of Psychology, January 1936, p. 276.

${ }^{214}$ For references to Freudian views and sexuality, and other psychologist and psychiatrists' views see: 'Publications Recently Received', British Journal of Psychology, June 1921, p.109, for a review of A Young Girls' Diary is prefaced by a letter from Freud himself, and notes "the importance of sexual thoughts in early life" in relation to psychoanalysis; 'Publications Recently Received', British Journal of Psychology, Vol.18, October 1927, p.229, for the review of Charles Fox's Educational Psychology. Its Problems and Methods, which notes that he discusses psychoanalysis and the "Sexual Theory; P. E. Vernon, 'The Psychology of Rowing', British Journal of Psychology, January 1928, pp.320-321; 'Publications Recently Received', British Journal of Psychology, April 1928, p.467; Godfrey H. Thomson, 'Critical Notice', British Journal of Psychology, Vol.19, October 1928, p.200; 'Publications Recently Received', British Journal of Psychology, July 1930, p.98; 'Publications Recently Received', British Journal of Psychology, January 1933, p.335; 'Publications Recently Received', British Journal of Psychology, Vol.25, January 1935, p.410, for the review of J. D. Unwin's Sex and Culture; 'Publications Recently Received', British Journal of Psychology, Vol.26, October 1935, p.214; 'Publications Recently Received', British Journal of Psychology, Vol.29, January 1939, p.311, for the review of Mental Conflicts and Personality by Mandel Sherman, in which he, "considers culture conflicts, conflicts of inferiority and insecurity, sex conflicts, conflicts and neuroses, and conflicts and antisocial behaviour."
} 
fear." 215 The idea of un-controlled emotions and the notion of repression is also something that was linked with sex and sexuality, and with the idea of un-masculine behaviour and ways of being. For example in the 'Notes on Recent Periodicals' section of the July 1924 BJOP issue, an article written by J. H. Cooper titled 'The Psychoanalytical Method Applied to the Study of Repression' (for The Journal of Abnormal Psychology and Social Psychology), was referenced. In it the idea that "Repression serves as a gratification of a sexual desire towards the parent and represents a sexual life of the individual, and resistance is an effort to retain the sexual pleasure derived from repressing" was proposed. Linked repression, a failure in maturation (in detaching from parental figures), and sexual desire were all ideas that also appeared in theories behind the origins of sexual deviancy and homosexuality. ${ }^{216}$

In a discussion of Freud's theories and sexual maturity, Ernest Jones notes that Freud proposes that, "At puberty a regression takes place in the direction of infancy," 217 and that this regression is much stronger and more common that had previously been thought. ${ }^{218}$ This relation of regression to the infantile - and by proxy, the ways in which primitiveness was linked to this too - can also be seen in the review for John T. MacCurdy's book Problems of Dynamic Psychology. ${ }^{219}$ Here the reviewer notes that in cases where sex instincts are not functioning ideally, which may be due to a failure to pass through the normal stages of the progression into adulthood, psychoanalysis might be of benefit. MacCurdy, the reviewer writes, "shows that the normal adult passes through the three stages of narcissism, homosexuality, and heterosexuality", with the first and third of these stages being, "essential for normal development." ${ }^{220}$ It is noted that MacCurdy "briefly indicates the way in which regression may be caused" - i.e. a regression or step backwards rather than forwards through these steps of development. ${ }^{221}$ In this view the man acting on homosexual desires was therefore seen as regressive, infantile, and primitive, compared to the successful, adult, civilised heterosexual man. Masturbation, and same-sex desires and actions were understood as infantile forms of narcissism, and were indicators of abnormality, and maybe even pathology (for the individual and for the society at large).

\footnotetext{
${ }^{215}$ W. McDougall, 'Instinct and the Unconscious VI', British Journal of Psychology, Vol.10, November 1919, p. 40 .

216 'Notes on Recent Periodicals', British Journal of Psychology, Vol.15, July 1924, p.91.

217 Jones, 'Some Problems on Adolescence', p.41.

218 Jones, 'Some Problems on Adolescence', p.46.

219 'Publications Recently Received', British Journal of Psychology, Vol.17, July 1926, pp.70-78.

${ }^{220}$ Publications Recently Received', British Journal of Psychology, Vol.17, July 1926, p.73.

221 Ibid.
} 
What is also noteworthy are the ways in which 'hysteria' was discussed and brought up in conversations around abnormality. ${ }^{222}$ This diagnosis prior to the war had been a traditionally 'feminine' one, with its applications to men with mental disorders, Elaine Showalter proposed, influencing the ways in which their masculinity and sexuality were viewed. ${ }^{223}$ In the review of Ernest Jones' Treatment of the Neuroses, hysteria is commented on in regards to the Freudian view that it is to be "attributed to suppressed sexual wishes."224 Whilst the sexual wishes are not specified, this link between a mental disorder - hysteria and the sexual illustrates the ways in which conceptions of sex and sexuality were also used to help understand mental disorders, and vice versa. ${ }^{225}$ In this instance, the Freudian perspective of other mental disorders is also presented, and again, sexuality plays a large role in the explanation of their causation:

neurasthenia in its narrower, more literal sense [attributed] to excessive sexual self-abuse accompanied by intense moral conflict, hypochondria to "excessive erogenicity of certain areas of the body", alcoholism to repressed homosexuality, anxiety neurosis to "undue sexual excitation... and inadequate relief," anxiety hysteria (e.g. mostly phobias) to the symbolisation of some sexual situation arising in the early development of the psychosexual life, obsessional neurosis to buried selfreproach dating from childhood and referring "to certain sexual performances or tendencies", war neurosis generally to "repressed narcissism." 226

Unsurprisingly, homosexuality is directly addressed in some of the $B J O P$ volumes during the interwar period this thesis examines. For example, in the above quoted 'Treatment of the Neuroses' article, ${ }^{227}$ and the review of John MacCurdy's book; ${ }^{228}$ and in the discussion of Sándor Ferenczi's views on suggestibility. ${ }^{229}$ Ernest Jones addresses homosexuality as a "trend" and "phase" that he says is, "far commoner during adolescence that at any later

\footnotetext{
${ }^{222}$ For references to hysteria, see, for example: 'Publications Recently Received', British Journal of Psychology, Vol.10, May 1919, p.373; Alfred Carver, 'The Generation and Control of Emotion', British Journal of Psychology, Vol.10, November 1919, p.60; E. Prideaux, 'Suggestion and Suggestibility', British Journal of Psychology, Vol.10, March 1920, p.231, and pp.238-239; T. H. Pear, 'Critical Notice', British Journal of Psychology, Vol.11, April 1921, pp.356-357; 'Publications Recently Received', British Journal of Psychology, Vol.12, April 1922, p.385; A. G. Tansley, 'The Relations of Complex and Sentiment. II', British Journal of Psychology, Vol.13, October 1922, p.114; and 'Publications Recently Received', British Journal of Psychology, Vol.20, January 1930, p.298.

223 Showalter, p. 171.

224 'Publications Recently Received', British Journal of Psychology, Vol.10, July 1920, p.348.

${ }^{225}$ Ibid.

226 Ibid.

${ }^{227}$ Ibid.

228 'Publications Recently Received', British Journal of Psychology, Vol.17, July 1926, p.73.

${ }^{229}$ Sándor Ferenczi in, E. Prideaux, 'Suggestion and Suggestibility', British Journal of Psychology, Vol.10, March 1920, pp.233-234. Here Ferenczi makes a distinction between 'homo-eroticism' and 'homosexuality', with his preference being the former due to it being less ambiguous in regard to impulse and action (p.234).
} 
age," 230 thus linking it to a more infantile state of being, with which comes the connotations for adult men who partake in homosexual acts as not having reached male maturity, and therefore as un-masculine, or even effeminate. They were stuck in the developmental phase of a progression towards a 'normal' adult sexuality. Jones also classifies homosexuality as, "a variety of narcissism", as with "auto-eroticism". ${ }^{231}$ These terms were also related to masturbation, which was seen as a phase that one must age-out of through adolescence, ${ }^{232}$ and was linked to insanity, ${ }^{233}$ and in some cases, as with psychiatrist Richard von KrafftEbing, was thought to potentially, "provoke same-sex desires in 'untainted' individuals". ${ }^{234}$ It is also referenced in the review of Prynce Hopkins' Father or Sons?.235 and a review of Havelock Ellis' The Psychology of Sex: A Manual for Students. ${ }^{236}$ The research for this thesis uncovered but one reference to effeminacy in the BJOP during the interwar years. This was in an article by C. W. Valentine on 'The Relative Reliability of Men and Women in Intuitive Judgements of Character', where a "well-known dramatic critic" was referred to - amongst a series of other descriptions - as being, "rather effeminate". ${ }^{237}$ There was a reference to Oscar Wilde and Dandyism too, however it is to be noted that not all dandies were homosexual. ${ }^{238}$ There was one reference to bisexuality too, in a review of Fritz Wittels' Critique of Love, where it is listed as one of the topics he discusses alongside: "sex deviations, masked sadism... narcissism, parents and children, le grand amour, great haters, love and marriage and the childwoman [sic.]." 239

There were a number of articles and books that tried to explain perceived, and inherent, differences between men and women during the interwar period. This includes the review for Paul Bousfield's Sex and Civilisation in the October 1925 issue of the BJOP. Bousfield "tries to show the sources of the many current and widespread notions in regard to the inferiority of women." 240 This admittance of the perceived inferiority of women is helpful

\footnotetext{
${ }^{230}$ Ernest Jones, 'Some Problems of Adolescence', Vol.13, July 1922, pp.41-42.

${ }^{231}$ Ernest Jones, 'Some Problems of Adolescence', Vol.13, July 1922, p.43.

${ }^{232}$ Hera Cook, The Long Sexual Revolution: English Women, Sex, and Contraception, 1800-1975 (New York: Oxford University Press USA, 2004), p.208, and p.210.

${ }^{233}$ Warwick Brunton, Sitivation 125: A History Of Seaview Hospital, Hokitika And West Coast Mental Health Services 1872-1997 (Hokitika: Seaview Hospital 125 Jubilee Committee, 1997), p.12.

${ }^{234}$ Brickell, 'Sexology, the Homo/Hetero Binary, and the Complexities of Male Sexual History', p.431.

235 'Publications Recently Received', British Journal of Psychology, Vol.18, April 1928, p.466. In this book, Hopkins discussed some of the main tenets of the Freudian doctrine.

236 'Publications Recently Received', British Journal of Psychology, Vol.24, July 1933, p.126.

237 C.W. Valentine, 'The Relative Reliability of Men and Women in Intuitive Judgements of Character', British Journal of Psychology, Vol.19, January 1929, p.231.

${ }^{238}$ See 'Publications Recently Received', British Journal of Psychology', Vol.27, July 1926, p.74, for a review of Der Moderne Dandy by Otto Mann.

239 'Publications Recently Received', British Journal of Psychology, Vol.21, October 1930, p.212.

240 'Publications Recently Received', British Journal of Psychology, Vol.16, October 1925, p.146.
} 
for this thesis as women and the feminine act as a binary opposite to men and that which is masculine. The fact that a contemporary psychoanalyst was trying to demonstrate the negative connotations of the feminine and female, means that we can use this to help understand the negative light in which men who did not fulfil masculine ideals, or were effeminate, were viewed in as related to this inferior view of women. The same issue also contained the notice for an article in the Journal of Experimental Psychology, which, on the flipside, tried to explain something specifically male - it was titled, 'Experimental Studies of Two Important Factors underlying Masculine Sexual Behaviour: The Nervous System and the Internal Secretion of the Testis', written by a C. P. Stone. ${ }^{241}$ In the January 1935 issue there was a review for J. C. Flugel's Men and their Motives, which was a series of essays, "all written from the point of view of a Freudian Psychology, and the motives attributed to men are in every case those which appeal most powerfully to a student of psychoanalysis."242

The construction of men as consumers, which Gail Reekie has analysed, was also present in pages of the BJOP. ${ }^{243}$ In a review of J. C. Flugel's The Psychology of Clothes the reviewer notes that Flugel includes, " a provocative discussion of the causes of the "Great Masculine Renunciation". This was described as the abandonment by man at the end of the eighteenth century of his claims to be considered one of nature's beauties - "Since then [...] man's clothing has become relatively uniform and standardised, symbolising at once his devotion to the principles of duty, his renunciation and self-control, and, through the phallic attributes of the individual garments, the fundamental features of his sexual nature."244

The BJOP also published articles, reviews, and mentions of a number of key figures in the world of sexology. These include numerous references to the physician, eugenicist, and writer Havelock Ellis. His Studies in the Psychology of Sex (published in six volumes between 1897-1910), were hugely influential in the study of human sexuality. ${ }^{245}$ The book he co-authored with John Addington Symonds in 1897 - originally published in German a year prior - was especially important as it was the first English medical textbook on homosexuality. References to Ellis can be seen in the BJOP in the following places: in passing in an article written by G. Dawes Hicks 'On The Nature of Images'; 246 and in a

\footnotetext{
241 'Publications Recently Received', British Journal of Psychology, Vol.16, October 1925, p.149.

242 'Publications Recently Received', British Journal of Psychology, Vol.25, January 1935, p.409.

${ }^{243}$ Gail Reekie, Temptations: Sex, Selling and the Department Store (Sydney: Allen \& Unwin, 1993), p.56. Reekie discusses the influence of psychology on this construction of men as consumers, noting that their instincts were described as having, "a higher social value than women's shopping, bargain-hunting or nestbuilding instincts," as they included, "sex, pride of possession and fighting."

244 'Publications Recently Received', British Journal of Psychology, Vol.22, January 1932, pp.277-278.

${ }^{245}$ Angus McLaren, Twentieth-Century Sexuality: A History, (Oxford: Blackwell Publishers Ltd, 1999), p.95.

${ }^{246}$ G. Dawes Hicks, 'On The Nature of Images', British Journal of Psychology, Vol.15, October 1924, p.142.
} 
review of the book Whither Mankind? A Panorama of Modern Civilisation, where it is mentioned that he wrote a section on "The Family"; 247 in an article by John T. MacCurdy, 'The Biological Significance of Blushing and Shame', in which his work on the human evolution of shame is noted. ${ }^{248} \mathrm{He}$ is also mentioned in a review of The New Generation: The Intimate Problems of Modern Parents and Children; ${ }^{249}$ and in the Shepherd Dawson article, 'Intelligence and Fertility' ${ }^{250} \mathrm{He}$ is also discussed in a review of a book by Houston Peterson called Havelock Ellis: Philosopher of Love - in which it is stated that, "Ellis dedicated his life to the study of the problems of sex-psychology; in his attitude to these he contrasts strongly with his contemporary, Freud"; 251 and an article by Ernest Jones on 'Psycho-Analysis and the Instincts' where he remarks that Havelock Ellis, on the topic of self-love as a form of sexual perversion, was, "the first to describe [it] by the name "narcissistic"" ${ }^{252}$ The July 1933 issue has a review of Ellis' The Psychology of Sex: A Manual for Students - a book in which he discusses, "the Biology of Sex; the Sexual Impulse in Youth; Sexual Deviation; the Erotic Symbolisms; Homosexuality; Marriage, and the Art of Love". ${ }^{253}$ And in the "Publications Recently Received' section of the January 1935 issue of the BJOP a new journal is mentioned, Marriage Hygiene, whose first volume included articles from Havelock Ellis on 'The Problem of Sterilization', as well as from another key figure who advocated for contraception and sexual love within marriage, Marie Stopes (who wrote an article titled, 'Some New Concepts and Laws in Human Biology'). ${ }^{254}$

Marie Carmichael Stopes was an author, campaigner for eugenics and women's rights, and the author of the highly controversial, and influential, sex manual Married Love (first published in 1918). Stopes is referenced in the BJOP in the following instances: in a review of her book, Contraception: its Theory, History and Practice, ${ }^{255}$ as well as in the

\footnotetext{
247 'Publications Recently Received', British Journal of Psychology, Vol.20, July 1929, p.95.

${ }^{248}$ John T. MacCurdy, 'The Biological Significance of Blushing and Shame', British Journal of Psychology, Vol.21, October 1930, p.180.

249 'Publications Recently Received', British Journal of Psychology, Vol.21, April 1931, p.430, in a review of The New Generation: The Intimate Problems of Modern Parents and Children, where he contributed a paper on "Perversion in Childhood and Adolescence'.

${ }^{250}$ Shepherd Dawson, 'Intelligence and Fertility', British Journal of Psychology, Vol.23, July 1932, p.42.

251 'Publications Recently Received', British Journal of Psychology, Vol.20, April 1930, pp.392-393. This contrast with Freud (and his views) is made even more explicit by the reviewer who goes on to state that, "Freud is unhappy unless he is engaged in intellectual warfare: Ellis refuses controversy. Unlike Freud, he wishes patiently to search out all that is bad... in civilised life, and to replace it by what is better" (p.393). This is perhaps more telling of the reviewer's view of Ellis and Freud than the reality, but nonetheless it is interesting to consider for this thesis in their approaches to sexuality, and especially homosexuality.

${ }^{252}$ Ernest Jones, 'Psycho-Analysis and the Instincts', British Journal of Psychology, Vol.26, January 1936, p.278.

253 'Publications Recently Received', British Journal of Psychology, Vol.24, July 1933, p.126.

254 'Publications Recently Received', British Journal of Psychology, Vol.25, January 1935, p.412.

255 'Publications Recently Received', British Journal of Psychology, Vol.15, April 1925, p.420.
} 
review of her later book Love's Creation, which is commended as, "[making] interesting reading"; 256 and in the review of another of her works, Birth Control To-day - with the following comment from the reviewer, "Naturally the psychology of the matter cannot receive much consideration in this volume, although its importance is freely admitted." 257

The BJOP also published reviews, in their 'Publications Recently Received' section, of a series of texts that more broadly spoke on themes of sex, sexuality, and marriage. These include the likes of Love in the Machine Age: A Psychological Study of the Transition from Patriarchal Society, ${ }^{258}$ Eros und Sexus $;{ }^{259}$ Sex Hostility in Marriage (noted as being best read alongside its companion novel, Fertility and Sterility in Marriage); ${ }^{260}$ The Sex Factor in Marriage; ${ }^{261}$ Love and the Sex Emotions, ${ }^{262}$ Sexual Regulations and Human Behaviour; 263 Prostitution: A Survey and a Challenge; ${ }^{264}$ A Thousand Marriages: A Medical Study of Sex Adjustment; ${ }^{265}$ The Single Woman: A Medical Study in Sex Education; ${ }^{266}$ Sexual Regulations and Cultural Behaviour; ${ }^{267}$ Race, Sex and Environment; ${ }^{268}$ Nature Hits Back, ${ }^{269}$ Successful Living, ${ }^{270}$ Sex, Custom and Psychopathology: A Study of South African Pagan Natives $;{ }^{271}$ and Mis-Mated: The Psychology of the Unhappy Marriage. ${ }^{272}$

Topics relating to sex and sexuality, masculinity, and marriage also are present in articles and advertisements of the NZMJ. For example, in a piece on 'The Egregious Miss Rout', ${ }^{273}$ which noted the "appalling conditions" that soldiers faced in Cairo, it was commented that, "Naked dances, sodomy, and wholesale prostitution" were day-and-night affairs. ${ }^{274}$ Rout was mentioned again in the next issue of the journal in a piece titled, 'Medicine and Morality: TO THE EDITOR', where her prophylactic kits were debated, and

\footnotetext{
256 'Publications Recently Received', British Journal of Psychology, Vol.20, October 1929, p.200.

257 'Publications Recently Received', British Journal of Psychology, Vol.25, January 1935, p.411.

258 'Publications Recently Received', British Journal of Psychology, Vol.22, October 1931, pp.182-183.

259 'Publications Recently Received', British Journal of Psychology, Vol.22, October 1931, p.190.

260 'Publications Recently Received', British Journal of Psychology, Vol.23, July 1932, p.82.

261 Ibid.

262 'Publications Recently Received', British Journal of Psychology, Vol.24, July 1933, p.126.

263 'Publications Recently Received', British Journal of Psychology, Vol.25, October 1934, p. 258.

264 'Publications Recently Received', British Journal of Psychology, Vol.25, October 1935, p.259.

265 'Publications Recently Received', British Journal of Psychology, Vol.26, July 1935, p.111.

266 Ibid.

267 'Publications Recently Received', British Journal of Psychology, Vol.27, July 1936, p.117.

268 'Publications Recently Received', British Journal of Psychology, Vol.27, October 1936, p.233.

269 'Publications Recently Received', British Journal of Psychology, Vol.28, July 1937, p.111.

270 'Publications Recently Received', British Journal of Psychology, Vol.28, January 1938, p.361.

271 'Publications Recently Received', British Journal of Psychology, Vol.29, July 1938, p.81.

272 'Publications Recently Received', British Journal of Psychology, Vol.30, July 1939, p.70.

${ }^{273}$ Ettie Rout was a New Zealand nurse who helped to raise awareness around prophylaxis kits for soldiers at the Front during WWI.

274 'The Egregious Miss Rout', New Zealand Medical Journal, Vol.17, No.77, February 1918, p.27.
} 
the morality of pre-marital sex was discussed. ${ }^{275}$ The August 1918 issue included a review of Abraham Flexner's Prostitution in Europe - in which the inferiority of women is ascribed, but so too is it noted that, "as regards prostitution there must be demand as well as supply.",276 In the February 1937 issue, there is an advertisement for 'TESTONAD' which is said to be helpful, "In all cases of sexual disharmony, impotence, general neurasthenia, etc."277 The August 1938 issue includes a review of the book The Adrenal Cortex and Intersexuality and details the latest research on adreno-genital syndrome, which is described as being, "essentially bisexual in nature and is defined as "the appearance of male secondary sex characters in the female, accompanied by a retrogression of the female secondary characters and sex function"”. 278

The October 1937 issue of the NZMJ published an article titled, 'Masturbation and Mental Illness - With Report of a Case', by A. D. Latham. ${ }^{279}$ Whilst the case described in this article, "illustrates only one of the causes of mental breakdown," Lathan argues that its value in being discussed, "lies in the fact that it is a preventable cause." ${ }^{280}$ Masturbation, as described in its reference in the $B J O P$, was seen as an juvenile act, that if left un-checked could potentially lead to same-sex sexual acts. ${ }^{281}$ Thomas W. Lacquer argued that this link may have been due to the fact that: "the solitary vice also made its appearance precisely when a major reconfiguration of masculinity was in full swing", and that concerns around masturbation therefore "seemed to track new anxieties about the collapse of decent heterosexuality". ${ }^{282}$ It presented the same kind of worries that homosexuality, and same-sex actions more generally, did. As the Latham article outlines the link between masturbation and insanity, so too did several well-known psychiatrists connect masturbation and homosexuality, and in turn, tied them both to the notion of "inversion". ${ }^{283}$ Masturbation,

\footnotetext{
275 'Medicine and Morality: TO THE EDITOR', New Zealand Medical Journal, Vol.17, No.78, April 1918, p.73.

276 'Review's, New Zealand Medical Journal, Vol.17, No.80, August 1919, p.151.

277 'TESTONAD', New Zealand Medical Journal, Vol.36, No.191, February 1937, p.xxxv. See also the advertisement for 'PURE SEX HORMONE PREPARATIONS', New Zealand Medical Journal, Vol.40, No.209, February 1940, p.xiii, which stated to use Testoviron, "in lack of testicular hormone" as well as for, "Mental and physical fatigue; Insomnia of presenile type."

278 'Reviews', New Zealand Medical Journal, Vol.37, No.200, August 1938, p.236. Here we can see an interest in the topic of intersexuality, though it is noted here that the use of the term "bisexual" does not necessarily have to do with sexuality itself, as opposed to the biological sex being researched here.

${ }^{279}$ A. D. Latham, 'Masturbation and Mental Illness - With Report of a Case', New Zealand Medical Journal, Vol.36, No.195, October 1937, pp.319-321.

${ }^{280}$ Latham, p.319.

${ }^{281}$ Brickell, 'Sexology, the Homo/Hetero Binary, and the Complexities of Male Sexual History', p.431. See also Thomas W. Laquer, Solitary Sex: A Cultural History of Masturbation (New York: Zone Books, 2003), pp.254260 on the linking of views between masturbation and homosexuality.

282 Laquer, p. 255.

${ }^{283}$ Most notably it was Krafft-Ebing who made this point. See Laquer, p.258.
} 
Chris Brickell has outlined, was sometimes also linked to sexual offences, when it was classified as an 'undesirable act' (i.e. in cases where men mutually masturbated each other); a fact that reflects Krafft-Ebing's idea that: "Masturbation could induce neurasthenia, draining the body of its vitality and leading to effeminacy an sexual perversion”, like the committing of undesirable acts. ${ }^{284}$

Marie Stopes' Married Love: A New Contribution to the solution of Sex Difficulties is reviewed in the April 1923 issue of the NZMJ, with the journal's reviewer condemning it. They wrote, "If this book had been intended only for the use of doctors, we should have commended it, but seeing that it is for general circulation, we dislike it", however it was also noted that the book has "sold like hot cakes". ${ }^{285}$ Stopes' Contraception: Its Theory, History and Practice - A Manual for the Medical and Legal Professions is also reviewed in the October 1923 issue, to even harsher condemnation than Married Love was subjected to. ${ }^{286}$ The NZMJ reviewer argued that, “'Contraception' is certainly a book which should be banned to the general public, and is probably prohibited in New Zealand", however, they accepted that it is a topic that should be studied by medical professionals. ${ }^{287}$ References to marriage include the notice of the receipt of the book A Marriage Manual: A Practical Guide Book to Sex and Marriage by H. M. Stone, and A. Stone, in the June 1939 issue. ${ }^{288}$

In their denunciation of certain behaviours such as drunkenness and the criminal, some of the medical students implicitly infer what the opposite of these behaviours ideally was. It is through these implications that we can start to understand things like ideas around sex, sexuality, and masculinity and femininity. For example, in W. A. Fitzherbert's Preventive Medicine dissertation he states that, "The normal man is not a drunkard nor a criminal, and these states of life constitute a disease in a very real sense of the term." ${ }^{289}$ In this context, Fitzherbert is discussing the problem of mental diseases and the number of New Zealanders confined in mental hospitals by 1929 . He groups together "drunkards" and "criminals" with those with more well-defined mental disorders, and in doing so he describes

\footnotetext{
${ }^{284}$ Chris Brickell, 'Sex instruction and the construction of homosexuality in New Zealand, 1920-1965', Sex Education, Vol.5, No.2, p.123.

285 'Reviews', New Zealand Medical Journal, Vol.22, No.108, April 1923, p.138.

286 'Reviews', New Zealand Medical Journal, Vol.22, No.111, October 1923, pp.313-314.

${ }^{287}$ Reviews', New Zealand Medical Journal, Vol.22, No.111, October 1923, p.314. They do also seem to undermine Stopes' credentials on the topic of contraception: she argues that it does not add to the highly improbable "race suicide" that was feared by many, and they immediately follow up this with the sentence, "she has a strong tendency to brand all opinions on sex matters contrary to her own opinion as pseudo-scientific", however.

288 'Books Received', New Zealand Medical Journal, Vol.38, No.205, June 1939, p.229.

${ }^{289}$ Fitzherbert, p.4.
} 
these people as 'abnormal' - they are not the "normal man". By reading through the lines of Fitzherbert's classifications, one can start to determine what and who the 'normal man' was; and even through examining what made one fall short of the standards of the 'normal man' we can see the ways in which understandings of mental illnesses and neuroses overlapped with notions of criminality, and masculinity.

J. M. Staveley also noted that "sex relations and alcohol"290 were issues for the Whangamata Māori, and that the "virulence of the Maori [sic.] race" needed to be corrected (with "physical education, conducted by qualified men") as relating to a need to, "direct Maori [sic.] culture along the lines of correlating their psychological and physical developments". ${ }^{291}$ What this indicates is a concern with both the virility of Māori, and their mental plus physical health as all were viewed as interconnected. ${ }^{292}$

As discussed regarding the eugenic side of their comments, Nola M. Ivory, and M. Watson's dissertations about infant mortality both use the language of "virility". ${ }^{293}$ Virility was a term that carried connotations of sex and reproduction, as well as a degree of energy and vigour. The utilisation of this language in regard to Ivory and Watson's research indicates that it was not only child health and welfare, but also the future success and masculine strength of New Zealand's population that underpinned worries about infant mortality.

Medical sources illustrate the centrality of knowledge networks to the New Zealand medical sphere during the interwar period. Ties to international journals and scholarship, maintained through readership, subscription, and references, continued to frame New Zealanders' discussions, debates, and understandings of mental illnesses and neuroses, masculinity, and male sexuality between the two wars. As publications of authoritative voices of medical topics, the medical journals (such as the BJOP and the NZMJ), and, to a lesser extent, the preventive medicine dissertations written by senior medical students, presented expert opinions and up-to-date theories on subjects related to mental health and fitness, psychology and psychiatry, and evolutionary and eugenic theories. This expertise presented

\footnotetext{
290 Staveley, p.37.

${ }^{291}$ Staveley, p.38.

292 Staveley also commented on the low standard of living of the people he researched, and on their tendency towards polygamy (p.24). This, plus his discussion on intermarriage with Pākehā, in which he described the "half-castes" they produce (p.21), demonstrates an interest in the sexual life and sexuality of this group of Māori; and it 'others' them compared to their more 'traditionally' relationship-minded Pākehā counterparts. ${ }^{293}$ See Ivory, p.4; and Watson, p.15.
} 
interpretations and conversations around effeminacy, masculinity, and male sexuality that attempted to control the spread of these 'problems' in New Zealand following the Great War until the eve of the Second World War. The ways in which popular culture attempted to control the dissemination of such ideas of New Zealand men and their masculinity and sexuality will now be discussed in chapter three. 


\section{CHAPTER THREE}

\section{Popular Culture and Effeminacy}

This chapter will consider the popular discussion of effeminacy by examining commercial magazine and newspaper sources. Popular print culture, though ephemeral in its nature, is a medium through which historians can ascertain a sense of everyday, popular articulation, production, and distribution of conversations and topics of interest during the interwar period. These ideas had a popular circulation as well as, and simultaneous to, the medical texts discussed in chapter two. Discussions of 'effeminacy' were often more explicit in popular print culture than the discourse in the medical sphere as they were not restricted in the same stringent scientific ways. The debates around effeminacy and masculinity published in tabloid newspapers and more specialist interest magazines drew on, and extended, existing threads of concerns about gender, masculinity, metal disorders, eugenics, and sexuality. Commercial newspapers and magazines relied on continued consumer patronage to survive, so whilst they at times introduced readers to ideas that were new, they also printed articles on topics that were proven to attract the interest of existing readerships, as well as those which could entice new readers to pick up a copy of the publication to learn more. These sources contain a vast richness for historians of gender, which Adrian Bingham argues has been little tapped into by British historians, and that has also been little explored in New Zealand around these questions, despite the acknowledgement of their importance. ${ }^{1}$

The article that alerted me to the existence of Health and Sunshine magazine (which this chapter uses as a source) is one that directly addresses concerns around masculinity and effeminacy from interwar New Zealanders. This letter, written to the editor in the February 1937 issue of $H \& S$ was headed 'Is Tennis Effeminate?'. ${ }^{2}$ The author of this letter used the pseudonym 'He-Man', and wrote that they had come to the conclusion that, "tennis is an effeminate game" because it is a "woman's sport", and any man who plays it, "must have a kink ... [to] stand on a tennis court playing pitter-pat with a lot of similarly afflicted

\footnotetext{
${ }^{1}$ Adrian Bingham, Gender, Modernity, and the Popular Press in Inter-War Britain (Oxford: Clarendon Press, 2004), p.4.

2 'Is Tennis Effeminate?' Health and Sunshine, Vol.1, No.4, February 1937, p.43.
} 
associates". ${ }^{3}$ It "sickens" He-Man to see such "strong, healthy men" play tennis when they could be "indulging in some invigorating healthy sport", and thus they, "decided that most tennis players are mental deadbeats, and inclined to [be] "nice boys"."4 This small letter, which took up not even half a column of text, is packed full of the kinds of opinions that bring together multiple threads of this thesis. He-Man is concerned with the fact that some men are choosing to associate themselves with a "woman's sport", thus diminishing their own masculinity, and turning them as effeminate as the game itself. His conclusion that these men are "afflicted", and "mental deadbeats" echoes the psychological and mental health language that demonstrates general usage and understanding of such terminology, in such a way that could be utilised in an attack of un-masculine men. This letter, which connects effeminacy, homosexuality, physical vigour (or lack of it), and mental capacity, captures the ideas expressed in the popular press of the time.

There are four key sources this chapter will discuss: a tabloid newspaper and three magazines. They are: The New Zealand Truth (The NZ Truth), Health and Physical Culture (H\&PC), Health and Sunshine (H\&S), and The Monocle: The New Zealand Monthly Magazine (The Monocle). Through an examination of these sources, this chapter will demonstrate the ways in which discussions that were occurring in medical circles played out in the popular print culture available to New Zealanders between 1918-1939. Themes appear in the popular print mediums, similar to those in the medical journals and the dissertations of medical students - themes which this chapter sorts into five sections for the sake of clarity. These are: Psychology and Mental Fitness; Evolutionary Framework of Understanding and Eugenics; Sex, Sexuality, Marriage, and Masculinity; Mind and Body; and The Clothed Man and The Naked Man. The examination of these popular culture sources will therefore further establish societal interest and awareness in the fear of effeminacy, and understandings of the debates around masculinity in interwar New Zealand.

The NZ Truth was an incredibly popular and widespread tabloid newspaper in New Zealand during the interwar period. Adrian Bingham, in Gender, Modernity and the Popular Press in Inter-War Britain, detailed the rich historical source that was the weekly national press, and argued that these newspapers were "one of the most successful products of the inter-war period." 5 Popular newspapers, he states, were "all very conscious that they had to interest their audience sufficiently to persuade them to part with their money," and were

\footnotetext{
3 ‘Is Tennis Effeminate?' Health and Sunshine, Vol.1, No.4, February 1937, p.43.

4 Ibid.

${ }^{5}$ Bingham, p.3.
} 
aware that they "could not operate in isolation from the demands of their readers." Explorations of effeminacy and masculinity therefore spoke to the anxieties of the New Zealand readership of The NZ Truth, which claimed to have 40,000 readers a year after its first publication, ${ }^{7}$ whilst also acting as an illustration of the negotiations made between contributors, editors, and advertisers to the newspaper.

Heath and Physical Culture was a lifestyle magazine published monthly between 1929-1943. An article from $H \& P C$ was the starting point from which my interest in the topic that is this thesis arose. The article, titled 'The Menace of Effeminacy', referenced in Caroline Daley's book Leisure and Pleasure, sparked off my inquiry into why there existed this "menace" and fear around that which was dubbed 'effeminate'. ${ }^{8}$ It has been through further research into Health and Physical Culture's holdings, as well as the other primary sources this thesis examines that this inquiry has evolved. This chapter delves further into the articles and topics presented in Health and Physical Culture from the period of its publication during the interwar years (1929-1939), in order to gain insight into Australasian physical culture, and the realm of discussion around the mind and body during the interwar period. The Trans-Tasman readership of $H \& P C$ was evidenced by letters published from subscribers that noted where they were from in New Zealand, and in articles that mentioned New Zealand, or were written (in some cases) by New Zealanders. ${ }^{9}$ The 1930 s saw an increased interest in physical culture and the modern culture of the body, as established by Charlotte Macdonald in her book Strong Beautiful and Modern: National Fitness in Britain, New Zealand, Australia and Canada, 1935-1960. ${ }^{10}$ This interest was expansive. It was not purely about sport, or physical training; nor was it purely about education (and thus could shed didactic or military associations). It was a movement that was about potential, the potential for culture, civilisation, purpose, beauty, strength, and health. ${ }^{11}$ This chapter aims to extrapolate that which was of interest - or, at least, of interest enough to print, as thought by the publishers of $H \& P C$ - related to the sphere of effeminacy, masculinity, and male sexuality in order to try to present the wider understanding of what these things meant to New Zealanders during this time in history.

\footnotetext{
${ }^{6}$ Bingham, p.9.

${ }^{7}$ Redmer Yska, Truth: The Rise And Fall Of The People's Paper (Nelson: Craig Potton Publishing, 2010), p.19.

${ }^{8}$ Caroline Daley, Leisure and Pleasure: Reshaping and Revealing the New Zealand Body 1900-1960 (Auckland: Auckland University Press, 2003), p.74.

${ }^{9}$ For example, see: the 'Pen Friends' segment in issues such as Health and Physical Culture, Vol.6, No.11, November 1935, pp.55-56.

${ }^{10}$ Charlotte Macdonald, Strong Beautiful and Modern: National Fitness in Britain, New Zealand, Australia and Canada, 1935-1960 (Wellington: Bridget Williams Books, 2016).

${ }^{11}$ Macdonald, p.72.
} 
$H \& P C$ is a source that provides rich insight for historians into the Australasian physical culturalist sphere and way of thinking. As a magazine it combines a number of different themes and topics that this thesis engages with as a whole, such as theories around and interest in the physical body, which can veer towards the realm of eugenics and hereditary theorem. Additionally, it talks about marriage, sex, and sexuality; and the rising interest in mental health and psychology (including Freud) in this period; as well as post-war commentary; fashion; and unemployment; amongst other things.

Founded in 1936 by Trevor G. Bain, Health and Sunshine was a monthly magazine, published in Auckland between October 1936 to July 1937. Bain was a strong proponent of the nudist movement in New Zealand, and in 1937 he published a book titled Nudism: Is It Desirable?. ${ }^{12}$ This interest in nudism and the body pervaded the pages of the subscriptionbased Health and Sunshine, as the magazine aimed to reach proponents and practitioners of nudism, as well as potential body-culturalists in New Zealand. $H \& S$ saw itself as a magazine for those who were interested in health, eugenics, and broader body concerns in this period. ${ }^{13}$

The Monocle published between 1937-1939 is another New Zealand-based magazine that, though later evolving to target a broader readership, started out concerning itself with what it saw as being topics related to men's interests. This initial focus on a male readership makes The Monocle an incredibly interesting source for historians of masculinity as it gives us an indication of what was thought - by the contributors to this magazine at least - to be of interest to New Zealand men in the interwar period.

The highly popular and widely circulate The NZ Truth along with the more niche magazines with smaller readerships illuminate the character of the commercial print culture conversations around effeminacy anxieties in interwar New Zealand. Discussions that were more explicit in their address of effeminacy and deviant sexualities and behaviours than their medical counterparts because of their intrinsic ability to explore topics of more sensationalist topics in their efforts to acquire and maintain commercial subscription bases and readerships.

\footnotetext{
${ }^{12}$ Bain also wrote and had published another book The More Excellent Way (1935); and a pamphlet, The Human Torch (1935).

${ }^{13}$ Many in this period used 'sun' and 'sunshine' as a title - see Sunshine League; Children's Health Camps, see Margaret Tennant's work, Children's Health, the Nation's Wealth: A History of Children's Health Camps (Wellington: Bridget Williams Books, 1994); sunshine programmes on the radio; etc. It was popular and emblematic, as the sun was both advocated for as good for one's health, but also as a sign of hope, light, health, and vigour.
} 


\section{PSYCHOLOGY AND MENTAL FITNESS}

The NZ Truth covered a wider range of topics in the 1920s than the magazines this chapter discusses published in the 1930s. Among these topics, the tabloid published articles and advertisements that related to, and mentioned, psychological topics and interests, as reflected the general increasing interest in the field during the interwar period. From the end of the Great War, the concept of nerves, and the neurasthenic, appeared a number of times in The NZ Truth. For example, in the numerous advertisements for medications aimed at those with weak nerves, reflecting understandable concerns with the mental fitness of returned men. Dr. Williams' Pink Pills were targeted at those whose "nervous systems are run down by overwork or worry," and "to those who are on the verge of neurasthenia" whose bad nerves were exacerbated by the war; ${ }^{14}$ as well as for patients actively suffering from neurasthenia, as the result of, "some nervous shock... or some severe overstrain on the nervous system."15 Other advertisements for Dr. Williams' Pink Pills connected the nervous states of those it targeted to a weakened masculinity, proffering the Pills as a solution to this, as evidenced by the following lines: "Many one-time victims of nerve trouble have reason to bless the day they began to take Dr. Williams' Pink Pills, for instead of nervous wrecks they are now virile and strong, and get the best out of life". ${ }^{16}$ Advertisements for Dr. Cassell's Tablets also aimed to reach those like, "Mr. Alfred H. Churm, author and novelist, [who] suffered shellshock when in France. This led to complete nervous collapse." 17 The tablets, the advertisement promised, were a "World-famous Home Remedy for: Nervous Breakdown, Neuritis, Neurasthenia, Headache, etc.", and if a NZ Truth reader should take them then like Mr. Churm, they could be in "splendid health" in about a month's time. ${ }^{18}$ The NZ Truth also published a number of other advertisements targeted at those with nerve problems, such as: those for 'Otis Tonic Tablets for Blood \& Nerve'; 19 and those for "Aspro", which is said to

\footnotetext{
14 'A Time For Strong Nerves', The NZ Truth, 19 October 1918, p.6.

15 'Neurasthenia', The NZ Truth, 3 June 1922, p.2.

16 'Nerves In Distress: How Sufferers Are Handicapped', The NZ Truth, 8 August 1929, p.3. For other examples of Dr. Williams' Pink Pills advertisements see the following issues (amongst others): 'The Nerves and Their Needs', The NZ Truth, 7 June 1919, p.8; 'Sleepless and Irritable: Signs of Disordered Nerves', The NZ Truth, 31 October 1928, p.17.

17 'His Nerves Collapsed!: Dr. Cassell's Tablets', The NZ Truth, 19 April 1924, p.12.

${ }^{18}$ Ibid. This is also only one of a number of advertisements for Dr. Cassell's Tablets, see also: 'His Nerves Collapsed!: Dr Cassell's Tablets', The NZ Truth, 29 December 1923, p.14; and 'His Nerves Collapsed!: Dr Cassell's Tablets', The NZ Truth, 14 June 1924, p.13.

${ }^{19}$ Which called for sympathy for, "The poor nerve sufferer... whether afflicted with a slight nerve attack, neurasthenia or shell-shock": 'Otis Tonic Tablets for Blood \& Nerve', The NZ Truth, 24 February 1923, p.3. See also: Otis Tonic Tablets for Blood \& Nerve', The NZ Truth, 24 January 1923, p.6; and 'Otis Tonic Tablets for Blood \& Nerve', The NZ Truth, 16 June 1923, p.9.
} 
be "invaluable" for "the boys from the front" suffering from shell-shock; ${ }^{20}$ and a number of advertisements for the services and advice of Garnet Sim (Physical Culture Expert) called out to those who, "are a failure, suffer from Mental Lethargy, Nervousness... General Weakness, Nervous Debility... Sexual Weakness" to get in touch with him in order to, "stop nervous waste, conserve the energies, accumulate good nerve reserve, and build up virile manhood." 21 For advertisers of these remedies The NZ Truth offered a powerful platform to reach readers and potential buyers. Many of these advertisements were continued to be ran year after year, demonstrating their profitability, and the demand for such products in New Zealand.

In addition to advertisements, like those discussed above, nerves and neurasthenia also appeared in numerous articles of the tabloid. For example, in a September 1923 article, "the extraordinary increase in lunacy in recent years" is mentioned; with it being noted too that, "Neurasthenia and hysteria have produced many results that are probably not recorded in mental hospitals." 22 What is noteworthy in regards to the conversation about mental disorders is that the article calls out the fact that, "There is still a lack of Government money to provide for proper classification and treatment in mental hospitals." 23 This reflected the growing public concern over these subjects, with The NZ Truth, in part, fuelling that concern. A February 1923 article on 'Shell Shock' described how the condition was still affecting those who suffered from it even years after the end of the war, ${ }^{24}$ stating that, "Many a returned man sufferers from "nerves" severely still, and no one knows it but himself. In regular work and with no excesses such men carry on, and to all intents and purposes appear to be quite normal." 25 The article goes on to quote a "prominent doctor after the war", who said that, "once a neurasthenic always a neurasthenic", thus indicating that this was an issue New Zealanders still had to tackle.

Shell-shock, and the effect of the war, was more broadly discussed in a number of other articles published in The NZ Truth during the interwar period. For example, the October 1920 article, 'Insane Civilisation: Great Britain In War Time - Delirium of Hysteria',

\footnotetext{
${ }^{20}$ It also claimed that it, "calms the nerves as nothing else can". See: 'Smashing the Profiteer: An Australian Industry Takes the Lead - Deeds Versus Talk', The NZ Truth, 17 January 1920, p.3.

21 'Man Making', The NZ Truth 13 December 1924, p.11. Sims also advertised his services in a number of different issues of the newspaper, for example see: 'New Life', The NZ Truth, 19 January 1924, p.10; and 'Man Making', The NZ Truth 25 April 1925, p.10.

${ }_{22}$ 'Weakness At The Top', The NZ Truth, 15 September 1923, p.1.

${ }^{23}$ Ibid.

${ }^{24}$ In fact, it comments on the mishap of Mr. Justice Chapman, who the paper says remarked, "Oh! shell-shock has died by this time, surely?", to which they respond: "shell-shock has by no means died, except in cases where it has died with the sufferer", see: 'Shell Shock', The NZ Truth, 17 February 1923, p.1.

25 'Shell Shock', The NZ Truth, 17 February 1923, p.1.
} 
referenced the impact the war had on the mental wellbeing of those in Britain (and, by association, New Zealand too) - "There were some happy people to whom the war meant nothing [...] But the ordinary war-conscious civilian went mad." ${ }^{26}$ An article from October 1922 referenced the Report of the War Office Committee of Enquiry into "Shell-shock", describing its findings to the tabloid's readership; ${ }^{27}$ and several detailed the cases of returnedsoldiers with shell-shock who were charged with assault. ${ }^{28}$ The link between mentally unfit veterans and criminality is a topic that Elizabeth Nelson has explored in the Australian context, arguing that notions of this connection between returned soldiers' domestic violence and mental disturbance helped to contribute to the shift in the understandings of this issue to the psychological. ${ }^{29}$ The interrelation of such concepts also mirrored discussions of sexually deviant men, who also came to be more understood in psychological terms during the interwar years.

Numerous articles in the tabloid discussed the problem of mental defectives in Aotearoa during the interwar years, with some even referencing the legislation and reports that chapter one of this thesis discussed. For example, the article, 'Soldiers In Asylums: Treatment of Mental Patients -Colonel McDonald Hits Out', quoted from the Mental Defectives' Act 1911 (as well as from the annual report of Mental Hospitals for 1917) in McDonald's irritation at the, "callous treatment meted out to soldier mental patients, and the irregular system adopted for placing them in mental hospitals." ${ }^{30}$ In the defence of a James Stewart Sutherland, the newspaper reported that he wanted to plead not guilty, "under the provisions of section 31 of the Mental Defectives' Act"; 31 in a February 1926 article, the lack of action in taking up the recommendations that the Commission on Mental Defectives had made a year prior was commented on. ${ }^{32}$ In the article 'Degenerate Abnormals: What Treatment? - Perverted Passions and Painful Problems' the issue of mental degeneracy is

\footnotetext{
${ }^{26}$ Insane Civilisation: Great Britain In War Time - Delirium of Hysteria', The NZ Truth, 2 October 1920, p.5.

27 'Shell Shock', The NZ Truth, 7 October 1922, p.1.

${ }^{28}$ See, for example: 'A Flogging Ordered: Roy Delaney Found Guilty By The Jury - The Fiendish Outrage At Petone', The NZ Truth, 16 August 1919, p.5; and 'Shell Shock: Davies' Doings - Returned Soldier's Conduct At Roslyn', The NZ Truth, 20 March 1920, p.5.

${ }^{29}$ See Elizabeth Nelson, 'VICTIMS OF WAR: The First World War, Returned Soldiers, and Understandings of Domestic Violence in Australia', Journal of Women's History, Vol.19, No.4, 2007, pp.83-106, 163.

30 'Soldiers In Asylums: Treatment of Mental Patients -Colonel McDonald Hits Out', The NZ Truth, 21 May 1921, p.6. For another take on this topic, see also: 'Soldier In Asylums: Treatment of Returned Men', The NZ Truth 20 March 1920, p.6. And for more on this topic, see: Gwen A. Parsons, 'The Construction of Shell Shock in New Zealand, 1919-1939: A Reassessment', Social History of Medicine, Vol.26, No.1, 2013, pp.56-73; and John Weaver, and David Wright, 'Shell Shock and the Politics of Asylum Committal in New Zealand, 19161922', Health and History, Vol.7, No.1, 2005, pp.17-40.

31 'Sutherland's Sanity', The NZ Truth, 23 February 1928, p.6.

32 'Dealing With The Mental Defective: Indictment of New Zealand's Judicial System - Need For Immediate Action', The NZ Truth, 25 February 1926, p.4.
} 
dubbed both a "menace", and, "one of the most serious evils of modern civilisation", and the Mental Defectives Act was referenced in relation to the sentencing of a man who had committed assault; ${ }^{33}$ and in a piece titled 'Will World Become Mad?: Mankind Must Solve "Mental" Problem Or-!', English legislation on the topic of mental defectives was referenced (the Mental Deficiency Act of 1913) in order to demonstrate to New Zealanders that, along similar lines, the mental defectives problem could be tackled before it gets too overwhelming. ${ }^{34}$ These articles, amongst others, ${ }^{35}$ demonstrated The NZ Truth's amplification of the issue of mental defectives and deficiency in New Zealand.

Other articles relating to 'mental defectives' also discussed the problem of the 'feeble-minded'. For example, in the February 1924 article that stated that: "Whether as the result of the Great War, which has turned our morals topsy turvy, or because the hectic rush of modern civilisation is producing neurotics wholesale through the making of feeble minded defectives, offences against children are increasing." ${ }^{36}$ Here the focal point is the increasing number of assaults against minors, yet the way in which this is linked to both the effect of the Great War, and the number of neurotics and feeble-minded produced by the problems of modernity is telling in terms of how such topics were approached. Additionally, this shows the entanglement of things like the war, mental disorders, and criminality, which in turn influenced the way in which men and masculinity were understood and discussed. The NZ Truth reported disparagingly on these assaults, showing little to no sympathy for the men who partook in the crimes.

Some of The NZ Truth articles also directly talked about Freud, and psychoanalysis. ${ }^{37}$ For example, in an October 1924 article "Professor" Underdown stated that, "“"Truth" mentions William James, Doctors Drummond, Freud, and Jung, the most celebrated Psychologists of the day", going on to say that though they are celebrated figures, "this does not mean to say that I have not a definite, proved theory of my own, or that my knowledge

\footnotetext{
33 'Degenerate Abnormals: What Treatment? - Perverted Passions and Painful Problems', The NZ Truth, 17 March 1923, p.3

34 'Will World Become Mad?: Mankind Must Solve "Mental” Problem Or-!', The NZ Truth, 21 June 1924, p.1.

${ }^{35}$ Such as the 1923 article that described the sexual assault of Dr Charles Theimer on one of his patients. He had submitted himself as a voluntary boarder at the Sunnyside Mental Hospital, "But after a period in that institution it was decided that his mentality was defective and the authorities had kept him there since." See: 'Love, Lunacy and Law: Doctor Struct Off The Roll', The NZ Truth, 5 May 1923, p.6.

36 'The Hectic Rush: Don Juans Who Kiss And Ride Away', The NZ Truth, 16 February 1924, p.6.

37 'Psychology' brings up hundreds of search results on Papers Past in The NZ Truth, though not all were relevant to this thesis, nor was it possible to search through them all. The fact there were so many results, however, also seems to indicate that the newspaper reflected that broadening interest in the subject following the war.
} 
was first founded on their lines of thought." ${ }^{38}$ A March 1924 article noted Freud's theories regarding sexuality; ${ }^{39}$ a May 1924 article demonstrated an understanding of psychoanalysis' view of consciousness; $;^{40}$ and, another issue advertised in the 'Books By Post' section, William J. Fielding's Health and Self-Mastery Through Psycho-Analysis and Autosuggestion..$^{41}$

Health and Physical Culture magazine also identified Psychology and Mental Hygiene as some of its key areas of interest. As such, it is unsurprising that such topics were tackled in articles across the volumes of the publication. Mental deficiency was a topic addressed in a number of $H \& P C$ issues. For example, in an article on the 'Sterilisation of the Unfit' reforms through legislative Acts “aimed at the betterment of humanity" were called for. The article emphasised "the vital importance of the individual and social tragedy of mental deficiency". ${ }^{42}$ Another example comes from the following month's issue in February 1930, where again, the problem was dubbed, "the tragedy of mental deficiency". ${ }^{43}$ Two such articles published in early 1930, a relatively short time after the 1928 Mental Defectives Amendment Act went into effect in January 1929, indicates the magazine's awareness of the eugenic 'mood' in New Zealand (and Australia) at this time. A number of lobby groups in New Zealand were disappointed by that which the legislation failed to achieve, especially authorised sterilisation, and they continued to press for reform. ${ }^{44}$ This context is telling in the continued discussions of topics relating to eugenics and sterilisation in $H \& P C$. The use of the term 'Mental Hygiene' is indicative here of a link made by contemporaries between eugenic concerns and worries about the state of mind and mental fitness of citizens.

Mental health conditions such as shell-shock, and neuroses (more generally) are also addressed within $H \& P C$ articles. The February 1930 article, 'Insanity and the Decemberborn', discusses the topic of "mentality" and "mental derangement". 45 The piece describes the work of a Dr. Tramer, of the Rosegg Mental Hospital in Solothurn, Switzerland, in

\footnotetext{
38 'Out-Freuded: Underdown Will Show Them The Way - "Mentography” And Its Marvels', The NZ Truth, 4 October 1924, p.5.

39 'How Sex-Sin Sears Society: Man And Social System - Both Are To Blame For Laches and Losses That Are Avoidable', The NZ Truth, 29 March 1924, p.6.

40 “"New Race of Super-Men”: Forth Dimensional Consciousness', The NZ Truth, 31 May 1923, p.1.

41 'Books By Post', The NZ Truth, 16 February 1924, p.4.

42 'Sterilisation of the Unfit', Health and Physical Culture, Vol.2, No.1, January 1930, p.12.

${ }^{43}$ Marion Piddington, 'Breeding Out the Unfit: Eugenics and Sterilisation', Health and Physical Culture, Vol.2, No.2, February 1930, p.42.

${ }^{44}$ Stephen Garton, 'Liberty of the Nation': Eugenics in Australia and New Zealand and the Limits of Illiberalism', in Diane B. Paul, John Stenhouse, and Hamish G. Spencer (Eds.), Eugenics at the Edges of Empire: New Zealand, Australia, Canada and South Africa (Cham: Springer International Publishing, 2018), p.28.

45 'Insanity and the December-born', Health and Physical Culture, Vol.2, No.2, February 1930, p.13, and p.40.
} 
observing mental patients over a period of 30-plus years to if it can be derived whether the month you are born in affects the possibility of one developing insanity. ${ }^{46}$ The August 1932 issue carried an article 'Shell-Shock Caused by Courage?!'. ${ }^{47}$ The January 1933 issue of the magazine published an article 'Educate for Sanity', which echoed the desires of many (in the field of psychology, and medicine - for example those in Preventive Medicine, as discussed previously in relation to the dissertations written by the fifth-year medical students at the University of Otago) that education was the way forward in preventing unnecessary mental diseases. ${ }^{48}$ In addition to these cases, there are also articles such as: 'Border-Line Cases', by Marion Piddington; ${ }^{49}$ 'Why the Mentally Ill Need Work and Interest', by Stella Pines, ${ }^{50}$ and those that looked at the nervous system and nervous diseases. ${ }^{51}$

Health and Physical Culture covered many topics in which mental and physical health were intertwined, and discussed together. It is notable that some of these articles also employed Freudian language and theories, as well as general discussions of psychology and psychoanalysis. One example is the article 'Is Nudism Neurotic?', written by Oliver Olver, published in the August 1933 issue of $H \& P C .^{52}$ In this article Olver states that he believes that "The problem of nudism... is inseparable from the problem of sex"; and that in order to understand nudism and sex instinct, who better to discuss the topic than Freud? ${ }^{53}$ Olver talks about this instinct in terms that seem to relate an understanding of civilisation and how it

\footnotetext{
46 'Insanity and the December-born', Health and Physical Culture, Vol.2, No.2, February 1930, p.13. The conclusion that is drawn for $H \& P C$ readers is that it depends where you live geographically, but also that those born in December are potentially more likely than others to develop mental disorders if their mothers are not cared for, or are poor and unable to adequately cope with a new baby in the cold-winter months (p.40).

47 'Shell-Shock Caused by Courage?!', Health and Physical Culture, Vol.4, No.8, August 1932, p.9.

${ }^{48}$ The notion of prevention of these mental diseases very much related to eugenic concerns. For example, see 'Sterilisation for Human Betterment', Health and Physical Culture, Vol.2, No.2, February 1930: in a review of Clarice Irwin's work, it was argued that "all these admittedly preventable social evils" in society that manipulate and proliferate mental diseases, such as feeble-mindedness, were preventable.

${ }^{49}$ Marion Piddington, 'Border-Line Cases', Health and Physical Culture, Vol.2, No.6, June 1930, p.12. For more information about Marion Piddington, see: Joy Damousi, Freud in the Antipodes: A Cultural History of Psychoanalysis in Australia (Sydney: University Of New South Wales Press, 2005), p.86. Damousi described Piddington as "One of the strongest advocates of eugenics and feminism at this time"; and stated that, "In theorising within the inter-war social assumptions of the universal nature of heterosexuality and motherhood, Piddington nonetheless shifted the emphasis away from the repression of heterosexual sex per se, as the cause of women's neurosis, to an examination of the loss felt by women of being childless."

${ }^{50}$ Stella Pines, 'Why the Mentally Ill Need Work and Interest', Health and Physical Culture, Vol. 6, No.8, August 1935, p.41.

${ }^{51}$ For example, see: 'More Medical Notes About the Nervous System', Health and Physical Culture, Vol.8, No.1, January 1936, p.22; 'How to Understand Your Nervous System', Health and Physical Culture, Vol.8, No.2, February 1936, p.47; 'More Facts About Your Nervous System', Health and Physical Culture, Vol.8, No.3, March 1936, p.47; and 'A Survey of Prevalent Nervous Diseases', Health and Physical Culture, Vol.8, No.4, April 1936, p.47, all by Dr. Stanley Nelson.

${ }^{52}$ Oliver Olver, 'Is Nudism Neurotic?', Health and Physical Culture, Vol.5, No.8, August 1933, pp.30, 47, 50.

${ }^{53}$ Olver, p.30. The idea around sex instinct at all is a large part of Freud's work, so for Olver to discuss nudism in relation to sex instinct seems to indicate Freud's influence.
} 
functions. ${ }^{54}$ Such ideas are reflective of an evolutionary framework of understanding approach. What is important in this instance is the fact that there was a connection made regarding the topic and the increasing interest in psychology, psychiatry and the 'neurotic'.

Freud's influence can also be seen in articles such as 'The Mighty Atom: How to Rear Our Sons', which talks about the importance of Physical Culture in the lives of young boys, and repression. ${ }^{55}$ W. R. Jamieson's article, 'Personality Through Muscular Development: A psychological course on Mental and Physical Harmony', from the August 1929 issue, also employs Freudian-like terminology. ${ }^{56}$ Jamieson states that to reach a healthy mental position it includes, "focussing of the conscious mind on to one point" in order to be successful, ${ }^{57}$ and that concentrated thought is needed for mental health in addition to physical exercise. ${ }^{58}$ The editorial piece for the June 1933 issue also talks of the notion of conscious - in this case as related to "conscious evolution", by which it is meant actively using the power of one's mind (as Psychology has taught) hand-in-hand, "with Nature herself in the moulding of a super manhood". ${ }^{59}$ Here the language of Psychology is deployed to describe the creation of a masculinity and manhood that far supersedes that which came before - an ideal which the magazine tries to promote through the articles it publishes, and in its outlook and targeted readership. ${ }^{60}$

Psychology, and its uses, was promoted as a tool of self-improvement in a number of articles, and advertisements in $H \& P C$. For example, the November 1935 issue had an advertisement for the I.C.S. (International Correspondence School), "Whose training has put thousands of average men into big jobs - and kept them there", where one of the courses offered was for "Psychology and Personality in Business". ${ }^{61}$ The same issue also included an article called 'How Psychology Can Cure', written by Owen Prentice. ${ }^{62}$ In this piece Prentice, "Gives Another Lucid Explanation of the Potentialities of Psychotherapy, and how

\footnotetext{
${ }^{54}$ Olver, p.47.

${ }^{55}$ MATRON, 'The Mighty Atom: How to Rear Our Sons', Health and Physical Culture, Vol.1, No.6, June 1929, p.20.

${ }^{56}$ W. R. Jamieson, 'Personality Through Muscular Development: A Psychological Discourse on Mental and Physical Harmony', Health and Physical Culture, Vol.1, No.8, August 1929, pp.28, p.35.

57 Jamieson, p.28.

${ }^{58}$ Ibid.

${ }^{59}$ Health and Physical Culture, Vol.5, No.6, June 1933, p.3. The idea of "conscious evolution" can be seen to have been discussed in a previous issue of the magazine, in an article of the same name almost two years prior too, see: "Porkobidni”, 'Conscious Evolution', Health and Physical Culture, Vol.3, No.10, October 1931 p.19. ${ }^{60}$ The magazine describes itself as "written by authoritative people and presented entertainingly for thinking men and women". See: Health and Physical Culture, Vol.5, No.6, June 1933, p.3, but also this self-description was published in almost every issue of the magazine.

61 'Be a "Yes" Man!', Health and Physical Culture Vol.6, No.11, November 1935, p.4.

${ }^{62}$ Owen Prentice, 'How Psychology Can Cure', Vol.6, No.11, November 1935, pp.29-30, 32.
} 
Psychology Can Be a Priceless Help to the Individual [sic.]". He discusses how the pursuit of individual psychology is also beneficial to society at large too. ${ }^{63}$ Prentice's approach seems to align with the Freudian view in regards to the role sex instinct(s) play in neuroses; though he states that there are three main problems, "every human being must, in order to be normal, solve for himself ... the problems of society, of work, and of sex."64 The July 1937 issue of the magazine includes an article on, 'The Key To Our Twenty Psychology Questions (A Guide to Character)' ${ }^{65}$

Mental fitness was a subject of interest in the pages of Health and Sunshine, even though its prime focus was physical health. The Auckland-based magazine referenced psychology in a number of articles and advertisements during its publication. For example, on the cover of the November 1936 issue there was an advertisement for a "Popular Radio Lecturer", who was a "Well-known New Zealand Psychologist", and "Expert in all matters of Sex", who you could call or meet in person to "cure your "Nerves", your fears, and your ability to adapt yourself to what appears to be a long vale of sorrow." 66 The same issue also included an advertisement for a Practical Psychology Course; ${ }^{67}$ and an article by the magazine's founder, Trevor G. Bain, on 'Suggestion and Auto-Suggestion'. In this article Bain addressed the increasing interest and spread of psychological terms such as "autosuggestion" and "the subconscious", which he said, "seem to be on every tongue." 68 Bain here illustrates the way in which these terms had entered the popular realm, in the language of everyday people who talked about them, not just by experts in medical circles. Bain also wrote an article in the February 1937 issue, in which in an attack on "Mr. Money-bags" (i.e. capitalism) he stated that he did not want to compromise with Mr. Money-bags as he wished to, "accomplish two glorious obsessions". These obsessions were to, "establish Psychology

\footnotetext{
${ }^{63}$ Prentice, p.29.

${ }^{64}$ Prentice, p.30. He places less importance sex being the sole problem, as Freud does, yet he also states that it is the "most important problem"; going on to say that it can only be solved, "in useful social terms only by love and marriage".

65 'The Key To Our Twenty Psychology Questions (A Guide to Character)', Health and Physical Culture, Vol.9, No.7, July 1937, p.47.

${ }^{66}$ Health and Sunshine, Vol.1, No.2, November 1936, front cover.

${ }^{67}$ Health and Sunshine, Vol.1, No.2, November 1936, p.32. The course covered many topics, including: "Mind Control - Mind and Body - Mental Mastery - Consciousness - Fundamental Processes of Mind... The Secret of Mental Efficiency... Hypnotism and How Applied... Suggestion and Auto-Suggestion - The Mystery of the Unconscious - Etc., etc." This advertisement was also printed in the February 1937 issue, see: Health and Sunshine, Vol.1, No.4, February 1937, p.1.

${ }^{68}$ Trevor G. Bain, 'Suggestion and Auto-Suggestion', Health and Sunshine, Vol.1, No.2, November 1936, p.33.
} 
permanently in New Zealand", and "to establish two Homes - one for nerve-wrecked and suffering mothers, and one for backward children". ${ }^{9}$

Weak nerves and other mental disorders were also discussed in Health and Sunshine. The magazine published an article 'Do Not Get The Blues?', in which it addressed the problem that "in these post-war days... there is a tendency to depression in many of us", stating that, "we may face this matter fairly and squarely". ${ }^{70}$ The same February 1937 issue also addressed hysteria and hysterics on several occasions. For example, it included an article on, 'The Hysterical Person', in which it was stated that: "Some repressed emotion, some fright or dream may be the cause of his losing some of his self-control and stability of mind", and that, "It is more common among women than among men". ${ }^{71}$ In another article by Bain, 'Nerves', he wrote that: "Whilst it is not wise to pamper an hysterical person unnecessarily, it is helpful to try to understand the peculiar swingings of emotion, and further to realise that the outbursts are not products of malingering tendencies." functional nervous disorders; and - even in 1937 - he described how the Great War "with its outcrop of shell-shock cases and nerves was responsible for a great deal of light on the treatment of Psychasthenia and Neurasthenia”, which meant that for post-war cases of "nerves", through the "correct therapeutic treatment the majority... can be completely cured." This recognition of the influence the war had on the treatment of such mental disorders reflects one of the broader points this thesis makes. That because of this impact, it also influenced the way in which men who could be described in such terms (i.e. psychological and/or medical) were perceived. 'Hysteria' was understood as something that affected women, but the with the war this was connected more so to men. Here Bain, in the late 1930s, discussed such things - the problem of neurasthenic men continued to be present in society, hence Bain addressed them. The associations of such disorders and diseases therefore also seeped out into the larger societal conceptions of the masculine and masculinity too.

\footnotetext{
${ }^{69}$ Trevor G. Bain, 'It Beats Me!', Health and Sunshine, Vol,1, No.4, February 1937, p.42. Bain here shows a genuine passion for Psychology and its place in Aotearoa, as well as linking it to the problem of those with troubled nerves, and backward children. The concept of nerves was heavily intertwined with understandings of mental diseases and neuroses, and the notion of being "backward" tied in with evolutionary framework type views of those with mental diseases, or who were dubbed mentally deficient.

70 'Do Not Get The Blues?', Health and Sunshine, Vol,1, No.4, February 1937, p.20. The problem is now able to be addressed because the magazine states that the ways in which people understand mental disorders such as depression has changed from that which had previously been taught, "that melancholia was a brain disease, accompanied by severe mental disturbance, great depression, and a desire to commit suicide", to now being more of a physical problem as, "nearly all the cases are due to the absorption of poisonous matter into the blood from the waste that should have been thrown out of the body".

71 'The Hysterical Person', Health and Sunshine, Vol,1, No.4, February 1937, p.34.

72 Trevor G. Bain, 'Nerves', Health and Sunshine, Vol.1, No.4, February 1937, p.45.
} 
The Monocle, whilst having a broader scope in the topics it dealt with than the other magazines this chapter discusses, did also have occasions where it mentioned psychology and mental fitness. For example, in its May 1937 issue it published an article 'Industrial Psychology: Its Developments and Present Status', written by R. Winterbourn (a Lecturer in Psychology and Education, Canterbury University College). ${ }^{73}$ This article discusses the history of Industrial Psychology, with origins in the Industrial Revolution; ${ }^{74}$ its application during the Great War; ${ }^{75}$ and its position since the war. ${ }^{76}$ The March 1939 issue also published an article on, 'The Significance of Psychology: Applications to Industry', by a C. J.A., which similarly discussed the benefits of psychology - as evidenced by The National Institute of Industrial Psychology, England - on efficiency in the workplace. ${ }^{77}$ Such articles addressed the perceived interests of the working New Zealand man of the 1930s. The articles and advertisements that addressed topics relating to psychology and mental fitness in these popular culture publications demonstrated the continued influence and impact of the Great War. They also illustrate the way that the sustained effects of the war shaped discussions of men and masculinity in interwar New Zealand.

\section{EVOLUTIONARY FRAMEWORK OF UNDERSTANDING AND EUGENICS}

Debates around mental illness and criminality competed and crossed-over in conceptions and constructions of men, masculinity, and male sexuality during the interwar period. Peter Boston has described the ways in which sexually 'perverted' men were contained in New Zealand at this time, alongside patients and citizens who were dubbed 'feeble-minded' ${ }^{78}$ One of the places where these two notions connected was seen in eugenic ideas. An evolutionary framework approach, and the influence of eugenics, can be seen across many articles published by The NZ Truth in the interwar years. Most notably in relation to issues around the problem of criminality and mental defectives or the feeble-minded and the idea of

\footnotetext{
${ }^{73}$ R. Winterbourn, 'Industrial Psychology: Its Developments and Present Status', The Monocle, Vol.1, No.1, May 1937, pp.32-33.

${ }^{74}$ Winterbourn, p.32

${ }^{75} \mathrm{Ibid}$. It discussed its application in regard to tests for certain military jobs, including as pilots, drivers, range fingers, etc. Winterbourn also noted that, "The war also increased our knowledge of industrial fatigue in relation to hours of work."

${ }^{76}$ I.e. with its continuous process of improvements. Winterbourn, p.33.

${ }^{77}$ C. J. A., 'The Significance of Psychology: Applications to Industry', The Monocle, Vol.2, No.11, March 1939, p.65.

${ }^{78}$ Peter Boston, “A Caged Tiger': The Regulation Of Male Sexuality In The New Zealand Penal System, 1917 To 1952’, Unpublished Conference Paper, NZPGSA Conference, 1998, p.1
} 
sterilisation (or segregation). For example, in the article 'Feeble Minds And Motherhood', it is pointed out that: "One phase of the mental defective problem ... is that of the feebleminded adolescent girl," who presents an issue for New Zealand due to her ability to reproduce, and potentially increase the number of feeble-minded in the nation. ${ }^{79}$ This article presented segregation as a possible solution, as does the March 1924 article about the treatment of "dangerous sex degenerates"; 80 whilst others spoke more directly to sterilisation. In the article 'The Degenerate And The Unfit: Science Seeks A Way', sterilisation, or desexualisation, of the degenerate was suggested as possible solutions for the increasing problem of mental degeneracy in New Zealand. ${ }^{81}$ These were put forward as potential solutions as it was stated that the "savage" practice of infanticide - that is, purposefully removing mentally deficient or unfit children from society in childhood - was not tolerable to civilised society. ${ }^{82}$ The framing of this problem as related to savagery or civilisation demonstrates the evolutionary framework of understanding when it came to this issue of mental disorders. ${ }^{83}$

In the article 'Moral Weaklings: Serious Problem Of The Feeble-Minded', the severity of the problem, as believed by some, was outlined. "The unchecked multiplication of the feeble-minded and epileptic," the author wrote, "is leading to a continually growing addition to the sum of human misery, and ever-increasing burden on the State and the serious deterioration of the race", with the article going on to suggest the implementation of a Eugenic Board ${ }^{84}$ (such as the one described in the 1928 Mental Defectives Amendment

\footnotetext{
79 'Feeble Minds and Motherhood', The NZ Truth, 12 July 1924, p.1.

80 'How To Treat Them?: Doctors Say That Surgical Desexualisation Is Not Always Final', The NZ Truth, 15 March 1924, p.6. The article reported that, "Perpetual segregation, then, it would seem, was the only sure and certain protection from a repetition of the offence", however it was also felt that, "this would be too severe on those offenders who owed to heredity an uncontrollable perverted sexual instinct". This therefore distinguished between the different categories of sexual offenders as related to the heredity of their mental and/or criminal problem.

81 'The Degenerate And The Unfit: Science Seeks A Way', The NZ Truth, 12 May 1923, p.4.

${ }^{82}$ Yet the problem still remained, so they had to do something about it, or so the article states: 'The Degenerate And The Unfit: Science Seeks A Way', The NZ Truth, 12 May 1923, p.4.

${ }^{83}$ See also: 'Don't You Agree', The NZ Truth, 31 January 1929, p.15, which too touched on this notion of savagery and primitiveness as it discussed the modern, civilised man. It stated that, "Modern man goes to his club when the primitive husband would have reached for it." This also links violence, criminality, and assault, as discussed in a large number of these articles relating to mental defectives, with the primitive, therefore making further comment on those men who carry out such assaults (sexual or otherwise). Other articles that discussed sterilisation include: 'Disease of Sexuality: Uncontrollable Passions - Victim Suggests Sterilisation', The NZ Truth, 10 May 1924, p.3; 'Manners, Morals, Molestation: Surgical Sterilisation - How Licence Leads to Lewdness - Defectives Who Prey On And Ruin Little Children', The NZ Truth, 16 February 1924, p.6; and 'Unpleasant, Yet A Fact: The Growth of Degeneracy And Sex Crime - Some Statistics Of Indecency', The NZ Truth, 23 February 1924, p.3.

84 'Moral Weaklings: Serious Problem Of The Feeble-Minded', The NZ Truth, 7 February 1925, p.5. See also: 'Manners That Corrupt Morals: Is It Not High Time That We All Looked Facts In The Face?', The NZ Truth, 9 February 1924, p.7, which also outlines the seriousness of the problem of degeneracy.
} 
Act. $)^{85}$ The October 1926 article 'Preferential Treatment Of Prisoners And Problem Of The Degenerate' also outlined what is said were, "two very difficult and complex problems... each country has to face" which were, "the punishment of crime and the care of the mental and moral degenerate." 86 These two problems were often discussed together - as is evidenced by much of the material this thesis examines - because of the ways in which different sexual crimes, in particular, were classified ${ }^{87}$ the cross-over that existed here with existing treatments of people with mental disorders and illnesses; and the fact that the vast majority of such people, and those that exhibited such behaviours, ended up as state responsibilities. ${ }^{88}$

In the article 'Weakness At The Top', the increasing number of "lunacy" cases is discussed in a way that related the problem to one of race and civilisation. It was reported that, "H. Atmore, M.P., states that whereas one Maori in 1400 Maoris [sic.] is mentally afflicted, the proportion of deranged whites is one in 280," meaning that for Pākehā New Zealanders, they faced a larger problem. ${ }^{89}$ The piece also related this problem to the war, stating that even though: "Before the war, white civilisation was already wearing heavily on its human material", that, "The war weakened the physique - particularly the nervous physique - and at the same time boosted all practices of the jazz order and of the hysterical type, so that the capital of life was diminished and the drain upon it was augmented." 90 This emphasis on the physical toll of the war, which impacted the nervous system, demonstrates one understanding of the way in which mental disorders and diseases were developed; and the notion that the war also "boosted the practices" of the "jazz order" and "the hysterical type" further demonstrates Atmore's belief that the war exacerbated existing conditions and placed a heavy toll on human society, thus depleting and weakening it. Though Atmore relates this issue to race (in his discussion of Māori and Pākehā), what is important is the way in which this relates to evolutionary ideas of primitivism as linked to mental fitness. This

\footnotetext{
${ }^{85}$ Mental Defectives Amendment Act 1928.

86 'Preferential Treatment Of Prisoners And Problem Of The Degenerate', The NZ Truth, 14 October 1926, p.6.

${ }^{87}$ For example, the ways in which male-male desire was classified as a sexual perversion and was put together with incest, rape, and bestiality. Chris Brickell, Mates and Lovers: A History of Gay New Zealand (Auckland: Godwit, 2008), p.30.

${ }^{88}$ For example, also see the way in which these two things were both addressed in the Mental Defectives and Sexual Offenders: Report of the Committee of Inquiry Appointed by the Hon. Sir Māui Pōmare, K.B.E., C.M.G., Minister of Health 1925.

89 'Weakness At The Top', The NZ Truth, 15 September 1923, p.1.

${ }^{90}$ Ibid.
} 
association ranged from the idea of the 'noble savage' to eugenic decay during the interwar years in New Zealand. ${ }^{91}$

A number of NZ Truth articles made direct references to eugenics. For example, in the article 'The Cure of Criminals - Social Salvage', published in July 1924, it was reported that as the cure of criminals was complex (due to the factor played by heredity), and that, "Reformers looking for a preventive treatment turn increasingly towards eugenics" for a solution. ${ }^{92}$ Other examples include those like 'The State's Imbeciles: A Family of Degenerates', in which the author wrote that the case of the family related in the article, "should appeal to every conscientious social reformer and induce him to bend his mind more in the direction of eugenics than prohibition". ${ }^{93}$ As well as the article titled, 'Breed Better Britons: Quantity - Or Quality?', which argued that "Mere birth control is not sufficient unless it goes hand in hand with eugenics, the elimination of the unfit, and the weeding out of sexual degenerates, venereal victims, and others utterly unfitted for procreation purposes"; 94 and 'Undetected Sex Perversion: Figures That Shock, Yet Are Incomplete', which reported that, "there is a useful suggestion that New Zealand should set up a Eugenics Board for considering this [undetected sex perversion] and other phases of the matter." 95 Not all those writing in The NZ Truth agreed with the eugenics movement though, as evidence by a comment in a September 1924 article which stated that "No healthy-minded person is really interested in eugenics", thus the author of the article made a judgement on those who did follow the expanding field..$^{96}$

The influence of the evolutionary framework of understanding, and interest in eugenic ideas, was evident in a number of articles published in Health and Physical Culture magazine. To begin with, the editors of the magazine described themselves as "devoted to...

\footnotetext{
${ }^{91}$ The article even went on to state that, "Mental diseases may yet prove a more dangerous thing to humanity than any other disease", despite the potential for preventive and curative treatments: 'Weakness At The Top', The NZ Truth, 15 September 1923, p.1.

92 'The Cure of Criminals: Social Salvage', The NZ Truth, 5 July 1924, p.6.

93 'The State's Imbeciles: A Family of Degenerates', The NZ Truth, 30 September 1922, p.5.

94 'Breed Better Britons: Quantity - Or Quality?', The NZ Truth, 11 July 1925, p.5. The article went on to state that with these measures in place, "Then the medical examinations of our man power in war time, the reports of our school clinics, and the ghastly tales told by our criminal courts, hospitals, and asylums, will be more in keeping with our national pride of race and place, and less appalling to the true patriot who judges his country by the quality and not the quantity of its people," further indicating the author of the article's clear views on the problem of society as it was being weakened by mental and sexual degenerates and the unfit, in a way that thus diminishes the status of the race.

95 'Undetected Sex Perversion: Figures That Shock, Yet Are Incomplete', The NZ Truth, 28 March 1925, p.1. This article also goes on to proport the potential benefit of psychoanalysis in treating this problem: "From the accumulated mass of evidence concerning sexual perversion and the successful researches of psychologists with the health and disease of the mind, there is surely some hope that the case of the pervert will find some solution at the hands of the psycho-analyst."

96 'The Critic', The NZ Truth, 13 September 1924, p.1.
} 
embracing" both Heredity and Eugenics, alongside other topics. ${ }^{97}$ This devotion presented itself through the publication of articles on emotions and emotionality, concepts that were at the time intertwined with an understanding of primitive versus civilised peoples. For example in articles such as 'Control those Emotions and Learn to Smile';98 'Fear - Man's Greatest Enemy';99 'How Fear Can Bring Disease'; ${ }^{100}$ and 'How Emotional Are You?'. ${ }^{101}$ A great deal of slippage existed between racial theory, types of emotionality and effeminacy, as Mrinalini Sinha has described in the nineteenth-century Indian context. ${ }^{102}$

Eugenic interests also presented in articles that discussed sterilisation. For example, Marion Piddington's 'Sterilisation of The Unfit', which stated that, "The paramount problem of civilisation to-day is applied eugenics." ${ }^{103}$ She also quoted the eugenicist Paul Popenoe, who wrote that whilst "The human race has developed through countless ages under the laws of heredity by the survival of the fittest," with, "the weak and defective" perishing; but, "Modern civilisation, human sympathy, and charity have intervened in Nature's plan. The weak and defective are now nursed to maturity, and produce their kind."104 Popenoe, and Piddington, proposed that modernity and its intervention in the lives of physically and mentally defective peoples have caused issues within civilised society through allowing these problems to proliferate. Marion Piddington published another article on the topic of eugenics and sterilisation in the February 1930 issue of the magazine. ${ }^{105}$ In this piece she again quoted Paul Popenoe, as well as E. S. Gosney, who co-wrote the book Sterilisation for Human Betterment, and noted that they argued that, "sterilisation should not be a primitive measure, but one for protection only, "to the subject, to his family, to the State, and to future generations"." 106 The same issue of $H \& P C$ also published a review of Popenoe and Gosney's book; ${ }^{107}$ and an article about 'The Peril of Family Limitation' regarding the use of birth

\footnotetext{
${ }^{97}$ See Health and Physical Culture, Vol.5, No.6, June 1933, p.3 for an example of this, but it was also published in almost every issue of the magazine too.

98 'Control those Emotions and Learn to Smile', Health and Physical Culture, Vol.1, No7, November 1929, p.28.

99 'Fear - Man's Greatest Enemy', Health and Physical Culture, Vol.1, No7, November 1929, p.39.

100 'How Fear Can Bring Disease', Health and Physical Culture, Vol.10, No.3, March 1938, p.27.

101 'How Emotional Are You?', Health and Physical Culture, Vol.5, No.11, November 1933, p.7.

102 See Mrinalini Sinha, Colonial masculinity: the 'manly Englishman' and the 'effeminate Bengali' in the late nineteenth century (Manchester: Manchester University Press, 1995).

${ }^{103}$ Marion Piddington, 'Sterilisation of The Unfit', Health and Physical Culture, Vol.2, No.1, January 1930, p.12.

104 Ibid.

${ }^{105}$ Marion Piddington, 'Breeding Out the Unfit: Eugenics and Sterilisation', Health and Physical Culture, Vol.2, No.2, February 1930, pp.19, 42.

${ }^{106}$ Piddington, 'Breeding Out the Unfit: Eugenics and Sterilisation', p.19.

${ }^{107}$ Clarice Iriwn, "'Sterilisation for Human Betterment": A Review of this Work', Health and Physical Culture, Vol.2, No.2, February 1930, pp.42-43.
} 
control, warning against its use. ${ }^{108}$ Other examples of this interest in eugenics and sterilisation can be seen in articles $H \& P C$ published like those that dealt with birth control, such as 'The Moral Aspects of Birth-Control' by Ernest G. Finney, ${ }^{109}$ and 'Birth Control' by Dr. James Booth; ${ }^{110}$ and those more directly about sterilisation like 'The Truth About Sterilisation'. ${ }^{111}$

Other articles published in $H \& P C$ that indicated an interest in topics related to the evolutionary framework way of thinking include those like, 'Is Nudism Neurotic?'. This article argued that sex and sex instincts were not such a prolific problem "among primitive people" as it was for those in "higher civilisations", because the primitive people were more likely to be nude, and therefore would have less concerns about sex and sexuality as related to the bodies of the opposite sex. ${ }^{12}$ The interest is also seen in articles like 'Towards a Higher Civilisation';113 and those that touched on heredity like 'The Menace of the FeebleMinded', by Ralph Piddington. ${ }^{114}$ Frederic Slater's piece on firemen in the May 1929 issue, 'The Making of Men', commented on the fact that views of "the development of civilisation" had grown over the last half-century, to reach one conclusion that "the highest form of civilisations can only be attained by keeping as near as possible in harmony with Nature."115 By this, he referred to the importance to communities of staying physically as well as mentally fit and superior. This general interest in, and utilisation of, an evolutionary framework approach was also demonstrated in articles such as: 'Is Eugenics Possible?' by Doctor Dixon Jones; 116 “"I Have Gone Bush”, by Ernest Leslie; 117 'Shocking Neglect of National Health';18 'Will the Mad Mullah of Militarism Destroy Civilisation?';119 'What a

\footnotetext{
${ }^{108}$ A. J. Briton, 'The Peril of Family Limitation: Does Birth-Control Spell Race Extinction?', Health and Physical Culture, Vol.2, No.2, February 1930, pp.22-23. In this article, A. J. Briton, the founder of $H \& P C$, described the potential dangers birth control faced the "young and virile race" of Australia; noting too that, "Amongst practically all races of so-called savages fruitfulness is looked upon as a virtue and blessing," so why should civilised peoples actively choose to sterilise themselves, in what he described would be, "a crime against the true and natural love between the sexes" (p.22).

${ }^{109}$ Ernest G. Finney, 'The Moral Aspects of Birth-Control', Health and Physical Culture, Vol.2, No.6, June 1930, p.6.

${ }^{110}$ Dr. James Booth, 'Birth Control', Health and Physical Culture, Vol.2, No.9, September 1930, p.22.

111 'The Truth About Sterilisation', Health and Physical Culture, Vol.3, No.12, December 1931, p.19.

${ }_{112}$ Olver, p.30, 47.

113 'Towards a Higher Civilisation', Health and Physical Culture, Vol.3, No.9, September 1931, p.13.

${ }^{114}$ Ralph Piddington, 'The Menace of the Feeble-Minded', Health and Physical Culture, Vol.6, No.3, March 1933, p.28. Piddington argued that "the most serious" menace facing civilisation was the threat of the feebleminded, who were in the majority of cases, feeble-minded due to heredity.

${ }^{115}$ Frederic Slater, 'The Making of Men', Vol.1, No.5, May 1929, p.22.

${ }^{116}$ Doctor Dixie Jones, 'Is Eugenics Possible?' Health and Physical Culture, Vol.5, No.10, October 1933, p.30.

${ }^{117}$ Ernest Leslie, "'I Have Gone Bush"', Health and Physical Culture, Vol.7, No.7, July 1934, p.49.

118 'Shocking Neglect of National Health', Health and Physical Culture, Vol.8, No.3, March 1936, p.22.

119 'Will the Mad Mullah of Militarism Destroy Civilisation?', Health and Physical Culture, Vol.8, No.4, April 1936, p.18.
} 
Scientist Means by "Evolution"',120 and 'The Australia That Might Be'. ${ }^{121}$ The magazine generally seemed to support eugenic ideas, certainly giving them a platform throughout the issues of its publication.

Mentions of degeneration and degeneracy also appeared in the $H \& P C$, bringing to the fore an evolutionary framework of ideas. They can be seen in articles such as 'Australia Offers Biggest Prize On Earth!', which spoke of the advantages, and disadvantages, that Australia presents in terms of men reaching their fullest potential. ${ }^{122}$ The article states that currently "our young men are growing into a demoralised manhood", because, "they can see no places for themselves in the world of Australian affairs, because of the dole and degenerative dole labour." ${ }^{123}$ Unemployment in Australia, this article argues, has caused a degeneration of the masculinity and manhood of its young men because they have to do this primitive labour rather than purposeful civilised labour. Dignity of work and employment were central tenets and proofs of Australian manhood in the modern nation state. It is also seen in the article 'Eutelegenesis - A Short Way To Superman', which detailed the way in which potentially artificial insemination could be used as a form of contraception and sterilisation to eliminate the "hereditary defect" from society, which it notes is the current preoccupation of eugenics. ${ }^{124}$ It proposes that this process "might produce a great and rapid improvement in the hereditary qualities of the race", however, it also acknowledges that this is not an easy undertaking: "To attempt the elimination of such degeneracy by sterilisation is, as it appears, rather like clearing a river of fish by catching the few which jump from the water." 125 Comments on degeneracy and racial decay can also be seen in articles such as: "All Men Must Fight!’;126 'The Race Suicide of Royalty’;127 ‘An Object Lesson in Racial Decay’,

\footnotetext{
120 'What a Scientist Means by "Evolution”', Health and Physical Culture, Vol.8, No.5, May 1936, p.53.

121 'The Australia That Might Be', Vol.9, No.3, March 1937, p.40.

122 'Australia Offers Biggest Prize On Earth!', Health and Physical Culture, Vol.6, No.11, November 1935, pp. 18-19.

123 'Australia Offers Biggest Prize On Earth!', Health and Physical Culture, Vol.6, No.11, November 1935, p.19.

${ }^{124}$ Herbert Brewer, 'Eutelegenesis - A Short Way To Superman', Health and Physical Culture, Vol.6, No.11, November 1935, p.22.

${ }^{125}$ Brewer, p.24.

126 'All Men Must Fight!', Health and Physical Culture, Vol.7, No.1, January 1934, p.4.

127 'The Race Suicide of Royalty', Health and Physical Culture, Vol.3, No.6, June 1931, p.26.
} 
by Eric Ramsden;'128 ‘Are We Becoming a Race of Poor Whites?'; ${ }^{129}$ and 'Indicated for Wilful Race Suicide! Australia Stands Accused'. ${ }^{130}$

The problem of the unemployed was also evident in $H \& P C$ articles. For example in Ralph Piddington's, 'The Menace of the Feeble-Minded', he not only discussed the issues of heredity, but also noted that "the feeble-minded make up a large part of the "unemployable" element since their mental weakness prevents them from doing effective work"; and it was this inability to hold down a job that would often "drive them to crime", or for the female feeble-minded, "to prostitution." 131 So the worry here is not only the fact these people are unemployed (which was seen to emasculate men), but also that this state could, and would, lead them to crime too, causing another blight to civil society. It was a path that led to general, widespread, and irredeemable degeneration. Anxieties around men at leisure, and the effect of the dole, can also be seen in articles like 'Educating for Leisure','132 'How Dole Psychology Is Killing Initiative'; ${ }^{133}$ and 'Forty Thousand Graduates for the Dole!'. 134

The evolutionary framework, and a eugenic view can be seen in a number of articles within Health and Sunshine magazine. For example, in the article 'Nudism- Is It Desirable', which included letters sent in from subscribers to the magazine. ${ }^{135}$ A "C. F. H." wrote of nudism and the physical culture movement that: "Any movement that destroys hypocrisy and prudery, that helps to convert a C.3 nation to a normal one, that reduces the number of hospitals and asylums, is most desirable, especially when the remedies are free to all and can be properly applied" ${ }^{136}$ Here C. F. H., in praising nudism and physical culture, connected them both to the idea of a population that was weak and physically below standard (i.e. was a C.3 population), and to the idea that these movements could also help to reduce the number of mentally ill in New Zealand too.

\footnotetext{
${ }^{128}$ Eric Ramsden, 'An Object Lesson in Racial Decay', Health and Physical Culture, Vol.6, No.6, June, 1935, p.15.

129 'Are We Becoming a Race of Poor Whites?', Health and Physical Culture, Vol.6, No.10, October 1935, p.16.

130 'Indicated for Wilful Race Suicide! Australia Stands Accused', Health and Physical Culture, Vol.9, No.5, May 1937, p.18.

${ }^{131}$ Ralph Piddington, 'The Menace of the Feeble-Minded', Health and Physical Culture, Vol.6, No.3, March 1933, p.28.

132 'Educating for Leisure', Health and Physical Culture, Vol.6, No.3, March 1935, p.30.

133 'How Dole Psychology Is Killing Initiative', Health and Physical Culture, Vol.6, No.11, November 1935, p.43.

134 'Forty Thousand Graduates for the Dole!', Health and Physical Culture, Vol.8, No.1, January 1936, p.18.

${ }^{135}$ C. F. H., in Trevor G. Bain, 'Nudism- Is It Desirable?', Health and Sunshine, Vol.1, No.2, November 1936, pp. 2,10

${ }^{136}$ C. F. H., in Trevor G. Bain, 'Nudism- Is It Desirable?', p.2.
} 
In a discussion of the problem of unemployment and women in the workplace, "SCRIPTO" linked this to the notion of degeneracy. 137 "SCRIPTO" argued that men who were afraid of women in business, and who saw them as "a menace to his sex", was not in fact a man, "but a degenerate"; as they went on to propose that, "The real men are working, unafraid of competition." 138 The link here is then made between a man who is employed, and who is 'man-enough' to not worry about women taking over his work and infiltrating business during the war and continuing on in the post-war period. The flipside being that a man who does fear this situation is degenerate, backwards, and not a real man, also indicating that a real man was one with a job.

Health and Sunshine also printed an article about young men and links to criminal activity. ${ }^{139}$ In this article Jasper Calder claimed that, "Most crimes arise from two causes weakness or selfishness"; 140 and also tied the development of a criminal character in young boys to a coddling-nature of mothers. ${ }^{141}$ The idea that overprotective mothers had a negative effect on their sons is something that featured prominently in discourses around boys who grew up to become effeminate men, ${ }^{142}$ and that played into fears of absent and/or negligent fathers who had either not returned from the war, or who had returned changed (i.e. physically disabled, or mentally unfit - shell-shocked, aggressive, or turned alcoholic). These articles therefore commented on the Great War's effect on fatherhood, and the impact this had on the next generation of boys and men.

The Monocle published a number of articles that referenced evolutionary framework ways of thinking, as well as the eugenics movement. For example, in the first volume of the magazine, it printed an article titled 'The Body Beautiful but... why C.3. in New Zealand?" by "MEDICUS". ${ }^{143}$ The article proclaimed that "You," the reader, "MUST be interested in this national work" of improving the state of national health in New Zealand; describing how "Medicus", "will show how, by means of diet, exercise, proper use of leisure and right

\footnotetext{
137 “SCRIPTO”, 'Ought Women To Go?', Health and Sunshine, Vol.1, No.4, February 1937, p.17.

${ }^{138}$ Ibid.

139 Jasper Calder, 'The Younger Criminal... Giving the Lad a Break', Health and Sunshine, Vol.1, No.4, February 1937, p.38.

140 Ibid.

${ }^{141}$ Ibid. Calder, in his general discussion of the young boy-criminal stated that whilst, "His mother has made him safe. She should have made him strong," again linking the concept of strength (physically and of character) to a more masculine, well-adjusted, and 'normal' boyhood and manhood.

${ }^{142}$ For example: Carl Hertzig, 'The Menace of Effeminacy', Health and Physical Culture Vol.4, No.1, January 1932, p.40.

143 “Medicus”, 'The Body Beautiful but... why C.3. in New Zealand?', The Monocle, Vol.1, No.1, May 1938, pp.38-39.
} 
thinking many of our C3 citizens can approach the A1 class." 144 It was noted that whilst "We had always harboured the impression that New Zealand men were well above the average an impression gathered from the descriptions of the Anzac forces which evoked so much admiration among the English people during the war," many New Zealand men were below the expected average of height, and also lacked in other physical ways. ${ }^{145}$ This evocation of the war and the much admired Anzacs was used to promote the idea that, "A chain is only as strong as its weakest link and national health is only as good as the health of the individuals composing the nation." 146 "Medicus", in this article, and The Monocle, by publishing it, are promoting the betterment of the health and fitness of New Zealanders, to prevent them (literally) falling-short in the future; and also to ensure that they can compete on the worldstage. The June 1938 article by G. H. Donald on 'Nutrition' also spoke to this population concern. ${ }^{147}$ Donald asserted that, "The Great War disclosed the fact that a large proportion of our manhood were sufferers from incipient ill-health", and that in order to keep the nation "fit" there needed to be a greater focus on physical culture and nutrition. ${ }^{148}$

Another of the ways in which evolutionary-type concerns played out in the pages of The Monocle was around the topic of employment, unemployment, and the duty of men. One of the recurring features of the magazine was titled 'Busy Men About The Cities' which gave short descriptions of prominent business and working New Zealand men. ${ }^{149}$ References are also found in articles such as 'Men Must Work To Live', which argued that, "in order to grow in civilisation and to progress in any true human manner", then man must work; ${ }^{150}$ and 'Management Means "Closer Touch", which recognised the importance of men in the modern workplace, more-so than machines. ${ }^{151}$ The allusions to the duty of men appear in articles such as 'Moral Law is the Measure of Duty', ${ }^{152}$ and 'Liberty and Duty'. ${ }^{153}$ These pieces talk to the idea that it is men's duty to respect the law, and that "men cannot be left to

\footnotetext{
144 “Medicus”, 'The Body Beautiful but... why C.3. in New Zealand?', p.38.

145 Ibid.

146 Ibid.

${ }^{147}$ G. H. Donald, 'Nutrition', The Monocle, Vol.2, No.2, June 1938, pp.42, 69.

148 Donald, p.42.

${ }^{149}$ From the research this thesis undertook, it appears as if this feature was first published in The Monocle, Vol.1, No.4, August 1937, p.45. It was then seen in every subsequent issue of the magazine up to 1939.

150 'Men Must Work To Live', The Monocle, Vol.2, No.1, May 1938, p.32. This article does also note that despite the great progress of Western civilisation, the problem of extreme poverty is vast and in dire need of attention. This hints at the notion of the civilised-primitive dichotomy, whilst simultaneously pointing out the flaws in this system too.

${ }^{151}$ Graham Cunningham, 'Management Means "Closer Touch”, The Monocle, Vol.2, No.11, March 1939, pp.71, 73.

152 'Moral Law is the Measure of Duty', The Monocle, Vol.1, No.10, March 1938, pp.31, 50.

153 'Liberty and Duty', The Monocle, Vol.1, No.11, April 1938, pp.31, 54.
} 
decide their own duties". ${ }^{154}$ In wartime the duty of men is to serve the nation in the armed forces, whilst in peacetime as a civilian they have the duty to be a worker, citizen, husband and father. The increasing concern with health in the interwar period meant that maintaining health was seen as a duty of citizens in modern nations. The compliance with, and performance of, these duties meant that men were maintaining a successful masculinity.

\section{SEX, SEXUALITY, MARRIAGE, AND MASCULINITY}

The discussion of sex, sexuality, and masculinity was more direct in The NZ Truth than some of the other sources. A lot of this was related to the reports on sexual assault and other sexual crimes which is unsurprising given the fact that much of the activities that were deemed unmasculine, effeminate, homosexual, or perverted were criminalised; and they provided part of the lurid and sensationalist content such tabloid papers relished. Examples of this can be seen in articles such as 'Suppressing Sex Crimes', which argued that, "The day has arrived when New Zealand must devise means to suppress the foul crimes of the sexual pervert"; ${ }^{155}$ and in the article 'Weeping And Wailing: Degenerate Dissolves In Tears', where it was described how an "effeminate young man" blubbered his defence against charges of indecent assault of a 12-year-old boy and his sister. ${ }^{156}$ The notion of inversion as related to "sex perversion" was also noted in the NZ Truth. In the December 1921 article 'Law And The Lash', it was stated that sex perversion was on the rise; and it was pointed out that the average juryman was unaware of the complexities of such people, ${ }^{157}$ and that judges, "should be acquainted with the latest scientific research on sex perversion by students like Haylock [sic.] Ellis, Kraft Ebbing, August Forel, and others." 158

\footnotetext{
154 'Moral Law is the Measure of Duty', The Monocle, Vol.1, No.10, March 1938, p.31.

155 'Suppressing Sex Crimes', The NZ Truth, 9 February 1924, p.1.

156 'Weeping And Wailing: Degenerate Dissolves In Tears', The NZ Truth, 3 November 1923, p.5. See also: 'Awful Alphonso: Tears Shed In Vain', The NZ Truth, 17 November 1923, p.6 for another article on the same case, in which the accused is dubbed a "sexual degenerate." Also see: 'Degenerate Abnormals: What Treatment? - Perverted Passions and Painful Problems', The NZ Truth, 17 March 1923, p.3 for another case in which an assault by a man on a boy is reported.

${ }^{157}$ The article stated that, "They do not know that psychopaths and sexual hyperaesthetetics often lapse into states of mental and nervous excitement from forced continence, so that their neurosis becomes accentuated and ends in insanity." See: 'Law And The Lash', The NZ Truth, 3 December 1921, p.1.

${ }^{158}$ These men, it is noted, have "proved beyond shadow of a doubt" in their research, "that the pervert is a child of heredity." This comment links understandings of sex and sexuality back to an evolutionary framework approach that acknowledged the role heredity played in such 'perversions' - with the next steps being those eugenic ideas around this heredity factor needing to be eliminated to prevent the continued increase of such sex perverts in society. See 'Law And The Lash', The NZ Truth, 3 December 1921, p.1. See also: 'How We Breed Degenerates: Prolificacy Of Bad Stock - Hereditary Offender To Be "Reformed" For Seven Years', The NZ Truth, 4 October 1924, p.1, for another example of this link between the sexual crime and perversion and heredity. Also see in other issues of the newspaper advertisement for Havelock Ellis' A Study In The Psychology
} 
In a June 1920 article, the case of Whanganui Mayor Charles Ewing Mackay was referenced. Though it did not deny Mackay's guilt in the attempted-murder of Walter D'Arcy Cresswell, it did argue he was privileged in a number of ways (by being educated, and a previously respected citizen) compared to others charged before the courts. The article proposed that "If some weak-minded and uneducated person had pleaded guilty to the same crime as Mackay did, with his homosexual monomania thrown in, the judge would have told him he was a being unfit for human society and expressed no sympathy for his feeble intellect and degenerate character." ${ }^{159}$ Whilst there is much in this article, and case, that is interesting, of note here is the reference to Mackay's "homosexual monomania". According to historian Paul Diamond, Mackay's 1920 court case was the first time 'homosexual' was used publicly in New Zealand. ${ }^{160}$ The way in which The NZ Truth journalist connected this to being feeble-minded and degenerate in this article demonstrates the ways in which forms of male same-sex desire were linked at this point in time both to criminality (literally in the case of Mackay's attempted murder charge), and to notions of mental deficiency and disorder. Effeminacy is something that is explicitly referenced in a number of The NZ Truth articles. Effeminacy was much more of a concern to The NZ Truth than sodomy (judging by the number of articles alone. $)^{161}$ From a defence W. P. Rollings in a July 1928 article where it

Of Sex, for example: 'Books By Post', The NZ Truth, 19 April 1924, p.4; and 'Books By Post', The NZ Truth, 25 April 1925, p.4. And also those that advertised Marie Stopes' book, Married Love, see: 'Books By Post', The NZ Truth, 16 February 1924, p.4.

159 'Mackay V. Alice Parkinson', The NZ Truth, 12 June 1920, p.3. Mackay’s sentence was to 15 years hard labour, but what the article writer wanted to point out was that, compared to Parkinson who was sentenced to life, the judge, "expressed the opinion that in a few years' time the Prison Board would review the sentence."

${ }^{160}$ For more information about Charles Mackay see: 'The curious case of Charles Mackay', RNZ, www.rnz.co.nz; accessed 21 July 2020; 'Paul Diamond: murder and the mayor', RNZ, www.rnz.co.nz; accessed 21 July 2020; and Michael King, The Penguin History of New Zealand (Auckland: Penguin Books, 2003). ${ }^{161}$ Sodomy appeared only in three of the search results for the 1918-1930 period on Papers Past. For example, in an article on the "coddling of convicts", in which "The Practice of Sodomy" which was once "lightly regarded" in ancient Rome and Greece is now considered amongst, the article reported, "The crimes which disgust us most." ('Crime And The Criminal: Arthur Moffett Poynton, S.M., On Pentology', The NZ Truth, 15 December 1923, p.5). Then it was also referenced in a May 1925 article that stated that, "In the opinion of some members of the legal profession there was not on the records of the country a divorce on the grounds of sodomy till last week" ('Simmonds' Sordid Sin: Crime And Divorce', The NZ Truth, 30 May 1925, p.9). The article also wrote that, "The respondent was a man notorious for revolting sexuality, and is at present serving a life sentence for unnatural offences on boys." In a September 1930 article it was announced that, "No opinion can be expressed in this column as to the effects of sodomy in those who participate in it", because they said, "It is a crime whatever the age of the criminal." ('Brief Replies To Correspondents', The NZ Truth, 18 September 1930, p.20). For other articles from The NZ Truth that referenced effeminacy, see: 'Law and Music', The NZ Truth, 4 August 1927, p.6, where it is noted that, "people who usually associate a musician with slim, effeminate hands"; 'Jungle Thrills', The NZ Truth, 2 August 1928, p.6, "For "Julie", despite the effeminate tinge to his cognomen, is just about one of the most popular men who have ever donned an Old Boy's jersey in Christchurch"; "An Optimist', The NZ Truth, 9 February 1928, p.6, where the "purring" voice of Walter J. Watson, optician and jeweller is noted as, "not an effeminate pussy cat's purr"; 'The Soldier's Vote: The Why And The Wherefore', The NZ Truth, 17 May 1919, p.4, where it was noted that the "effeminate effusions" of prohibitionists had not effect on the vote or "fighting manhood of God's Own"; "Wilful Wanton Waste: Deplorable Destruction By The 
is noted that, "There is nothing effeminate about this clever young lawyer"; 162 to the opinion of a woman that, "Cigarettes... are rather effeminate"; ${ }^{163}$ to the more serious cases such as that of a young Māori boy George Grace, who was, "charged with being idle and disorderly," amongst other things. ${ }^{164}$ Grace was described as being "very effeminate in nature, but not sufficiently queer to warrant a medical examination," and it was concluded that following a medical examination, "Grace was perfectly sane, but of an effeminate nature."165 The repeated comment on Grace's effeminacy is interesting to consider, particularly given the fact that he was Māori; ${ }^{166}$ and the way in which his punishment is described is also telling of how this kind of masculinity, or rather, lack-thereof, was viewed. It was reported that, "No doubt his sojourn in gaol will instil in him a little manliness." 167 In a similar case the "effeminate" Stanley Griffiths ${ }^{168}$ was said to have taken on "feminine habits" and to have dressed as a woman - in particular it was said that he wore women's "suede gloves" and "dainty lingerie" beneath his "masculine garbs" - deceiving the Hando family, and the young man of the family, Charles Hando, into believing he was a woman and hiring him as a cook. ${ }^{169}$ Police became involved in this affair due to the perceived deception of Griffiths on the Hando family, and what makes the whole thing even more salacious for the newspaper's readers, was the fact that there was a potential relationship between Griffiths and the son, Charles. ${ }^{170}$

Defence Department', The NZ Truth, 28 February 1920, p.5, the “effeminate English spoken by the modern Briton" is referenced; "Insulting Advice: Clothing Manufacturer Writes Disgusting Note To Woman Applicant For Employment', The NZ Truth, 20 December 1928, p.7, the message was said to have been written, "in a wavering, effeminate hand"; 'The Deadhead's Diary', The NZ Truth, 11 November 1922, p.11, in regards to an actor who plays, "the "silly ass" type, which has been depicted mostly as an "effeminate" caricature of a man"; 'Threat Of Lynch Law At Blenheim Made Osgood Surrender His Bail', The NZ Truth, 30 May 1929, p.7, in which it is claimed that in the Denniston district, "There are no effeminate individuals"; 'The Deadhead's Diary', The NZ Truth, 10 August 1918, p.2, where a film that depicts, "a financial fight between the effete East and the vigorous West" is referenced; and 'Left-Handedness', The NZ Truth, 21 July 1923, p.1, where it is noted that left-handedness, "denotes an abnormal sex balance", and that left-handed men this means, "more or less effeminateness and in a woman more or less masculinity".

162 'Knows His Subject', The NZ Truth, 12 July 1928, p.6.

163 'Jottings About Town: Fair Fabians', The NZ Truth, 3 January 1929, p.15.

164 'The Glad Eye: George Was A Perfect Young Lady', The NZ Truth, 19 April 1928, p.5. The other charges were, "of stealing dresses and a signet ring at Tangoio."

165 Ibid.

${ }^{166}$ See also a similar case: 'Man With Female Mentality: Young Maori Posed As Woman And Worked As Housemaid - Masquerader Unmasked In Court', The NZ Truth, 9 May 1929, p.2. In this article, Nikora Hune Haora, is described as, "A human freak, a psychological enigma," so "obsessed" with being a woman that he, "assumed female attire, acquired habits of speech and manner alien to man and posed before the world - and successfully - as a woman", until this instance in the Auckland court.

167 'The Glad Eye: George Was A Perfect Young Lady', The NZ Truth, 19 April 1928, p.5.

168 'Station Tragedy: He Wore Lingerie Beneath Masculine Garments - Strange Love Affair', The NZ Truth, 19 April 1928, p.5.

169 Ibid.

${ }^{170}$ See reference to this ordeal also in: 'His Infatuation For Youth: Young Farmer Made To Think That Male Cook Is Really A Girl - Police Discover Extraordinary Letters', The NZ Truth, 19 January 1928, p.5. 
Masculinity and how it should exist was the subject of a number of articles in The NZ Truth. For example, in an article subtitled, 'What A Woman Has Observed For Christmastide [sic.]", the woman in question wrote, "I like the men of my country. They are fine fellows"; elsewhere stating that, "if you want to get the model of how men should look, pay a visit to Palmerston North when a high-toned play is in season", as she argues that, "From the shine of their shoes to the gloss of their hair, they are [Palmerstonians] Just It in well turned out masculinity." 171 This article thus depicts acceptable masculinity and manhood as exemplified by the men of Palmerston North. An article from August the following year was more cautious in its examination of New Zealand's men and boys though. It argued that "The arrival of the New Woman has done more damage to our growing youth than all the tantrums of the Old Woman", as they suggest that, "On every hand there is evidence of the growing masculinity of girls and the feminising of boys." 172 The article also remarked that: "Women teachers are accused of being the initial cause of this weakening of the male character," 173 playing into the concerns both around the Modern Woman and the next generation of men being raised by them, as seen in other popular culture publications that critiqued motherhood and women in the era of the Lost Generation and absent father.

Health and Physical Culture published a number of articles that dealt with topics relating to sex, sexuality, marriage, and masculinity. Articles that addressed marriage in $H \& P C$, included those like: 'The Secret Sin of Marriage';174 'Are Cousin Marriages Wrong?';175 'Marriage or Wedlock'; 176 'What Marriage Will Mean in the Future'; ${ }^{177}$ 'True Facts About Companionate Marriage'; 178 'The Marriage Trap'; 179 'The Truth About the Movie Divorce Mania'; 180 'Marriage Spells Failure';181 “"Young Marrieds Are Fools - But

\footnotetext{
171 'Adonis And His Clothes: New Zealand Quizzed - What A Woman Has Observed For Christmastide', The NZ Truth, 27 December 1924, p.12.

172 ‘Are Boys More Ladylike?', The NZ Truth, 8 August 1925, p.3.

${ }^{173}$ Ibid,. And that on the flipside, "the popularity of manly sports among young girls is blamed for their increasing masculinity".

174 'The Secret Sin of Marriage', Health and Physical Culture, Vol.3, No.1, January 1931, p.8.

175 ‘Are Cousin Marriages Wrong?', Health and Physical Culture, Vol.3, No.9, September 1931, page number obscured.

${ }^{176}$ V. May Cottrell, 'Marriage or Wedlock', Health and Physical Culture, Vol.2, No.9, September 1930, p.17. 177 'What Marriage Will Mean in the Future', Health and Physical Culture, Vol.3, No.5, May 1931, p.16.

${ }_{178}$ Ben Lindsey, 'True Facts About Companionate Marriage', Health and Physical Culture, Vol.3, No.5, May 1931, p.18.

179 'The Marriage Trap', Health and Physical Culture, Vol.3, No.12, December 1931, p.43.

${ }^{180}$ Noel Howarth, 'The Truth About the Movie Divorce Mania', Health and Physical Culture, Vol.5, No.9, September 1933, p.8.

${ }^{181}$ Bernard Hollander, 'Marriage Spells Failure', Health and Physical Culture, Vol.5, No.11, November 1933, p.45.
} 
Brave Fools”; 182 'Twenty Questions To Ask Your Fiance', by “A Psychologist”; 183 'When Marriage Crashes'; ${ }^{184}$ 'What's Wrong with Modern Marriage?'; 185 and 'Is It Possible to be Happily Married?'. ${ }^{186}$ Some articles were addressed to the female readers and subscribers to the magazine, such as those like, 'Are You A Cheating Wife'. ${ }^{187}$ Others confronted anxieties around mixed-race relations and marriages, such as the articles 'The Lure of the Coloured Husband'; ${ }^{188}$ and 'Can Racial Prejudice Be Killed By Inter-Marriage?';189 and in Will Lawson's 'How They Keep Fit in the Far East', it is commented that though the "“"mesteso" or half-caste" children that resulted from intermarriage were "often a better man physically and mentally", even in the East intermarriages were not encouraged. ${ }^{190}$ There was also a recurring feature where magazine subscribers would write-in to describe their ideal partner, titled 'What Is Your Ideal Boy, or Girl?' 191 These articles illuminate the reassertion of heterosexuality that was pushed in the interwar period, as anxieties around populations grew. They also demonstrate that heterosexual marriage and sex, like same-sex desires and actions, could be deemed unhealthy, and that they also needed to be controlled.

Health and Physical Culture printed several articles that directly addressed the theme of masculinity. For example those like, 'I Found My Manhood When I Lost My Girl';192 and the article in the March 1938 issue that asserted that, 'Male Ballet Dancers Are Not "Cissy". ${ }^{193}$ Other examples include the advertisement for "The Book of Life", which included "valuable information" on, "The Priceless Gift of Manhood", amongst other things; ${ }^{194}$ and articles like Francis Kelly’s description of 'The Most Perfect Man'; 195

\footnotetext{
${ }^{182}$ Owen Prentice, “'Young Marrieds Are Fools - But Brave Fools”, Health and Physical Culture, Vol.8, No.8, August 1936, p.20.

183 'Twenty Questions To Ask Your Fiance', Health and Physical Culture, Vol. 8, No.12, December 1936, p.18.

${ }^{184}$ Bertrand Russell, 'When Marriage Crashes', Health and Physical Culture, Vol.9, No.3, March 1937, p.47.

185 Valeria, Lady Brougham, and Vaux, 'What's Wrong with Modern Marriage?', Health and Physical Culture, Vol.9, No.4, April 1937, p.30.

${ }^{186}$ Ellaline Terris, 'Is It Possible to be Happily Married?', Health and Physical Culture, Vol.9, No.6, June 1937, p.25.

187 'Are You A Cheating Wife', Health and Physical Culture, Vol.1, No.7, November 1919, p.16.

188 'The Lure of the Coloured Husband', Health and Physical Culture, Vol.4, No.8, August 1932, p.14.

189 'Can Racial Prejudice Be Killed By Inter-Marriage?', Health and Physical Culture, Vol.10, No.8, August 1938, p.28.

${ }^{190}$ Will Lawson, 'How They Keep Fit in the Far East', Health and Physical Culture, Vol.1, No.6, June 1929, p.8.

${ }^{191}$ For example, see the feature in: 'What Is Your Ideal Boy, or Girl?', Health and Physical Culture, Vol.5, No.11, November 1933, p.41; or 'What Is Your Ideal Boy, or Girl?', Health and Physical Culture, Vol.7, No.1, January 1934, p.45.

192 'I Found My Manhood When I Lost My Girl', Health and Physical Culture, Vol.2, No.4, April 1930, p.7

193 'Male Ballet Dancers Are Not "Cissy", Health and Physical Culture, Vol.10, No.3, March 1938. p.36.

194 “"At Last! "The Book of Life” now ready for YOU to read!”, Health and Physical Culture, Vol.6, No.11, November 1935, p.8.

${ }^{195}$ Francis Kelly, 'The Most Perfect Man', Health and Physical Culture, Vol.6, No.4, April 1935, p.9.
} 
'Insurance Companies Pick the Ideal Man',196 'Why Not Carry Yourself Like a Man?', by Hal Roughley; ${ }^{197}$ and an article which displayed, 'Some of Our Male Readers' by showing pictures they had sent into the magazine. ${ }^{198}$

In the article 'The Mighty Atom: How to rear our Sons', the influence of the father on their sons was noted. ${ }^{199}$ This reflected the views that the absence of a father in a boy's life would lead to a failed progression from childhood to adulthood, and the boy was more likely to become effeminate (with the influence of his mother), and decidedly un-masculine. This notion is also seen in the February 1930 article, 'Present-Day Problems: The Menace of the Unmarried Mother', written by Christine Barrington. ${ }^{200}$ In this article Barrington doubts that society will ever accept unmarried women raising children on their own; stating that even under the circumstances where "we could live in a state of international peace and refrain from the wholesale slaughter of the best of our manhood," meaning that there would be a more even proportion of men to women in society than there was in the post-war period, that even then these women would still not be accepted. ${ }^{201}$ Barrington argued that the reason behind this fact was that "Science has proved that the absence of a father in the life of a child has [deterious] effects on the psychology of a child," and that, "So far no substitute has been found for a father whose influence has such an important bearing on the happy home life which every child needs for its normal development."202

A number of articles in $H \& P C$ also related to the increased interest in the field of sexology and sex education. For example in articles such as the December 1930 piece by Marion Piddington titled, 'The New Method of Sex Training';203 'Masochism and Sadism', by Mostyn Hume Wade; ${ }^{204}$ and in advertisements like those for books to order such as: 'Naked and Unashamed' by William Welby; 'Contraception, Birth Control: Its Theory, History and Practice', by Dr. Marie C. Stopes; 'The Mastery of Sex', by Leslie Weatherhead;

\footnotetext{
${ }^{196}$ Stephen Grimm, 'Insurance Companies Pick the Ideal Man', Health and Physical Culture, Vol.6, No.9, September 1935, p.38.

${ }^{197}$ Hal Roughley, 'Why Not Carry Yourself Like a Man?', Health and Physical Culture, Vol. 8,No.11, November 1936, p.16.

198 'Some of Our Male Readers', Health and Physical Culture, Vol.9, No.7, July 1937, p.34.

${ }^{199}$ MATRON, 'The Mighty Atom: How to Rear Our Sons', Health and Physical Culture, Vol.1, No.6, June 1929, p. 18.

${ }^{200}$ Christine Barrington, 'Present-Day Problems: The Menace of the Unmarried Mother', Health and Physical Culture, Vol.2, No.2, February 1930, pp.28, 46.

${ }^{201}$ Barrington, p.28.

202 Barrington, p.46.

${ }^{203}$ Marion Piddington, 'The New Method of Sex Training', Health and Physical Culture, Vol.2, No.12, December 1930, p.41.

${ }^{204}$ Mostyn Hume Wade, 'Masochism and Sadism', Health and Physical Culture, Vol.2, No.9, September 1930, p.7.
} 
and 'The Sex Factor in Marriage' by Helena Wright. ${ }^{205} H \& P C$ 's position on such subjects appears to have leant towards the more liberal-minded, sexually modern and open. Contributors saw the potential benefits in birth control and education, sex outside of marriage, the involvement of fathers in the rearing of their children, and in pursuing the pleasures of bodily health and fitness. Whilst the magazine largely promoted a masculinity that was uber-heterosexual in nature, it also existed as a space full of homoerotic potential in its discussions and illustrations of muscular, body-conscious men.

In an article titled 'It Beats Me!', Trevor G. Bain also addressed masculinity in relation to his attack on Capitalism and capitalists. ${ }^{206}$ Bain wrote of his disdain that, "Strong, virile samples of mankind, gifted with intelligence are forced almost literally to kneel at the feet of pot-bellied, dyspeptic, bloated capitalists." His disdain was so strong that even though he acknowledged that in writing this article he decreased his chances of "capitalistic assistance" in the publishing of $H \& S$, he cared more to argue against the negative affects "Mr. Money-bags" was having on the virility on the nation. ${ }^{207}$

Articles published in The Monocle also included references to masculinity, and desire(s). For example, in a piece by M. M. Pearson she describes how her interests were piqued when she saw that "a magazine of masculine interests was shortly to see the light of day." 208 In the article she also questioned "What... these men consist of?", concluding, "A lot of blarney, a pair of plus-fours, a spot or two of beer, an aura of smoke... and a tremendous capacity for being admired." "That", she said, "is civilised man," but she wanted to know about "the genuine article" - which later on in the piece she studies at a wrestling match. ${ }^{209}$ This article is interesting given that it purports to come from a woman's perspective - in what was initially, as she describes, a men's interests publication (which could be seen as reinforcing the heterosexual nature of the publication) - and as it talks of both the "civilised" man as well as the less refined, "jeering savage" type who attended the wrestling match. ${ }^{210}$ The same issue, the first in the magazine's publication, printed a piece on driving that

\footnotetext{
205 “'LIMITED STOCKS Place Your Order Now for these EXCEPTIONAL BOOKS! The World's Finest Course in BODY CULTURE, etc."', Health and Physical Culture, Vol.6, No.11, November 1935, p.57.

${ }^{206}$ Trevor G. Bain, 'It Beats Me!', Health and Sunshine, Vol.1, No.4, February 1937, p.42.

${ }^{207}$ Ibid.

${ }^{208}$ M. M. Pearson, 'Wrestling through a Woman's Eyes', The Monocle, Vol.1, No.1, May 1937, p.40.

${ }^{209}$ Ibid.

${ }^{210}$ Ibid.
} 
claimed you could learn "a man's character" through watching him drive; ${ }^{211}$ as well as an article that directly addressed the fear of effeminacy. ${ }^{212}$

Other examples of references to these topics include pieces such as 'Heroes are Like That!' which told the story of a man who stepped in to fly a plane to safety when the pilot was discovered to be a drugged up young boy. ${ }^{213}$ As well as 'Just Men To Me', by "TITANYA". They described the different ways leaders like Adolf Hitler, Kemal Pasha, Primo de Rivera, and Benito Mussolini portrayed their own power and masculinity, and how the author - who had met them - liked to view them as "just men whom [their] wanderings around the world have permitted [them] to meet." ${ }^{214}$ The May 1938 issue included an article titled 'Head-Hunting In Southland', by Frank Robson, in which he described the ways in which the men of Invercargill, "although apparently completely civilised and cultured," would become "primitive" when hunting in the wilderness of Southland. ${ }^{215}$ In describing this display of masculine behaviour as primitive, Robson, whilst demonstrating evolutionary framework views, also pointed to the "instinct" within these New Zealand men who carried on with the way of their "forebears", thus admiring their exhibition of the kind of mountainclimbing, hunting masculine ideal that those like Phillips have outlined. ${ }^{216}$

In 'Women Prefer Blondes', written by Frederick Griffin for the June 1937 issue of The Monocle, the masculine wiles of Mr. Ted Peckham from the "Guide Escort Bureau" are described. ${ }^{217}$ Griffin outlines the work Peckham does as a "guide or gigolo" for young women who pay him to take them out "to dine", ${ }^{218}$ with the work of Peckham and his men being of interest here in their display of a different kind of socially, and sexually, confident masculinity. This story also had the potential to act as a warning from the magazine to New Zealand men to hurry up and overcome their supposed inadequacies to find a woman.

\footnotetext{
211 'Through The Windscreen', The Monocle, Vol.1, No.1, May 1937, p.41.

212 This was the first of the 'Gallants in Embryo' articles, which will be discussed in full later in this chapter. Harrison Ford, 'Gallants in Embryo', The Monocle, Vol.1, No.1, May 1937, pp.43-44.

${ }^{213}$ J. H. Mosher, 'Heroes are Like That!', The Monocle, Vol.1, No,4, August 1937, pp.10-11.

214 “TITANYA”, 'Just Men To Me', The Monocle, Vol.1, No.5, October 1937, pp.27, 45.

215 Frank Robson, 'Head-Hunting In Southland', The Monocle, Vol.2, No.1, May 1938, p.16.

${ }^{216}$ Jock Phillips, A Man's Country? The Image Of The Pakeha Male - A History (Auckland: Penguin Books, 1996).

${ }^{217}$ Frederick Griffin, 'Women Prefer Blondes', The Monocle, Vol.1, No.2, June 1937, pp.3-6.

${ }^{218}$ Griffin, p.3.
} 


\section{MIND AND BODY}

The focus on the mind and body in popular culture publications of the interwar period in New Zealand had much overlap with discussions around nudism and fashion. The healthy mind and healthy body ideology is most prominent in relation to fashion and the bodily expression of state of mind, self-perception, and fitness in the articles this thesis examined in The NZ Truth. In several articles, the clothes worn by men, and their physical presentation, were linked to notions of masculinity and effeminacy as well as to psychology. For example, in a piece titled 'Bronzed Heroes: Cosmetic Frauds - Rouged Effeminacy of Men', it is noted that: "In Paris there is quite a business in the provision of lipsticks and face powder for men", which not only, "artificially aim[s] at creating an effeminate complexion. It also counterfeits with shameful success the bronzed complexion of the outdoor man." ${ }^{219}$ A remark that would have piqued the interest of New Zealand readers as they were 'outdoor men'. The article was designed to be provocative to readers, and to make them feel good in comparison to the 'queer' lifestyle of Parisians. In another article, the "latest craze of the tight-fitting jacket for men" is described, and according to the writer of the article, it is noted that, "This style is decidedly effeminate." 220

Much of what Health and Physical Culture published - with its interest in physical culture, and also mental hygiene and psychology - can be summed up by the phrase 'Mens Sana in Corpore Sano', i.e. a healthy mind depends upon a healthy body. This expression, which the magazine itself called upon in an editorial piece on 'The Power of Thought', ${ }^{221}$ is one whose sentiment echoed throughout not only $H \& P C$, but the other publications this chapter discusses. The notion of the mind being linked to the body is also one that connects much of the psychological, eugenic, and sexuality-based content this chapter (and thesis at large) also examines; and by nature of $H \& P C$ it appears in many of the issues of the magazine published between 1929-1939. It is also something that can be seen in the magazine's creed, in which it is stated that: "We Believe - That to maintain a healthy mind in a healthy body is the duty of every man and woman, and that any interfering influence is a menace to be eliminated." 222

\footnotetext{
219 'Bronzed Heroes: Cosmetic Frauds - Rouged Effeminacy of Men', The NZ Truth, 5 July 1925, p.5.

220 'The Ladies' Chain: Facts and Fiction for Femininity', The NZ Truth, 7 July 1923, p.14.

221 'A Common-Sense Editorial: The Power of Thought', Health and Physical Culture, Vol.5, No.6, June 1933, p.3. This editorial also stated the belief of the Editor that, "Without health - strong, virile, and active physical health - no mind can function to the fullness of its possibilities", and that it is "every man's duty" to urgently address his health, for a better future.

222 'Our Creed', Health and Physical Culture, Vol.1, No.7, July 1929, page number obscured.
} 
Examples of this linkage - of the importance of the mind and body - can be seen in articles such as Frederic Slater's ‘The Making of Men’ series. In the May 1929 issue of $H \& P C$ Slater expresses his admiration for firemen, saying that their training, "makes for him [the fireman] the best type of bodily development and mental alertness", even saying that because of this, "He is the pattern of manhood in the community". ${ }^{223}$ Slater goes on to describe the fact that many are beginning to realise that physical fitness, as well as the development of the mind, play a vital role in the "preservation of normal health" within professional men. ${ }^{224}$ In the following month's issue of the magazine, Slater wrote another instalment, this time discussing those men who work in the police force. ${ }^{225} \mathrm{He}$ praises policemen working in Great Britain and the Dominions, calling them "a tower of strength and mental alertness", stating that without them, "there would be chaos." 226 The mind and body sentiment is also present in the August 1929 article, 'Personality Through Muscular Development: A Psychological Discourse On Mental and Physical Harmony'. ${ }^{227}$ In this article W. R. Jamieson writes that whilst "Many people have an idea that physical culture consists only of using a pair of dumb-bells, or an elastic muscle developer. This is not so". In fact, "The development and maintenance of bodily health is only entirely successful when the mental processes are employed at the same time." 228 What is important here is the notion that both the physical and mental lie at the core of what physical culture is. Jamieson goes on to state that, by training the mind "in conjunction with physical exercise," one thus achieves "the harmonious toning up of the two sides of man - the mental and the corporeal." 229 The importance of physical culture (and the mind) can also be seen in articles such as, 'Berlin's Physical Culture University', by Dr. Seelos; ${ }^{230}$ 'How Your Body Works', by “Doctor X”;231 'The Great Harm Worry Does to Your Body', by Stanley Nelson;,232 'Men's “Body Beautiful” Page';233 and 'Bodily Fitness Killed My Nervous Fears', by Pamela Mason. ${ }^{234}$

\footnotetext{
${ }^{223}$ Frederic Slater, 'The Making of Men', Health and Physical Culture, Vol.1, No.5, May 1929, p.22.

${ }^{224}$ Frederic Slater, 'The Making of Men', Health and Physical Culture, Vol.1, No.5, May 1929, p.24.

${ }^{225}$ Frederic Slater, 'The Making of Men', Health and Physical Culture, Vol.1, No.6, June 1929, pp.34-38.

${ }^{226}$ Frederic Slater, 'The Making of Men', Health and Physical Culture, Vol.1, No.6, June 1929, p.34.

${ }^{227}$ W. R. Jamieson, 'Personality Through Muscular Development: A Psychological Discourse on Mental and Physical Harmony', Health and Physical Culture, Vol.1, No.8, August 1929, pp.28, 35.

228 Jamieson, p.28.

229 Ibid.

${ }^{230}$ Dr. Seelos, 'Berlin's Physical Culture University', Health and Physical Culture, Vol.3, No.12, December 1931, p.22.

231 "Doctor X", 'How Your Body Works', Health and Physical Culture, Vol,6, No.2, February 1935, p.6.

${ }^{232}$ Stanley Nelson, 'The Great Harm Worry Does to Your Body', Health and Physical Culture, Vol.8, No.9, September 1936, p.12.

233 'Men's "Body Beautiful” Page', Health and Physical Culture, Vol.9, No.8, August 1937, p.36.

${ }^{234}$ Pamela Mason, 'Bodily Fitness Killed My Nervous Fears', Health and Physical Culture, Vol.9, No.12, December 1937, p.32.
} 
The Monocle also demonstrated an understanding an application of the mind plus body theory in articles it published such as 'Posture and Health', by "Medicus". Published in the December 1937 issue, it promoted proper posture not only for the general population, but also for the potential recruits of the N.Z. Territorial Reserve. ${ }^{235}$ The correction of bad posture was also said to be to the benefit of "restless, nervous energy" that can distract children in the classroom, and consequently detracts from their ability to mentally improve themselves too. ${ }^{236}$

\section{THE CLOTHED MAN AND THE NAKED MAN}

The commercial print publications, particularly the magazines, that this chapter discusses were illustrated mediums. The potential for a queer reading of the illustrations and images in these sources is important, and presents an opportunity that the medical sources from chapter two could not. Chris Brickell, though discussing the nineteenth century, concluded that "in the absence of a rich language of naming" in historical sources, "visual material provides us with some valuable clues to erotic self-understanding." 237 This thesis takes this assertion to also apply to the interwar years in New Zealand, as a period in which language around sexuality, sex, and gender was continuing to evolve and take on psychological and eugenic tints. Claire Gooder has also advocated for the inclusion of the visual in studies of sexeducation literature due to their capacity to provide "valuable insights into sexual knowledge in historical contexts." 238 Whilst the primary focus of these commercial magazines was not sex-education, they did provide a place in which ordinary New Zealanders could learn about topics surrounding sex and sexuality (such as birth control, marriage, pleasure, and the body). They also presented visual a record of the people's bodies - men's bodies - and the fears around masculinity in interwar New Zealand. Whilst this thesis does not fully engage with the visual aspects of these magazines, it does acknowledge their potential for readings of masculinity and worries around effeminacy and weakness. It also recognises the appeal these images and illustrations had for the readers of these publications, adding to their capacity to

\footnotetext{
235 “Medicus", 'Posture and Health', The Monocle, Vol.1, No.7, December 1937, p.58.

236 "Medicus", 'Posture and Health', p.72.

${ }^{237}$ Chris Brickell, 'Visualizing Homoeroticism: The Photographs of Robert Gant, 1887-1892', Visual Anthropology, Vol.23, No.2, February 2010, p.136.

${ }^{238}$ Claire Gooder, 'To Know the Facts': The New Zealand Health Department's Sex Education Pamphlets, 1955-1983', New Zealand Journal of History, Vol.50, No.1, April 2016, p.109.
} 
exist as the literal physical embodiments of heterosexual assertions, and homosexual and homosocial anxieties.

More explicit concerns around the increasingly popular nudist movement, and the way in which men demonstrated their masculinity and sexuality through fashion and clothing were also present in the commercial print sources. In The NZ Truth a June 1925 article reported on the 'Dress Sins of the "Cissy" Boy', and noted that criticisms of "the effeminacy of a large proportion of the giddy male youth" of Christchurch - who were dressing in "Gaily-coloured" hats - "might as well be applied to some of the young "birds" of Auckland" too. ${ }^{239}$ In a number of articles it was noted that "Effete males ... dress to a color [sic.] scheme",240 and one article describes, "A tall, aesthetic person on one of the most important dress magazines", who is reported to have told the writer, amongst other things, "that the youthful figure of the modern male is to be made more distinctive than ever, and that lapels are one of the means to that end." 241

The dandy, fop, and aesthete are also mentioned in several articles of The NZ Truth, with a particular focus on the fashion. For example, in a March 1923 issue which, in reference to whether you can tell the character of a person through their feet, stated that, "You will notice the nervous, highly strung person, continually jerking his feet," and, "the over dressed foppish youth with feet much too small practically wearing women's boots"; 242 or in the review of the new movie about "the famous fop" Beau Brummel, who is played by John Barrymore in a way that, "fits right into the popular conception of the English dandy." 243 In a June 1925 article titled, 'The Dandy's Toilet', it is reported that, "West End hairdressers declared that every month there is an increasing number of men patrons for permanent waves"; 244 and in the April 1929 report on Parisian fashions is, "A tall, aesthetic person on one of the most important dress magazines" who told the piece's writer of changes

\footnotetext{
239 'Dress Sins of The "Cissy" Boy: Brainless Youth Would Emulate The Peacock', The NZ Truth, 20 June 1925, p.3. In this case it was written that it was understood that, "all this foppery is intended to attract the opposite sex", though not with much luck as, "Up to date the girlies merely giggle at it".

${ }^{240}$ For example, see: 'Pet Aversion', The NZ Truth, 14 February 1925, p.5; and also 'Evolving New Ideas: Eve Strikes Original Note In Evening Wear', The NZ Truth, 17 October 1929, p.20, where it was noted that, "One very effete gentleman has a different color for each day!"

241 'Parisian Fashion Parade: English Debutantes Choose Their Frocks For Occasion - Picturesque Blends With Chic', The NZ Truth, 26 April 1929, p.10.

242 'The Ladies' Chain: Facts and Fiction For Femininity', The NZ Truth, 3 March 1923, p.14. This close description of the nervous and the foppish, effeminate, youth, is interesting to note (though the article does also go on to describe the golfer, and the dancing girl too).

243 'The Deadhead's Diary', The NZ Truth, 20 September 1924, p.15.

244 'The Dandy's Toilet', The NZ Truth, 20 June 1925, p.8.
} 
to modern male's fashion. ${ }^{245}$ It was also noted in an July 1920 article that, "That species of masculinity commonly known as the knut (a word that has superseded "dandy") is having a hard struggle these days to garb his person in clothes befitting his delicate tastes," as prices of clothing continue to increase. ${ }^{246}$

A series of articles also appeared to discuss men who were cross-dressers, or who had been living as women. For example, in the May 1918 article about Julian Eltinge, the American actor and female impersonator, which stated that when he first arrived at the Paramount studios: "there was a howl of derision when it was discovered that no less than three car loads of trunks holding his wardrobe," of both his, "feminine fripperies and men's tailor-made clothes." 247 On a darker note, several articles detailed the cases of "pseudomaiden[s]"248 - i.e., men found-out to be dressing and living as women. These articles include that of the case of George Grace, ${ }^{249}$ and those relating to Stanley Griffiths who was said to be a man pretending to be a woman, working as a cook for the Hando family. ${ }^{250}$ Carl Hertzig outlined similar concerns in his 1932 article to the ones these articles from The NZ Truth present. Men who dressed as women were seen as 'effeminate', and were thus a problem society needed to deal with. ${ }^{251}$

For followers of the nudist movement in New Zealand, the achievement of a healthy and fit mind came hand-in-hand with the expression of a healthy and fit body. This is evidenced in the article 'Is Nudism Neurotic?', which addressed the role of sex with neuroses, and also the ways in which the repression of sex in society is backwards and causing emotional issues. It proposed that education around nudism - and all that "to do with the creation of new life" as being "pure, sacred, and beautiful" - was the best way to remove shame, and potential neuroses, from society. Therefore creating "a community composed of [such] healthy-minded citizens" in which, "the unhealthy mind will be scorned and the unhealthy body will scare exist." Once this stage is reached, the author Oliver Olver argued,

\footnotetext{
245 'Parisian Fashion Parade: English Debutantes Choose Their Frocks For Occasion', The NZ Truth, 26 April 1929, p.10.

246 'Going Up: Prices And Profits', The NZ Truth, 10 July 1920, p.1.

247 'The Deadhead's Diary', The NZ Truth, 4 May 1918, p.2.

248 'The Glad Eye: George Was a Perfect Young Lady', The NZ Truth, 19 April 1928, p.5.

${ }^{249}$ Ibid.

${ }^{250}$ See: 'Station Tragedy: He Wore Lingerie Beneath Masculine Garments - Strange Love Affair', The NZ Truth, 19 April 1928, p.5, in this case the focus of the headline is even on the gendered clothing of Stanley Griffiths (i.e. this is what the article's writer and the tabloid's editor thought would draw readers in to the story); and also 'His Infatuation For Youth: Young Farmer Made To Think That Male Cook Is Really A Girl', The NZ Truth, 19 January 1928, p.5.

${ }^{251}$ Carl Hertzig, 'The Menace of Effeminacy', Health and Physical Culture Vol.4, No.1, January 1932, p.40.
} 
"Then shall we indeed be able to boast of our advanced civilisation." 252 Other articles that tackled nudism include those such as 'The Sanity of the Nude', by G. W. R. Southern;253 “"How Nudism Saved My Life” by “A Doctor's Wife","254 'Let's O.K. Sane, But SemiNudism', by Hector Poole; ${ }^{255}$ and 'Why Is Society Going Nude', by Janet Geraldton. ${ }^{256}$ Nudism was advocated on the basis of various reasons: in allowing the body access to sunshine; freedom from the constrictions of clothes; the acceptance of, and the release from shame around the body and bodies, whether naked or not.

Another aspect of physical culture, and the way this played into both the perceived psychology and understanding of men and women during the interwar years, was fashion. The way in which fashion could be understood as a physical display of mental fitness and alertness, and a desire to demonstrate masculinity (or femininity), and also a way to 'show off' one's worked-on physique, is something that came up in several $H \& P C$ articles. This fashion-focus can be seen in the magazine in places such as the 'Fashion Page and Patterns Service'; ${ }^{257}$ and articles such as, 'Slacks! Why Not?’, by Pennington Beales,; 258 “"H.P.C.” Fashion Column'; ${ }^{259}$ and 'How Should We Dress', by “M.D.”260

Interest in and discussions of nudism graced many of the pages of Health and Sunshine. Trevor G. Bain, the magazine's founder, was a noted advocate of the nudist movement. In the November 1936 issue of $H \& S$, the first article is titled 'Nudism- Is It Desirable?', in which Bain collates comments from magazine subscribers. ${ }^{261}$ The February 1937 issue also demonstrates this passion for nudity and nudism - the front cover displays a bare-breasted woman, with the caption "A FREE GIFT TO OUR READERS"; ${ }^{262}$ and within the magazine there were four double-sided insert pages of images, which included two pages of nude women, and one page full of nude/nearly nude men posing. Though this may have

\footnotetext{
${ }^{252}$ Olver, p.50.

${ }^{253}$ G. W. R. Southern, 'The Sanity of the Nude', Health and Physical Culture, Vol.3, No.5, May 1931, p.5. 254 “A Doctor's Wife”, 'How Nudism Saved My Life', Health and Physical Culture, Vol.5, No.9, September 1933, p.41.

${ }^{255}$ Hector Poole, 'Let's O.K. Sane, But Semi-Nudism', Health and Physical Culture, Vol.6, No.3, March 1935, p.44.

${ }^{256}$ Janet Geraldton, 'Why Is Society Going Nude', Health and Physical Culture, Vol.6, No.8, August 1935, p.22.

257 'Fashion Page and Patterns Service', Health and Physical Culture, Vol.5, No.2, February 1933, p.47.

258 Pennington Beales, 'Slacks! Why Not?', Health and Physical Culture, Vol.7, No.2, February 1934, p.15.

259 “"H.P.C.” Fashion Column', Health and Physical Culture, Vol.7, No.2, February 1934, p.66.

260 "M.D.”, 'How Should We Dress', Health and Physical Culture, Vol.9, No.9, September 1937, p.30.

${ }^{261}$ Trevor G. Bain, 'Nudism- Is It Desirable?', Health and Sunshine, Vol.1, No.2, November 1936, pp.2, 10. Some of those writing in agree with Bain's views of the benefits of nudism, and his statement that, "A completely nude person is ... a thing of beauty" (p.2); whilst others have more reservations regarding total nudity (pp.2, 10).

${ }^{262}$ Health and Sunshine, Vol.1, No.4, February 1937, front cover. This image and caption is perhaps also a nod to the sexual liberty of such imagery, and lifestyle.
} 
just been a clever marketing ploy to increase sales of the magazine, these nude images presented the potential for both the heterosexual, and homosexual gaze. The publication of a series of images of nude, and partially nude, men in Health and Sunshine demonstrates the physical ideals of manhood the magazine promoted, whilst also leaving room both for heterosexual women to look at the naked male body, and for the potential for the men in the images to be utilised for homoerotic purposes by the male readership of the magazine. ${ }^{263}$ Fashion and clothing was the focus of a recurring feature in The Monocle called 'Gallants in Embryo'. Written and illustrated by Harrison Ford, this column discussed the 'dos and don'ts' of men's fashions, and was printed in the magazine much earlier than the introduction of its women's fashion section. ${ }^{264}$ Whilst centered around fashion, Ford's feature also discussed aspects of masculinity, sexuality, and psychology.

Fashion could be used as a defence against effeminacy, and men's knowledge of how to dress as a man, and in a masculine manner, was vital in this respect. The first 'Gallants in Embryo' column starts off with the following in its address to its readers: "Let's face it! What are our worst faults? Some of us don't care; but there are many gallants in embryo who fear the brand of effeminacy." 265 Ford establishes that this feature will help those men who fear being cast as effeminate; and he outlines how in each article he will separately deal with different items of dress in order to , "give a general guide to fashions." ${ }^{266} \mathrm{He}$ also points out that "The male has always been the more resplendent of the sexes", identifying male animals, such as, "The peacock - the golden pheasant - the lion with his mane," who are more striking than their female counterparts; and he finishes the article by stating, "what more justification could we want" for justifying a male interest in fashion and a consideration of one's appearance. $^{267}$

\footnotetext{
${ }^{263}$ The images mentioned here were from an insert spread of pages in Health and Sunshine, Vol.1, No.4, February 1937, pp.21-28. The insert also included images of fully and partially nude women, as well as scenes of children, and people out in nature.

264 'Gallants in Embryo' appeared in the very first issue of the magazine, in May 1937; whereas the first mention of specifically women's fashion I was able to find in the research of this thesis came a year later, in the May 1938 issue. This, of course, may too just reflect the nature of the magazine starting out as men's magazine, which then later expanded the aims of its readership to be broader and include women readers and subscribers. It is noteworthy that 'gallant' is also a word used to describe men who are both charming and chivalrous towards women, and who are dashing and fashionable; with 'embryo' referring to the fact that this column is targeted those men who are wanting to learn how to be such men.

${ }^{265}$ Harrison Ford, 'Gallants in Embryo', The Monocle, Vol.1, No.1, May 1937, p.43.

${ }^{266}$ Harrison Ford, 'Gallants in Embryo', The Monocle, Vol.1, No.1, May 1937, p.44.

${ }^{267}$ Ibid. Ford even actually remarks that those who are seeking justification in the first place are "weak" in needing this reassurance. Here Ford thus demarcates the kind of interest in fashion that he writes about, and prescribes to, not as something that makes one effeminate, rather as that which will aid in making a masculine man even more so.
} 
Other instalments of 'Gallants in Embryo' note the particular ways in which clothing items were masculine, or would make a man more proper. The June 1937 article points out trousers as, "still our very own distinguishing mark of masculinity"; 268 and in the October 1937 segment it is noted that, "“A man is never well dressed if his hat be not smart and clean'. Some famous person said this, or if he didn't, he should have."269 'Gallants in Embryo' also spoke to the ways in which men can complement their female partner's fashion with their own. For example, when Ford wrote, "if the pristine freshness of your partner's frock means anything to you, draw on a pair of white kid gloves", thus showing the chivalrous side of the young 'gallant'. ${ }^{270}$ Ford also discussed the psychological benefit of dressing well when he wrote that good variety in dress, "has a psychological effect on the tired business man and emboldening effect on the effete lover." ${ }^{271}$ In this same paragraph though, Ford noted that variety in dress is "only a matter of deciding how much you can get away with, without being thought "sissy,"272 proving that a year on from the initial print of the feature he still believed in the negative "brand of effeminacy"- ${ }^{273}$ though this time he made it clear that he believed that being a "sissy", "depends more on the man than on the clothes he wears." 274

'Gallants in Embryo' also demonstrated the influence of international fashions, and communities, on the styles being recommended to New Zealand men. For example, Ford references that, "a medium lapel looks better and happens to correspond with what they're doing in the West End"; 275 in another issue he notes that, "According to current films and American catalogues, they are doing extraordinary things with pleated backs just now";276 and he also references the Australian scene, when stating that: "It has been smart (in Sydney

\footnotetext{
${ }^{268}$ Harrison Ford, 'Gallants in Embryo', The Monocle, Vol.1, No.2, June 1937, p.42.

${ }^{269}$ Harrison Ford, 'Gallants in Embryo', The Monocle, Vol.1, No.5, October 1937, p.23. The article goes on to state that top hats, "are excellent garb, and suit every man, whether he be an Adonis or a cave-man,", and that in not wearing them, "It certainly savours of a Colonial inferiority complex." These comments are placed above a picture of a racially exaggerated image of an African man who does not wear a hat, adding to the already evolutionary framework style dichotomy of Adonis and cave-man - i.e. it seems to infer that to not partake in this fashion makes one less civilised, and less of a 'real' man.

${ }^{270}$ Harrison Ford, 'Gallants in Embryo', The Monocle, Vol.1, No.2, June 1937, p.42.

${ }^{271}$ Harrison Ford, 'Gallants in Embryo',The Monocle, Vol.2, No.2, June 1938, p.73.

272 Ibid.

${ }^{273}$ Harrison Ford, 'Gallants in Embryo', The Monocle, Vol.1, No.1, May 1937, p.43.

${ }^{274}$ Harrison Ford, 'Gallants in Embryo', The Monocle, Vol.2, No.2, June 1938, p.73. Despite Ford making this point, it is still significant that he brings clothing into this equation, as corporeal display of men's character fashion acted as a vector through which men could demonstrate and perform their masculinity to the world, and through which others could judge them - if they did not achieve masculine presentation, did this then ultimately make them effeminate, and also comment on their lesser character/temperaments/minds?

275 Harrison Ford, 'Gallants in Embryo', The Monocle, Vol.1, No.3, July 1937, p. 23.

${ }^{276}$ Harrison Ford, 'Gallants in Embryo', The Monocle, Vol.1, No.4, August 1937, p.23.
} 
at least for some time) to wear a white mess jacket" for summer wears. ${ }^{277} \mathrm{He}$ did also, in one article, point out the benefits of a specifically antipodean life as, "On account of the difference on seasons, we have notice to every change of fashion several months before the weather permits them to reach us." 278 Ford also occasionally commented on class in the feature. For example, when he wrote: "If you rejoice in the luxury of a valet, the information which follows will be superfluous. If you lack such a simple amenity, lend me your ears." ${ }^{279}$ This kind of tongue-in-cheek remark was in keeping with the title of the magazine - The Monocle - as the number of average New Zealand men who would have had a valet, or worn a monocle, was a very small number.

The debates around effeminacy, masculinity, mental and physical health and fitness, and male sexuality are profuse in the popular print culture sources this chapter has examined. The sources, unlike the medical journals and dissertations analysed in chapter two, were commercial. They relied on readers buying them, and advertisers sponsoring them. The magazines and newspaper this chapter discussed contributed to an even larger commercial print culture of New Zealand in the interwar years. Some magazines were dedicated to making the most out of bodies, minds, and the lives of men (like Health and Physical Culture and The Monocle); whilst others were about celebrating fitness and the pleasures of the body through nudism (such as Bain's Health and Sunshine). However, all of the magazines, and The NZ Truth, depicted, and facilitated conversations around, anxieties about manhood and masculinity. Whilst these publications took different positions on the topics that masculinity and effeminacy interact with (such as eugenics, birth control, and nudism), they still all raised many questions about the nature of masculinity, and in a form that was far more widely accessible than those produced and circulated within medical circles. Average New Zealanders were far more likely, and able, to turn to popular magazines or tabloids to learn about modern notions of masculinity and sexuality; and to seek answers for their concerns over their own sense of manliness and masculinity. Commercial publications presented

\footnotetext{
${ }^{277}$ Harrison Ford, 'Gallants in Embryo', The Monocle, Vol.1, No.7, December 1937, p.59. For other examples of these references to international fashions, see also: Harrison Ford, 'Gallants in Embryo', The Monocle, Vol.1, No.5, October 1937, p.23; Harrison Ford, 'Gallants in Embryo', The Monocle, Vol.1, No.8, January 1938, p.44; Harrison Ford, 'Gallants in Embryo', The Monocle, Vol.1, No.10, March 1937, p.40; Harrison Ford, 'Gallants in Embryo', The Monocle, Vol.2, No.1, May 1937, p.51; and Harrison Ford, 'Gallants in Embryo', The Monocle, Vol.1, No.2, June 1938, p.73.

${ }^{278}$ Harrison Ford, 'Gallants in Embryo', The Monocle, Vol.1, No.10, March 1938, p.51.

${ }^{279}$ Harrison Ford, 'Gallants in Embryo',The Monocle, Vol.1, No.11, April 1938, p.40. See also: Harrison Ford,

'Gallants in Embryo', The Monocle, Vol.2, No.1, May 1938, p.44.
} 
illustrated records and accounts of masculinity, the male body and fashion. They also addressed more serious issues such 'mental hygiene', 'mental defectives', and sex crimes topics which were framed in ways to help sell copies of newspapers and magazines. This chapter has illuminated the varied conceptions and discussions of the impact of the Great War, the interest in eugenics and Darwinist theories; the proliferation of psychological ideas and terminology; and shifting understandings of gender, masculinity, and male sexuality in a selection of popular print culture sources read by New Zealanders between 1918-1939. 


\section{CONCLUSION}

This thesis has traced and examined the ways in which masculinity, effeminacy, and male sexuality were defined, discussed, and disputed in Aotearoa/New Zealand during the interwar period (1918-1939). It has explored the government legislation and official reports that framed discourses around mental fitness and sexual behaviours; and illuminated the intertwined ways in which masculinity, gender, the body, and sanity were discussed and understood by both those in the medical field, as well as in popular culture. These were ideas and concerns that circulated in specialist circles and amongst the general readership of New Zealanders who consumed knowledge through popular print culture. Through looking at the material published in the medical journals and dissertations, it is possible to see the continued importance of international knowledge networks (with New Zealand and Britain, but also with other European nations, the United States, and Australia) in the diffusion of new and evolving theories around mental disorders and neuroses. These theories continually improved upon and wrangled over topics such as the unconscious, repression, and indeed the development of neuroses; the language itself suggesting new ways of approaching these subjects. Theories deepened the maturing conceptions of issues of sex, gender, and sexuality as transformed by key figures such as Richard von Krafft-Ebing, Magnus Hirschfeld, and Sigmund Freud. The examination of the popular culture publications this thesis analyses, added to this medical discourse by tracking how such rhetoric filtered through to the more widely accessible mediums the general population of New Zealand read weekly, or monthly. Together, these approaches have enhanced the existing histories of masculinity, effeminacy, and homosexuality by shifting the focus from the solely criminal to demonstrate a fuller picture of interwar masculinity and male sexuality in New Zealand. Such topics were being discussed by New Zealanders during the interwar years due to the ongoing impact of the Great War, the effects of unemployment, and increased concerns around population size and quality.

Masculinity is highly mutable. Yet because, as Bryce Traister has called attention to, "masculinity has for so long stood as the transcendental anchor and guarantor of cultural authority and "truth"," to demonstrate its "“contractedness', requires an especially rhetorical 
and critical insistence." In relation to this thesis, what this has meant is that in the effort to further excavate New Zealand masculinity, this research has contained the vital assertion that interwar New Zealand masculinity and male sexuality deserves more than just to be tarred with the brush of delinquency and criminality. As it stands, the existing historiography largely has not extended beyond these topics. This point also moulded the approach to this topic - this thesis investigated the explorations and deliberations of, and negotiations around, what masculinity, effeminacy, and male sexuality (both heterosexual and homosexual, as developed and defined against one another) came to mean for psychologists, general practitioners, medical students, magazine and newspaper publishers, and, by extension, their subscriber and readership bases.

"Masculinities," R. W. Connell argues, "are, in a word, historical”, their current iterations need to be understood through the lens of the shapes they took in the past. ${ }^{2}$ For New Zealanders, this task of historicising our masculinities has most notably been undertaken by Jock Phillips, who (as he himself has acknowledged) did not include all iterations of past masculinities in his history making. Phillips's focus on the Pākehā male, is also largely a history of the heterosexual, working-class or middle-class Kiwi bloke. ${ }^{3}$ Whilst this thesis similarly focuses mostly on Pākehā masculinities it does so in a way that more openly acknowledges these formulations of men as part of the ways in which Māori men were also understood, and spoken of - largely through the acknowledgment of the evolutionary framework of understanding that pervaded medical culture throughout the interwar period, and in its awareness of where Māori were excluded in discourse due to increasing eugenic concerns around the white population of New Zealand. ${ }^{4}$ This thesis also addresses the nonheterosexual masculinities, the 'queered' masculinities, those that were pathologised and 'abnormal'. It has verged from the hegemonic model of masculinity to encompass those previously excluded from (or left in the margins of) the existing historiography - men who

\footnotetext{
${ }^{1}$ Bryce Traister 'Academic Viagra: The Rise of American Masculinity Studies', American Quarterly, Vol.52, No.2, June 2000, p.281, in Rachel Adams, and David Savran (Eds.), The Masculinity Studies Reader (Oxford: Blackwell Publishers, 2002), p.2.

${ }^{2}$ R. W. Connell, 'The History of Masculinity', in Rachel Adams, and David Savran (Eds.), The Masculinity Studies Reader (Oxford: Blackwell Publishers, 2002), p.245.

${ }^{3}$ See Jock Phillips, A Man's Own Country?: The Image of the Pakeha Male- A History (Auckland: Penguin Books, 1996).

${ }^{4}$ Māori were also not seen as large of a concern to the quality of the New Zealand population as the Chinese were. (See Barbara Brookes, “Aristocrats of Knowledge': Māori Anthropologists and the Survival of the 'Race', in Diane B. Paul, John Stenhouse, and Hamish G. Spencer (Eds.), Eugenics at the Edges of Empire: New Zealand, Australia, Canada and South Africa (Cham: Springer International Publishing, 2018), pp.267288.).
} 
were mentally unwell, men who were deemed sexually deviant or inverted, men who were not quite masculine enough, who were not 'normal', and who were effeminate.

It is generally agreed upon by historians that the Great War exacerbated late nineteenth-century concerns about sexual deviance and men who were 'weaklings' and had thus lost their physical and moral fibre. ${ }^{5}$ This thesis has demonstrated that post-war conversations about masculinity in New Zealand were shaped by the experiences New Zealand medical professionals had in treating men suffering from 'shell-shock' during the war, and in their continued interactions with 'mentally deficient' men in the subsequent years. Similarly to their counterparts in Britain, New Zealand's medical professionals drew on these experiences, and the knowledge international medical professionals accrued and circulated in medical networks during the interwar period. The increased presence of, and exposure to physically and mentally disabled men, and the perceived rise in sexual deviancy in the post-war period amplified anxieties around men and masculinity in Aotearoa.

Masculinity, as this thesis has illustrated, became the focus of contention and concern because of the impact of the war - much in the same way it had in Britain, as has already been explored in the historiography of British interwar masculinity. The resulting desire to rebuild New Zealand men and their masculinity occurred simultaneously to the newly increased interest in preventive and public health measures. Whilst returned soldiers still remained a part of the debates around men, the focus largely shifted onto the next generation of New Zealand boys and men.

A society in which even the seemingly robust notion of martial masculinity, with its capacity for homosocial relations, can be seen to be threatened by the possibility of male intimacy (i.e. that which went beyond the acceptable bounds of same-sex male friendships) was the kind of society this thesis has argued existed in Aotearoa/New Zealand between the wars. ${ }^{6}$ This potential threat was one of the meanings of the 'menace' of effeminacy. Men who went beyond the socially acceptable framework of male friendship in this way presented a

\footnotetext{
${ }^{5}$ Carolyn J. Dean, The Frail Social Body: Pornography, Homosexuality, and Other Fantasies in Interwar France (Berkeley: University of California Press, 2000), pp.5-6.

${ }^{6}$ Whilst Chris Brickell's work explores much of these same-sex male 'friendships' (see Mates and Lovers: A History of Gay New Zealand (Auckland: Godwit, 2008), pp.91-92; Chris Brickell, Manly Affections: The Photographs Of Robert Gant, 1885-1915 (Dunedin: Genre Books, 2012); and Chris Brickell, Southern Men: Gay Lives In Pictures (Dunedin: Genre Books, 2014), as has already been acknowledged, he himself noted that the interwar years was a part of his work that was not as fully fleshed out as it potentially could be. This thesis has demonstrated another dimension of these relations - i.e. as viewed from the outside by those in the medical community, and by those in wider society - and has helped to show the ways in which they came to be understood, as related to the emerging field of psychology and psychoanalysis, and alongside the growing interest in eugenic movements following the Great War.
} 
sexually deviant danger to New Zealand society. Historians like Carolyn J. Dean have also argued that the way in which homosexuality was viewed as a "contagious and contaminating symbol of sexuality from which no man was immune," was a post-war invention. ${ }^{7}$ It is something that this thesis has aimed to demonstrate through delving into the ways in which effeminacy and deviant male sexuality and masculinity were framed as a 'menace' to society that needed to be confronted.

The story of masculinity and homosexuality in New Zealand becomes more familiar to us, and to written History, following the Second World War, and through the movements for Gay Liberation and equality that came in the final decades of the twentieth century. This thesis has illustrated that the first-half of the century can prove equally as fruitful (if not more-so in the more complex, less straight-forward ways it forces historians to approach it) as the successive decades of the century. "Past modes of life have enduring significance," Brickell proposed, with, "past and present times exist[ing] in active engagement with each other," and that to look at queer lives in history, "is to weave ourselves back into the past."" Historians of masculinity and sexuality in New Zealand must continue to examine the past, to 'weave' themselves back into it, and to continue to complicate these social constructions in order to write more expansive histories in the future. This thesis has worked in conversation with the existing queer historiography of Aotearoa to contribute another layer of the interwar history that also included un-masculine, sometimes homosexual, marginalised men.

As George L. Mosse has asserted, "Manliness was invoked to safeguard the existing order against the perils of modernity, which threatened the clear distinction between what was considered normal and abnormality." "What this thesis has demonstrated is how New Zealanders employed and shaped their impressions of what New Zealand masculinity was, whether implicitly or explicitly, deliberately or inadvertently, in order to make sense of the world, and their menfolk, following the tumult of the First World War, with the perceived threat of modernity and the Modern Man (and Modern Woman) knocking at the door of a nation who was still adapting to the 'new normal' of a post-war world. Part of this normality was the vigorous reassertion of heterosexuality in response to, and concurrent with, heightened anxieties about sexuality and behaviour that looked non-normal, and non-

\footnotetext{
${ }^{7}$ Dean, p.171. This way of viewing homosexuality, Dean proposed, also is what helped establish the male "heterosexual identity" in a more complex way; and this identity is that which acts in contrast to, and comparisons with, the un-masculine, queered male who this thesis has helped to further establish in the New Zealand context.

${ }^{8}$ Chris Brickell, Mates and Lovers: A History of Gay New Zealand (Auckland: Godwit, 2008), p.383.

${ }^{9}$ George L. Mosse, Nationalism and Sexuality: Middle-Class Morality and Sexual Norms in Modern Europe (Madison: The University of Wisconsin Press, 1985), p.23.
} 
heterosexual. The inclusion of this insistence on male heterosexuality adds to the current understanding of eugenics in interwar New Zealand, which has largely focused more on the heterosexual reproductive capacity of women. Interwar perceptions, and discussions of masculinity, effeminacy, and male sexuality, took on psychological, evolutionist, and eugenic tones. This dimension of the eugenic ideas circulating in the interwar years - the reassertion and regulation of male heterosexuality - was part of the wider drive to rebuild the nation following the disruption of the war to the lives of men as husbands and fathers, and the desire to improve the population standards in New Zealand.

The discussion of the medical and popular culture sources in this thesis has shown that in order to rebuild society, and masculinity after the war, New Zealanders (like those in other nations) turned to campaigns for public health and fitness. Whether they took on the guise of preventive medicine, mental health treatment, or physical culture, these national movements sought to create and maintain a New Zealand population, free from hereditary disease and sexual or moral weakness. Darwinist ideology believed that nature would reward a "healthy national organism", such as the one advocates in the medical sphere, or those who worked in the popular print medium sought to establish. ${ }^{10}$ As Ana Carden-Coyne proposed: "Since the war was regarded as masculine affair, and a test of individual, local, and national manliness," so the male body and mind became central to the efforts for reconstruction in the post-war years. ${ }^{11}$ This thesis has demonstrated these efforts through the increased attention given to the mental fitness and psychological well-being of New Zealanders, shown both in medical circles and the popular press. It has outlined the particular role of male sexuality (male heterosexuality) in the eugenic movement in interwar Aotearoa; and described the ways in which discussions about men, their bodies, minds, and masculinity sprawled between medical texts and commercial popular print culture.

This thesis has identified what the concerns and anxieties expressed through fears of effeminacy meant to New Zealand contemporaries of the interwar period. It has demonstrated how effeminacy was understood, as well as how it was described (as a 'menace' to New Zealand masculinity), and explained how interwar New Zealanders presented potential remedies for the danger. This thesis has illustrated that effeminacy was seen as a 'menace' by further revealing the ways in which the experience with, and exposure to, vast numbers of men with mental neuroses during the Great War; population concerns made more apparent by

\footnotetext{
${ }^{10}$ Mosse, p.33.

11 Ana Carden-Coyne, Reconstructing the Body: Classicism, Modernism, and the First World War (New York: Oxford University Press, 2009), p.137.
} 
the sub-standard health of troops being laid bare during the war; the subsequent increasing interest in, and expansion of, the field of psychology and psychoanalysis; and the simultaneous swelling in the fascination with eugenics and movements that were aimed at the betterment of the physical and psychological health and fitness of New Zealand citizens came together to help both preserve and compose an acceptable construction of masculinity that could endure in interwar Aotearoa.

Whilst this has been achieved through an examination of medical and popular culture sources - spanning from medical journals to populist tabloid newspapers - this thesis does also recognise that more work can still be done on the topic of masculinity, sexuality, and effeminacy in interwar New Zealand. There exist other arenas in which masculinity was deconstructed, debated, and formed. Spaces such as schools, sports, fiction, ${ }^{12}$ the personal accounts of men, and in those with a focus on Māori produced by Māori. There is more of this work to be done, but this thesis has extended much of the existing historiography on the topic in the New Zealand context. The 'menace' of effeminacy that Carl Hertzig described in 1932 in Health and Physical Culture was one that encapsulated a number of concerns about men and masculinity that this thesis has unfurled. This thesis has demonstrated the ways in which thinking and discussions in interwar New Zealand defined and responded to particular circumstances, actions, and conditions relating to men, masculinity, and effeminacy. It has established an understanding of the language, categories, and authorities that shaped and determined conceptions of 'normality' that created an environment in which other options than the norm could not thrive; and in fact, were relegated, denounced, and marginalised.

\footnotetext{
${ }^{12}$ See for example, the work of Martin Crotty who has tackled all three of these areas - schools, sports, and boys' fiction in his works such as 'Manly and moral: the making of middle-class men in the Australian public school', The International Journal of the History of Sport, Vol.17, No.2-3, 2000, pp.10-30; and Making the Australian Male: Middle-Class Masculinity 1870-1920 (Melbourne: Melbourne University Press, 2001); and 'Frontier Fantasies: Boys' Adventure Stories and the Construction of Masculinity in Australia, 1870-1920', Journal of Australian Colonial History, Vol.3, No.1, April 2001, pp.55-76; or James A. Mangan, who has done similar work in the British context, for example in Athleticism in the Victorian and Edwardian Public School (Abingdon: Routledge, 2006).
} 


\section{BIBLIOGRAPHY}

\section{Primary Sources}

\section{Legislation}

Mental Defectives Act 1911

Mental Defectives Amendment Act 1928

\section{Reports}

Great Britain War Office Committee Enquiry into "Shell-shock", Report of the War Office Committee of Enquiry into "Shell-shock" (London: H.M.S.O., 1922).

Mental Defectives and Sexual Offenders: Report of the Committee of Inquiry Appointed by the Hon. Sir Māui Pōmare, K.B.E., C.M.G., Minister of Health, Appendix to the Journals of the House of Representatives, 1925 Session I, H-31A.

\section{Medical Journals}

British Journal of Psychology (1918-1939).

New Zealand Medical Journal (1918-1940).

\section{Preventive Medicine Dissertations}

Blanc, A. D. G., and Paul, R. J., 'A Survey of Unorthodox Medical Treatment and the Sale and Promotion of Proprietary Medicines, Therapeutic Devices and Cosmetics Within New Zealand', Preventive Medicine Dissertation, University of Otago, 1939.

Christie, M., and Christie, R., 'A Study of Porirua Mental Hospital', Preventive Medicine Dissertation, University of Otago, 1936.

Cowie, G. B. A., and Wilson, R. A., 'Public Health Survey of Maoris in North Wairarapa District', Preventive Medicine Dissertation, University of Otago, 1934.

Findlay, Gordon N., 'A General Survey of Cripples with Special Reference to Crippling Diseases in New Zealand', Preventive Medicine Dissertation, University of Otago, 1931.

Fitzherbert, W. A., 'The Prevention of Mental Diseases in New Zealand', Preventive Medicine Dissertation, University of Otago, 1931.

Hall, G. F., 'St Joseph's Boys’ Home, Waverly, Dunedin: A Physical \& Mental Survey', Preventive Medicine Dissertation, University of Otago, 1939.

Ivory, Nola M., 'Infantile Mortality', Preventive Medicine Dissertation, University of Otago, 1930. 
Jamieson, E. S., and Eaton, O. L., 'Nelson Mental Hospital: An Historical Survey and a Public Health Examination', Preventive Medicine Dissertation, University of Otago, 1932.

Johnson, L. F., and Nicks, G. R., 'A Hygienic Survey of the New Zealand Division of the Royal Navy’, Preventive Medicine Dissertation, University of Otago, 1935.

Pitcaithy, R. H., 'Health Survey of Nelson', Preventive Medicine Dissertation, University of Otago, 1926.

Sandel, Jean M., 'Te Rohe Potae: Its Native People in Sickness \& in Health. A Public Health Survey of the General Health and Living Conditions of the King Country Maoris', Preventive Medicine Dissertation, University of Otago, 1938.

Shearer, John T., 'Typhoid in Seacliff Mental Hospital', Preventive Medicine Dissertation, University of Otago, 1938.

Stanton, A. M., 'Backward Children: What Is Being Done For Them In New Zealand', Preventive Medicine Dissertation, University of Otago, 1936.

Staveley, J. M., 'Public Health Survey of the Whangamata Maoris, with Special Reference to Their Psychology', Preventive Medicine Dissertation, University of Otago, 1937.

Stewart, Lindsay R., 'Student Life in Knox College. From a Public Health Aspect', Preventive Medicine Dissertation, University of Otago, 1939.

Sutherland, T. C., and Priest, N. A., 'Mental Backwardness and Mental Deficiency in Children (With Reference to Special School for Boys At Otekaike)', Preventive Medicine Dissertation, University of Otago, 1932.

Watson, M., 'Infant Mortality \& Infant Feeding', Preventive Medicine Dissertation, University of Otago, 1933.

\section{Newspapers}

The New Zealand Truth (1918-1930).

\section{Magazines}

Health and Physical Culture (1929-1938).

Health and Sunshine (1936-1937).

The Monocle: The New Zealand Monthly Magazine (1937-1939).

\section{Secondary Sources}

\section{Books}


Ballantyne, Tony, Webs of Empire: locating New Zealand's colonial past (Vancouver: UBC Press, 2014).

Bergling, Tim, Sissyphobia: Gay Men And Effeminate Behavior (New York: Harrington Park Press, 2001).

Bingham, Adrian, Gender, Modernity, and the Popular Press in Inter-War Britain (Oxford: Clarendon Press, 2004).

Bland, Lucy, Modern Women on Trial: Sexual Transgression in the Age of the Flapper (Manchester: Manchester University Press, 2013).

Bourke, Joanna, Dismembering the Male: Men's Bodies, Britain and the Great War (London: Reaktion Books Ltd., 1999).

Brickell, Chris, Manly Affections: The Photographs Of Robert Gant, 1885-1915 (Dunedin: Genre Books, 2012).

Brickell, Chris, Mates and Lovers: A History of Gay New Zealand (Auckland: Godwit, 2008).

Brickell, Chris, Southern Men: Gay Lives In Pictures (Dunedin: Genre Books, 2014).

Bristow, Joseph, Effeminate England: Homoerotic Writing After 1885 (New York: Columbia University Press, 1995).

Brookes, Barbara, A History of New Zealand Women (Wellington: Bridget Williams Books, 2016).

Brunton, Warwick, Sitivation 125: A History Of Seaview Hospital, Hokitika And West Coast Mental Health Services 1872-1997 (Hokitika: Seaview Hospital 125 ${ }^{\text {th }}$ Jubilee Committee, 1997).

Carden-Coyne, Ana, Reconstructing the Body: Classicism, Modernism, and the First World War (New York: Oxford University Press, 2009).

Coleborne, Catherine, and MacKinnon, Dolly (Eds.), Madness in Australia: Histories, Heritage and Asylum (Brisbane: University of Queensland Press, 2003).

Cook, Hera, The Long Sexual Revolution: English Women, Sex, and Contraception, 18001975 (Oxford: Oxford University Press, 2004).

Crotty, Martin, Making the Australian Male: Middle-Class Masculinity 1870-1920

(Melbourne: Melbourne University Press, 2001).

Daley, Caroline, Leisure and Pleasure: Reshaping and Revealing the New Zealand Body 1900-1960 (Auckland: Auckland University Press, 2003).

Damousi, Joy, Freud in the Antipodes: A Cultural History of Psychoanalysis in Australia (Sydney: University Of New South Wales Press, 2005). 
Dean, Carolyn J., The Frail Social Body: Pornography, Homosexuality, and Other Fantasies in Interwar France (Berkeley: University of California Press, 2000).

Guy, Laurie, Worlds in Collision: The Gay Debate In New Zealand, 1960-1986 (Wellington: Victoria University Press, 2002).

Hobsbawm, Eric, How to Change the World: Reflections on Marx and Marxism (London: Little Brown Books, 2011).

Hodge, William C., Homosexual law reform: questions and answers concerning the legality of male homosexual conduct in New Zealand: a discussion paper (Auckland: Human Rights Commission, 1985).

Hutchings, Jessica, and Aspin, Clive (Eds.), Sexuality \& The Stories Of Indigenous People (Wellington: Huia Publishers, 2007).

Kain, Jennifer S., Insanity and Immigration Control in New Zealand and Australia, 18601930 (Cham: Springer International Publishing, 2019).

King, Michael, The Penguin History of New Zealand (Auckland: Penguin Books, 2003).

Kirkman, Allison, and Moloney, Pat, Sexuality Down Under: Social and Historical Perspectives (Dunedin: University of Otago Press, 2005).

Laquer, Thomas W., Solitary Sex: A Cultural History of Masturbation (New York: Zone Books, 2003).

Laurie, Alison J., and Evans, Linda, Outlines: Lesbian \& Gay Histories of Aotearoa (Wellington: Lesbian and Gay Archives of New Zealand, 2005).

Loughran, Tracey, Shell-Shock and Medical Culture in First World War Britain (Cambridge: Cambridge University Press, 2017).

Macdonald, Charlotte, Strong, Beautiful and Modern: National Fitness in Britain, New Zealand, Australia and Canada, 1935-1960 (Wellington: Bridget Williams Books, 2011).

Manga, James A., Athleticism in the Victorian and Edwardian Public School (Abingdon: Routledge, 2006).

McLaren, Angus, Twentieth-Century Sexuality: A History, (Oxford: Blackwell Publishers Ltd, 1999).

Mosse, George L., Nationalism and Sexuality: Middle-Class Morality and Sexual Norms in Modern Europe (Madison: The University of Wisconsin Press, 1985).

Page, Dorothy, Anatomy of a Medical School: A History of Medicine at the University of Otago 1875-2000 (Dunedin: Otago University Press, 2008). 
Phillips, Jock, A Man's Own Country?: The Image of the Pakeha Male- A History (Auckland: Penguin Books, 1996).

Pietsch, Tamson, Empire of scholars: Universities, networks and the British academic world 1850-1939 (Manchester: Manchester University Press, 2013).

Reekie, Gail, Temptations: Sex, Selling and the Department Store (Sydney: Allen \& Unwin, 1993).

Reid, Fiona, Broken Men: Shell Shock, Treatment and Recovery in Britain 1914-1930 (London: Continuum, 2010).

Showalter, Elaine, The Female Malady: Women, Madness and English culture 1830-1980 (London: Virago, 1987).

Sinfield, Alan, The Wilde Century: Effeminacy, Oscar Wilde and the Queer Moment (New York: Columbia University Press, 1994).

Sinha, Mrinalini, Colonial masculinity: the 'manly Englishman' and the 'effeminate Bengali' in the late nineteenth century (Manchester: Manchester University Press, 1995).

Tennant, Margaret, Children's Health, the Nation's Wealth: A History of Children's Health Camps (Wellington: Bridget Williams Books, 1994).

Thomson, Mathew, The Problem of Mental Deficiency: Eugenics, Democracy, and Social Policy in Britain, c. 1870-1959 (Oxford: Clarendon, 1998).

Tolerton, Jane, Ettie: a life of Ettie Rout (Auckland: Penguin, 1992).

Wanhalla, Angela, Matters Of The Heart: A History Of Interracial Marriage In New Zealand (Auckland: Auckland University Press, 2013).

Yska, Redmer, Truth: The Rise And Fall Of The People's Paper (Nelson: Craig Potton Publishing, 2010).

\section{Chapters in Edited Collections}

Brookes, Barbara, “Aristocrats of Knowledge': Māori Anthropologists and the Survival of the 'Race', in Paul, Diane B., Stenhouse, John, and Spencer, Hamish G. (Eds.), Eugenics at the Edges of Empire: New Zealand, Australia, Canada and South Africa (Cham: Springer International Publishing, 2018), pp.267-288.

Brookes, Barbara,'Women and Madness: A Case-study of the Seacliff Asylum, 1890-1920', in Brookes, Barbara, Macdonald, Charlotte, and Tennant, Margaret (Eds.), Women in History 2 (Wellington: Bridget Williams Books, 1992), pp.129-147.

Connell, R. W., 'The History of Masculinity', in Adams, Rachel, and Savran, David (Eds.), The Masculinity Studies Reader (Oxford: Blackwell Publishers, 2002), pp.245-261. 
Daley, Caroline, 'Puritans and Pleasure Seekers', in Kirkman, Alison, and Moloney, Pat, Sexuality Down Under: Social and Historical Perspectives (Dunedin: University of Otago Press, 2005), pp.47-62.

Garton, Stephen, “Liberty of the Nation': Eugenics in Australia and New Zealand and the Limits of Illiberalism', in Paul, Diane B., Stenhouse, John, and Spencer, Hamish G. (Eds.), Eugenics at the Edges of Empire: New Zealand, Australia, Canada and South Africa (Cham: Springer International Publishing, 2018), pp.21-40.

Macdonald, Charlotte, 'Revisiting Three Eugenic Moments: 1903, 1928, and 1937: The Disappointments and Hopes of Antipodean Progressives', in Paul, Diane B., Stenhouse, John, and Spencer, Hamish G. (Eds.), Eugenics at the Edges of Empire: New Zealand, Australia, Canada and South Africa (Cham: Springer International Publishing, 2018), pp.219-241.

Paul, Diane B., 'Truby King, Infant Welfare and Boundaries of Eugenics', in Paul, Diane B., Stenhouse, John, and Spencer, Hamish G. (Eds.), Eugenics at the Edges of Empire: New Zealand, Australia, Canada and South Africa (Cham: Springer International Publishing, 2018), pp.243-265.

Spencer, Hamish G., 'Eugenic Sterilisation in New Zealand', in Paul, Diane B., Stenhouse, John, and Spencer, Hamish G. (Eds.), Eugenics at the Edges of Empire: New Zealand, Australia, Canada and South Africa (Cham: Springer International Publishing, 2018), pp.85106.

Stryker, Laurinda, 'Mental Cases: British Shellshock and the Politics of Interpretation', in Braybon, Gail (Ed.), Evidence, History and the Great War: Historians and the Impact of 1914-18, pp.154-171.

Thomson, M., “'Savage Civilisation”: Race, Culture and Mind in Britain 1898-1939', in Ernst, W., and Harris, B. (Eds.), Race, Science and Medicine, 1700-1960 (London: Routledge, 1999), pp.235-258.

Wanhalla, Angela, 'Debating Clause 21: 'Eugenic Marriage' in New Zealand', in Paul, Diane B., Stenhouse, John, and Spencer, Hamish G. (Eds.), Eugenics at the Edges of Empire: New Zealand, Australia, Canada and South Africa (Cham: Springer International Publishing, 2018), pp.107-127.

\section{Journal Articles}

Ballantyne, Tony, 'Reading the Newspaper in Colonial Otago', Journal of New Zealand Studies, Vol.12, 2011, pp.47-63.

Ballantyne, Tony, 'Strategic Intimacies: Knowledge and Colonization in Southern New Zealand'. Journal of New Zealand Studies, Vol.14, 2013, pp.4-18.

Ballantyne, Tony, 'Thinking Local: Knowledge, Sociability and Community in Gore's Intellectual Life, 1875-1914'. New Zealand Journal of History, Vol.44, No.2, 2010, pp.13856. 
Bennett, James, 'Keeping the Wolfenden from the Door? Homosexuality and the 'Medical Model' in New Zealand', Social History of Medicine, Vol.23, No.1, pp.134-152.

Bennett, James E., and Brickell, Chris, 'Surveilling The Mind And The Body: Medicalising And De-Medicalising Homosexuality in 1970s New Zealand', Medical History, Vol.62, No.2, 2018, pp.199-216.

Bishop, Catherine, 'The Serendipity of Connectivity: piecing together women's lives in the digital archive', Women's History Review, Vol.26, No.5, September 2017, pp.766-780.

Bogacz, Ted, 'War Neurosis and Cultural Change in England, 1914-22: The Work of the War Office Committee of Enquiry into "Shell-Shock", Journal of Contemporary History, Vol.24, 1989, pp.227-256.

Bourke, Joanna, 'Effeminacy, Ethnicity and the End of Trauma: The Sufferings of 'ShellShocked' Men in Great Britain and Ireland, 1914-39', Journal of Contemporary History, Vol.35, No.1, January 2000, pp.57-69.

Brickell, Chris, 'Queens Gardens, 1949: The anxious spaces of post-war New Zealand masculinity’, New Zealand Geographer, Vol.68, No.2, August 2012, pp.81-91.

Brickell, Chris, 'Sex instruction and the construction of homosexuality in New Zealand, 1920-1965', Sex Education, Vol.5, No.2, pp.119-136.

Brickell, Chris, 'Sexology, the Homo/Hetero Binary, and the Complexities of Male Sexual History’, Sexualities, Vol.9, No.4, 2006, pp.423-447.

Brickell, Chris, 'The sociological construction of gender and sexuality', Sociological Review, Vol.54, No.1, February 2006, pp.87-113.

Brickell, Chris, 'Visualizing Homoeroticism: The Photographs of Robert Gant, 1887-1892', Visual Anthropology, Vol.23, No.2, February 2010, pp.136-157.

Brickell, Chris, "“Waiting for Uncle Ben": Age-Structured Homosexuality in New Zealand, 1920-1950, Journal of the History of Sexuality, Vol.21, No.3, September 2012, pp.467-295.

Brookes, Barbara, 'Housewives' depression: the debate over abortion and birth control in the 1930s', New Zealand Journal of History, Vol.15, No.2, October 1981, pp.115-134.

Brookes, Barbara, 'Papering over madness: accountability and resistance in colonial asylum files: a New Zealand case study', The Journal of Theory and Practice, Vol.22, No.3, July 2018, pp.356-374.

Coleborne, Catherine, 'Insanity, Gender and Empire; Women Living a 'Loose Kind of Life' on the Colonial Institutional Margins, 1870-1910', Health and History, Vol.14, No.1, 2012, pp.77-99.

Crotty, Martin, 'Frontier Fantasies: Boys' Adventure Stories and the Construction of Masculinity in Australia, 1870-1920', Journal of Australian Colonial History, Vol.3, No.1, April 2001, pp.55-76. 
Crotty, Martin, 'Manly and moral: the making of middle-class men in the Australian public school', The International Journal of the History of Sport, Vol.17, No.2-3, 2000, pp.10-30.

Dalley, Bronwyn, 'Lolly shops 'of the red-light kind' and 'soldiers of the King', $\mathrm{New}$ Zealand Journal of History, Vol.30, No.1, April 1996, pp.3-23.

De Block, Andreas, and Adriaens, Pieter R., 'Pathologizing Sexual Deviance: A History', Journal of Sex Research, Vol.50, No.3-4, 2013, pp.276-298.

Gooder, Claire, "To Know the Facts': The New Zealand Health Department's Sex Education Pamphlets, 1955-1983', New Zealand Journal of History, Vol.50, No.1, April 2016, pp.109133.

Hunter, Kathryn M., 'Silence in Noisy Archives: Reflections on Judith Allen's 'Evidence and Silence - Feminism and the Limits of History' (1986) in the Era of Mass Digitisation', Australian Feminists Studies, Vol.32, No.91-92, August 2017, pp.202-212.

Labrum, Bronwyn, 'Looking beyond the Asylum: Gender and the Process of Committal in Auckland, 1870-1910', The New Zealand Journal of History, Vol.26, No.2, October 1992, pp.125-144.

Loughran, Tracey, 'A Crisis of Masculinity? Re-writing the History of Shell-shock and Gender in First World War Britain', History Compass, Vol.11, No.9, September 2013, pp.727-738.

Meyer, Jessica, 'Separating the Men from the Boys: Masculinity and Maturity in Understandings of Shell Shock in Britain', Twentieth Century British History, Vol.20, No.1, 2009, pp.1-22.

Nelson, Elizabeth, 'VICTIMS OF WAR: The First World War, Returned Soldiers, and Understandings of Domestic Violence in Australia', Journal of Women's History, Vol.19, No.4, 2007, pp.83-106, 163.

Parsons, Gwen A., 'The Construction of Shell Shock in New Zealand, 1919-1939: A Reassessment', Social History of Medicine, Vol.26, No.1, 2013, pp.56-73.

Traister, Bryce 'Academic Viagra: The Rise of American Masculinity Studies', American Quarterly, Vol.52, No.2, June 2000, p.281, in Adams, Rachel, and Savran, David (Eds.), The Masculinity Studies Reader (Oxford: Blackwell Publishers, 2002), p.2.

Wanhalla, Angela, 'To 'Better the Breed of Men': women and eugenics in New Zealand, 1900-1935', Women's History Review, Vol.17, No.2, April 2007, pp.163-182.

Weaver, John, and Wright, David, 'Shell Shock and the Politics of Asylum Committal in New Zealand, 1916-1922', Health and History, Vol.7, No.1, 2005, pp.17-40.

\section{Theses}


Boston, Peter J., “"The Bacillus Of Work”: Masculinity And The Rehabilitation Of Disabled Soldiers In Dunedin 1919 To 1939', Unpublished Ba(Hons) Thesis, Otago University, 1993.

Kerekere, Elizabeth, 'Part of The Whānau: The Emergence of Takatāpui Identity: He Whāriki Takatapui', PhD Thesis, Victoria University of Wellington, 2017.

Liebich, Susann, 'Connected Readers: Reading Practices and Communities Across the British Empire, c. 1890-1930', PhD thesis, Victoria University of Wellington, 2012.

Wallace-Buckland, Ailish, 'Understanding Effeminacy and Masculinity in Discussions of Shell-shock in British Medical Culture, 1914-1922', Honours thesis, Victoria University of Wellington, 2018.

\section{Unpublished Conference Papers}

Boston, Peter, “A Caged Tiger': The Regulation Of Male Sexuality In The New Zealand Penal System, 1917 To 1952', Unpublished Conference Paper, NZPGSA Conference, 1998.

Boston, Peter, "A Heaven For Homosexuals': A Brief History Of The New Plymouth Prison For Sexual Offenders, 1910-1952'.

\section{Digital Sources}

Brunton, Warwick, 'Mental Health Services: Mental hospitals, 1910s to 1930s', Te Ara: The Encyclopedia of New Zealand; www.teara.govt.nz; accessed 18 December 2019.

Brunton, Warwick, 'Theodore Grant Gray', Te Ara: The Encyclopedia of New Zealand; www.teara.govt.nz; accessed 6 July 2020.

'C3’, Merriam Webster; www.merriam-webster.com; accessed 9 July 2020.

Dow, Derek A., 'Hercus Charles Ernest', Te Ara: The Encylopedia of New Zealand; www.teara.govt.nz; accessed 12 August 2019.

'First World War by the numbers', New Zealand History; www.nzhistory.govt.nz; accessed 28 July 2020.

'NZMA History', New Zealand Medical Association; www.nzma.org.nz; accessed 23 June 2020.

Richards, Graham, 'Charles Macafie Campbell', Oxford Dictionary of National Biography; www.oxforddnb.com; accessed 9 July 2020.

'Paul Diamond: murder and the mayor', RNZ, www.rnz.co.nz; accessed 21 July 2020.

'The 1918 flu pandemic', New Zealand History; www.nzhistory.govt.nz; accessed 28 July 2020 .

‘The curious case of Charles Mackay', RNZ, www.rnz.co.nz; accessed 21 July 2020. 